\title{
Studies on the relationship between alcohol or nicotine use and panic
}

Citation for published version (APA):

Cosci, F. (2007). Studies on the relationship between alcohol or nicotine use and panic. [Doctoral Thesis, Maastricht University]. Maastricht University. https://doi.org/10.26481/dis.20070615fc

Document status and date:

Published: 01/01/2007

DOI:

$10.26481 /$ dis.20070615fc

Document Version:

Publisher's PDF, also known as Version of record

\section{Please check the document version of this publication:}

- A submitted manuscript is the version of the article upon submission and before peer-review. There can be important differences between the submitted version and the official published version of record.

People interested in the research are advised to contact the author for the final version of the publication, or visit the DOI to the publisher's website.

- The final author version and the galley proof are versions of the publication after peer review.

- The final published version features the final layout of the paper including the volume, issue and page numbers.

Link to publication

\footnotetext{
General rights rights.

- You may freely distribute the URL identifying the publication in the public portal. please follow below link for the End User Agreement:

www.umlib.nl/taverne-license

Take down policy

If you believe that this document breaches copyright please contact us at:

repository@maastrichtuniversity.nl

providing details and we will investigate your claim.
}

Copyright and moral rights for the publications made accessible in the public portal are retained by the authors and/or other copyright owners and it is a condition of accessing publications that users recognise and abide by the legal requirements associated with these

- Users may download and print one copy of any publication from the public portal for the purpose of private study or research.

- You may not further distribute the material or use it for any profit-making activity or commercial gain

If the publication is distributed under the terms of Article $25 \mathrm{fa}$ of the Dutch Copyright Act, indicated by the "Taverne" license above, 
Studies on the relationship between alcohol or nicotine use and panic 
Isbn 978-88-95533-00-1

C) Fiammetta Cosci, Maastricht 2007

All rights reserved. No part of this publication may be reproduced, stored in a retrieval system, or transmitted in any forms or by any means, electronic, mechanical, photocopying, recoding, or otherwise, without prior permission of the author. 


\title{
Studies on the relationship between
}

\section{alcohol or nicotine use and panic}

\author{
Dissertation: \\ to obtain the degree of \\ Doctor at the Maastricht University, \\ on the authority of the Rector Magnificus, Prof. dr. G.P.M.F. Mols \\ in accordance with the decision of the Board of Deans, \\ to be defended in public \\ on Friday, the $15^{\text {th }}$ of June 2007 , at 12 hours
}

by

Fiammetta Cosci 
Supervisor:

Prof. dr. E.J.L. Griez

Co-Supervisor:

Dr. K.R.J. Schruers

Assessment Committee:

Prof. dr. F. Verhey (Chairman)

Dr. D. Caldirola (San Raffaele Hospital, Milan, Italy)

Prof. dr. W. Riedel

Prof. dr. M. de Vries

Dr. G.J. Wesseling 
"Lo duca e io per quel cammino ascoso, intrammo a ritornar nel chiaro mondo; e sanza cura aver d'alcun riposo, salimmo sù, el primo e io secondo,

tanto ch'i' vidi de le cose belle che porta "I ciel, per un pertugio tondo.

E quindi uscimmo a riveder le stelle". (Dante Alighieri, Inferno; XXXIV, 133-139) 



\section{Table of Contents}

Chapter 1 General introduction

Chapter 2 Alcohol use disorders and panic: evidence of a direct relationship

Chapter 3 The influence of alcohol oral intake on the effects of $35 \% \mathrm{CO}_{2}$ challenge.

A study in healthy volunteers

Chapter 4 The influence of ethanol infusion on the effects of $35 \% \mathrm{CO}_{2}$ challenge.

A study in panic disorder patients and healthy volunteers

Chapter 5 Effect of nicotine on $35 \% \mathrm{CO}_{2}$ induced anxiety. A study in healthy volunteers

Chapter 6 Cigarette smoking and $35 \% \mathrm{CO}_{2}$ induced anxiety. A study in panic disorder patients

Chapter 7 Negative affectivity in individuals presenting for smoking cessation. A case control study 93

Chapter 8 Nicotine dependence, personality traits, psychological distress and withdrawal

symptoms as possible predictors of smoking cessation. Results from a double blind study with nicotine patch

Chapter 9 General discussion

Summary and concluding remarks 



\section{Chapter 1}

\section{General introduction}

\section{On alcohol}

The notion that drinking can become a chronic damaging behaviour in some individuals was first postulated more than 200 years ago (Levine et al 1978). Jellinek framed the idea of addiction (Jellinek 1952), with loss of control over drinking being its main symptom. During the mid-1970s, building on previous clinical and epidemiological work, Edwards \& Gross (1976) first proposed the concept of the alcohol dependence syndrome. By those years, the attention of researchers and clinicians was also directed toward the misuse of alcohol below the level of dependence. There was increasing dissatisfaction with the traditional notion of a medical disease, alcoholism, being sufficient to explain why people developed an array of harms from drinking alcohol.

Epidemiological studies showed that physical, social and psychological pathology of alcohol consumption occur in dependent as well as non dependent users. Indeed, community surveys showed that the greatest cumulative harm occurred in persons who were drinking excessively but did not show the characteristics features of alcoholism.

Nowadays, both ICD 10 (WHO 1992) and DSM IV (APA 1994) include 2 disorders that describe repetitive patterns of alcohol use that are considered pathological. In the ICD 10, the less severe disorder is the so called "harmful alcohol use". The corresponding condition in DSM IV is "alcohol abuse". The more severe disorder in both systems is termed the "alcohol dependence syndrome".

"Harmful alcohol use" denotes the repeated consumption of alcohol that results in actual physical or psychological harm. Repeated episodes of alcohol consumption occur over at least 12 months (or continually for 1 month) and significant harm results. Persons with harmful use must not fulfil the criteria for the alcohol dependence syndrome. The latter takes precedence if the criteria for both are satisfied in the same period.

The DSM IV definition of alcohol abuse emphasizes adverse social consequences. "Alcohol abuse" is described as a maladaptative pattern of use occurring over a 12-month period leading to failure to fulfil 
major role obligations, social and/or legal problems use despite persistent social or other problems.

Again, the presence of a dependence syndrome excludes this diagnosis.

Alcohol dependence is conceptualised in both the ICD 10 and DSM IV as a psychological syndrome comprising a set of symptoms, behaviours, experiences, and psychological responses that cluster together in the same time frame. Control over the level of consumption is impaired, drinking tends to dominate daily activities, and a craving for alcohol is typical. Neuroadaptation develops in response to repeated consumption, and is manifest by tolerance and withdrawal.

The whole spectrum of alcohol use and misuse concerns abstinence/rarely drinking, low risk drinking, harmful drinking/alcohol abuse, dependence. Although individuals do not remain in a fixed category, at any one time the drinking behaviour of the population can be summarised conveniently in this way.

The proportion of the population in each category varies from country to country, and differs between sex, ages, and ethnic groups. In developed countries, the proportion of persons with dependence would typically be under $5 \%$, alcohol abuse $5 \%$ to $15 \%$, low risk drinking $50 \%$ to $75 \%$, and non drinking $5 \%$ to $40 \%$ (Saunders et al 2000).

Dependence as well as sub clinical alcohol misuse have interesting implications in other clinical areas. They have been found to cause a significant impairment in daily functioning either considering working, social and recreational activities.

Indeed, it is nowadays well known that alcohol misuse may imply legal, interpersonal, familial and job related problems. All social consequences from drinking are more prevalent in alcohol dependent than non alcohol dependent drinkers, but in both cases consequences are relevant.

Individuals who are alcohol dependent report particularly high prevalence rates for becoming involved in arguments while drinking, job related problems (loss of promotion, raises) and problems with the spouse or someone they are living with when drinking (Midanik 2000).

Moreover, alcohol is causally related to more than 60 different medical conditions and around $4 \%$ of the global burden of disease is attributable to it. Alcohol consumption leads to poor health and premature death through its causal or contributing roles in numerous chronic health conditions and acute health outcomes, including various cancers, liver disease, and injuries. 


\section{On alcohol and anxiety}

From a psychopathological point of view, two out of three alcoholics meet criteria for an other major psychiatric disorder at some time in their lives. Besides the majority of these additional diagnoses relate to antisocial personality disorder and other drug dependencies, the rates of depressive and anxiety syndromes appear to be higher than expected by chance (Schuckit 1986; Kushner et al 1990).

The combination of alcoholism and major depression within individuals has been frequently observed in both treated and untreated populations. Cadoret and Winokur (1974) reported that $39 \%$ of the alcoholic patients had primary or secondary depression. In a community survey, Weissman and Myers (1980) found that $68 \%$ of subjects with alcoholism met the criteria for a lifetime diagnosis of major or minor depressive disorders.

As what concerns anxiety disorders, the odds of having either an anxiety disorder or an alcohol use disorder are two to fivefold greater when the other condition is present. Prospectively, the odds of developing a new alcohol dependence diagnosis at year 7 increased from 3.5 to 5 times for those diagnosed with an anxiety disorder at years 1 or 4 . Conversely, the odds of developing a new anxiety disorder at year 7 increased by about four times for those diagnosed with alcohol dependence at years 1 or 4 (Kushner et al 1999).

Subjects with an alcohol use disorder (abuse or dependence) are three times more likely to have an anxiety disorder. Subjects with an alcohol use disorder and a comorbid anxiety disorder end up significantly more disabled and higher users of health services than respondents with an alcohol disorder and no comorbid anxiety (Burns et al 2002).

While all of the anxiety disorders appear to have a significant association with alcohol dependence, the strength of that association may vary between anxiety disorders.

According to epidemiological studies, panic disorder (PD) presents a great increase in the odds of being diagnosed with alcohol dependence $(O R=3.3$ ) (Regier et al 1990). The odds nearly triples in women with panic disorder $(O R=2.9)$ and more than doubles in men $(O R=2.3)$ (Kessler et al 1997). Moreover, current heavy and frequent alcohol use, even without dependence, is strongly associated with panic disorder. The adjusted odds ratio explaining such an association is about $2.2(95 \% \mathrm{Cl}, 1.2-4.2)$ (Arch et al 2006).

The co-occurrence of anxiety disorders and alcohol use disorders is noteworthy and it may have clinical 
implications. For instance, it predicts a poor outcome in response to treatment for pathological use of alcohol (Ojehagen et al 1990). In fact, LaBounty et al (1992) reported 6-month post treatment relapse rates and reasons for relapse in a group of 35 alcoholics with symptoms of phobia and/or panic and in a group of alcoholics without comorbid anxiety disorder. They found that although relapse rates were similar between the groups, significantly more anxious subjects reported relapsing to cope with aversive emotional symptoms.

Similar results were proposed by Tomasson and Vaglum (1996). They looked at the association between anxiety disorder and alcohol use disorder relapse in a nationwide sample of inpatient alcoholics and reported that for men, panic disorder predicts a greater likelihood of relapse following treatment.

Finally, Kushner et al (2005) assessed the diagnostic status and daily drinking patterns of 82 individuals after they entered alcoholism treatment. Those with a baseline anxiety disorder were significantly more likely than others to meet various definitions of drinking relapse over the follow-up. Baseline social phobia was the single best predictor of a return to any drinking after treatment, whereas panic disorder was the single best predictor of a relapse to alcohol dependence after treatment. Cross-sectional analysis at the follow-up showed that anxiety disorder persisted in the absence of a relapse to alcohol dependence far more often than relapse to alcohol dependence occurred in the absence of a persistent anxiety disorder. In brief, alcohol use disorders and anxiety disorders are significantly related. Besides the strength of such an association varies among specific anxiety disorders, panic disorder is one of the strongest mental illness associated to alcohol use disorder.

Panic, when associated to alcohol use disorder, may worsen the clinical conditions, interfere with social functioning, as well as favour relapses to alcohol dependence after treatment.

According to this observation, further investigations on the co-occurrence of panic and alcohol misuse should be encouraged. Additional knowledge could clarify the temporal pattern of occurrence of the two disorders, the etiopathogenetic mechanisms underlying the comorbidity, the appropriate clinical and therapeutic approaches to use in double diagnosed patients. 


\section{On cigarette smoking}

Similarly to alcohol, cigarette smoking is usually used and abused in socially accepted conditions.

It seems likely that tobacco has been sucked, chewed and smoked for many centuries in different civilisations. When Columbus landed in the Americas in 1492 he was offered dried tobacco leaves at the House of the Arawaks. Tobacco smoking spread from North America to Europe around the middle of the sixteenth century and thereafter became an increasingly widespread habit around the world. Following the Second World War, approximately three men in four smoked cigarettes and somewhat less than one woman in four had acquired the habit.

Cigarette smoking had become ubiquitous. Cigarettes were relatively inexpensive and widely available and every group of society indulged in the habit. Cigarette advertising was virtually unrestricted, even appearing in medical journals, and different brands, and the smoking habit were endorsed by movie stars, sporting heroes and even by doctors.

The only cloud on the horizon was the adverse effects being increasingly demonstrated to be associated with the cigarette smoking habits. Thus, the habit soon became the focus of some suspicion and scrutiny. Historically important reports that documented systematically the evidence that tobacco smoking gives rise to physical disease such as cancer were published in the 1960s (Royal College of Physicians of London 1962; Surgeon General's Advisory Committee on Smoking and Health 1964). Since that time considerable research has clarified the health impacts and disease processes (WHO 1997).

The diagnosis of tobacco dependence was first added to the DSM in the 1980 third edition (APA 1980); the diagnosis was changed in nicotine dependence in the revised third edition published in 1987 (APA 1987). In the DSM III R criteria for psychoactive substance use disorders are considered, it is difficult to argue that cigarette smoking does not cause addiction.

The nine diagnostic criteria refer to: 1) substance often taken in larger amount or over a longer period than the person intended; 2) persistent desire or unsuccessful efforts to cut down or control substance use; 3) a great deal of time spent in activities necessary to get the substance, taking the substance, or recovering from its effects; 4) frequent intoxication or withdrawal symptoms when expected to fulfil major role obligations or when substance use is physically hazardous; 5) important social, functional or recreational impairment; 6) continuous substance use despite knowledge of having problems caused or exacerbated by the use of the substance; 7) marked tolerance; 8) characteristic withdrawal symptoms; 9) 
substance often taken to relieve or avoid withdrawal symptoms.

All nine of these diagnostic criteria apply almost universally to cigarette smokers. In addition, only three of the nine criteria need to be met to make the diagnosis of psychoactive substance dependence.

In 1992 the World Health Organization included tobacco smoking in the frame of mental and behavioural disorders due to psychoactive substance use. Thereafter, the fourth edition of the DSM specifically referred to nicotine dependence and nicotine withdrawal as psychiatric disorders. Finally, the DSM IV TR (APA 2000) referred to nicotine use disorders which include nicotine dependence, nicotine-induced disorders (that is nicotine withdrawal) and nicotine related disorder not otherwise specified.

Although reports of the health consequences of cigarette smoking began appearing in the medical literature in the 1950s, the social climate was such that the medical community for many years did not stress the importance of these problems and did not strongly confront the need to stop smoking.

Cigarette smoking is nowadays clearly and consistently associated with an increased risk of cancer at a variety of sites of the human body. Moreover, there are a number of very common diseases other than cancer which are also linked to tobacco smoking (e.g. ischemic heart disease, cardio-respiratory disease, chronic obstructive lung disease) (Boyle et al 1997). Thus, cigarette smoking is recognised as leading cause of preventable death, the death rate in smokers being $30 \%$ to $80 \%$ higher than non smokers (Holbrook et al 1983).

\section{On smoking and anxiety}

There is also considerable evidence for the co-occurrence of smoking and mental disorders. Studies have found high smoking rates among mixed samples of psychiatric outpatients and inpatients and especially high rates among patients with specific psychiatric diagnoses (Breslau 1995; Gonzalez-Pinto et al 1998).

Large surveys confirmed the elevated association of cigarette smoking and psychiatric disorders in the general population (Upadhyaya et al 2002; Rohde et al 2004). Based on a nationally representative sample in the USA, $44.3 \%$ of all cigarette smokers are estimated to have a mental disorder (Lasser et al 2000). Similarly, current smokers compared with never smokers in the adult population of Australia showed an odds ratio of 3.4 for alcohol use disorders $(95 \% \mathrm{Cl} 2.6-4.4)$, of $1.5(95 \% \mathrm{Cl} 1.2-1.8)$ for any 
affective and an odds ratio of $1.7(95 \% \mathrm{Cl} 1.4-2.0)$ for any anxiety disorders (Degenhardt et al 2001).

Finally, individuals dependent on nicotine had an odds ratio of 12.8 (95\% Cl 11.7-14.0) for dependence on alcohol compared with nicotine non dependent smokers. The rates of those who had a major depressive episode or any anxiety disorder increased from never and former users of cigarettes, non dependent current smokers, up to dependent current smokers (Kandel et al 2001). The odds ratios adjusted for socio-demographic variables were 1.8 for non dependent and 3.1 for dependent current smokers with a major depressive episode and 1.4 for non dependent and 2.6 for dependent current smokers who had any anxiety disorder compared to never smokers. The prevalence rates for any anxiety disorder among non dependent smokers or non smokers was $26.3 \%$, among the mild nicotine dependent subjects $36.8 \%$ and among the moderate dependent subjects $62.3 \%$ (Breslau et al 1991). Studies have also found a link between an elevated prevalence of smoking and particular anxiety disorders, including panic disorder (Amering et al 1999) and social phobia (Sonntag et al 2000).

A disproportionate number of persons with PD smoke cigarettes compared to people in the general population (Breslau et al 1991) and individuals with other anxiety disorders (Himle et al 1988). Daily smoking has been related to an increased risk of initial occurrence of panic attacks and panic disorder (Breslau et al 1999). Indeed, Breslau et al $(1991 ; 1999)$ found that mild to moderate nicotine dependence is associated with an $11 \%$ lifetime prevalence of PD; a rate of PD approximately 2.5 times higher than persons with no nicotine dependence.

In a representative investigation, Pohl and co-workers (1992) observed that $51.6 \%$ of patients with PD were smokers at the onset of the illness and that $36.8 \%$ were regular smokers.

A longitudinal study (Johnson et al 2000) showed that an heavier cigarette smoking during adolescence was associated with an elevated risk of agoraphobia, generalized anxiety disorder, and panic disorder in early adulthood.

Taken together, available studies suggest that smoking and panic co-occur at elevated rates, and these observed associations are not due to socio-demographic characteristics, other psychiatric conditions, or symptom overlap in diagnostic criteria for PD and nicotine dependence (Zvolensky et al 2005).

In the frame of the above data pertaining both alcohol and tobacco use in the relation with anxiety disorder and particularly with panic, it seemed worthwhile to analyse such a relationship to clarify the etiopathogenetic mechanisms explaining this co-occurrence as well as the clinical approach to use in smokers or alcohol users with a diagnosis of panic attacks or panic disorder. 
Chapter 1

\section{Drinking, smoking and panic; looking for links}

The subject of this thesis is panic disorder as it occurs in comorbidity with the abuse of alcohol or nicotine.

Chapter two provides a general introduction on PD and alcohol abuse and a critical review of the literature. Emphasis lies on the causal relationship between panic and alcohol use disorder as this topic is still controversial. Up to now, two main explanations have been hypothesised for such a co-occurrence. Panic may promote pathological alcohol use as self-medication, and chronic alcohol use as well as alcohol withdrawal may induce changes in the neurochemical system that trigger panic. A third factor has been considered as familial transmission might promote both conditions.

The review highlights that alcohol lessens anxious apprehension in panic subjects, thereby decreasing the likelihood of panic. In alcoholics, alcohol increases $\mathrm{CO}_{2}$ sensitivity, thereby promoting panic. In both cases, a significant familial transmission contributes to the co-occurrence of the two disorders.

The present findings seem to indicate that panic and alcohol use disorders can both serve to initiate the other via independent mechanisms. Thus, the self medication hypothesis and the neurochemical hypothesis result opposite but not mutually exclusive explanations. The first may explain the mechanism of the comorbidity when panic occurs temporally prior to alcohol use, the latter when alcohol use disorder is temporally prior to panic.

As an effort to clarify the effect of alcohol use on panic and verify the self medication hypothesis, an experimental model called $35 \% \mathrm{CO}_{2}$ model was used to study panic under laboratory controlled conditions.

A considerable amount of previous work has validated the $35 \% \mathrm{CO}_{2}$ challenge as an experimental model for panic. Such an experimental model should fulfil four criteria: specificity, clinical validity, replicability and symptom convergence. It was shown that the spectrum of disorders exists, with different degrees of sensitivity to $\mathrm{CO}_{2}$. By far the highest sensitivity is found for panic disorder, however. Clinically effective panic reducing agents have been shown to reduce the vulnerability to the $35 \% \mathrm{CO}_{2}$ challenge. Conversely, ineffective agents have failed to do so. The recreation to the challenge is also readily replicable in panic disorder patients, regarding the provoked anxiety as well as the different panic symptoms. It was shown that the $35 \% \mathrm{CO}_{2}$ challenge reproduces well the majority of natural panic symptoms. 
$\mathrm{CO}_{2}$ is supposed to have its panicogenic effect via triggering of chemioreceptive areas in the brainstem which causes, among other things, respiratory stimulation. This should be an essential quality of a panicogen, according to the false suffocation alarm hypothesis of Donald Klein $(1993,1994)$, a theory on panic that emphasizes the link between panic and respiratory system.

Chapter three proposes a study in which the symptoms of $35 \% \mathrm{CO}_{2}$ induced panic attacks observed after the intake of an alcoholic drink were compared with the symptoms of $35 \% \mathrm{CO}_{2}$ elicited panic attacks after placebo intake. It was shown that the subjects undergoing the $\mathrm{CO}_{2}$ challenge after alcohol oral assumption had a significantly lower response to the challenge than subjects who received a non alcoholic drink. Considering that no differences were observed for the pre challenge level of anxiety, it was argued that alcohol may have a specific anti panic effect.

This study, however, seemed to have some limitations. On one hand, alcohol was administered orally. This may imply that it acted on $\mathrm{CO}_{2}$ induced panic symptoms both via its pharmacological and psychological properties (e.g. the act to drink, the belief of being drinking an alcoholic beverage with sedating properties). On the other hand, the sample was constituted by healthy volunteers who could not be a gold standard to make inferences on panic disorder patients.

Because of these possible limitations, a second study was performed using ethanol intravenously in drug free panic disorder patients and healthy volunteers. This study is presented in chapter four. Compared to the placebo condition, the effect of the $35 \% \mathrm{CO}_{2}$ challenge was significantly smaller after ethanol infusion. No sedating effect was found in the pre challenge phase. Again, the findings confirm those showed in chapter three. They also comfort earlier findings of a direct pharmacological anxiolytic effect of alcohol on panic.

According to these studies, alcohol and panic might be linked via a causal relationship as alcohol can be used to reduce the severity of symptoms of panic. Thus, the self medication hypothesis seems supported.

Similarly to alcohol, nicotine and cigarette smoking are usually used and abused in socially accepted conditions and are strongly related to anxiety disorders, particularly to panic.

Once again, the pathogenetic mechanism underlying such a relationship is still discussed and several explanations have been advanced. One hypothesis suggests that PD patients smoke as means of selfmedicating their symptoms (Breslau et al 1991; Pohl et al 1992). On the contrary, some authors propose that pulmonary problems may predispose smokers to overreact to suffocation signals manifesting panic 
attacks (Breslau et al 1999).

Other possibilities of pathways from smoking to panic have been suggested. It has been observed that nicotine produces physiological effects characteristics of panic attacks via the release of epinephrine and norepinephrine (Dilsaver 1987). Alternatively, Zvolensky et al (2003) found that nicotine may modify the expression of PD by increasing potentially fear-producing bodily sensation. That is individuals with PD, who usually perceive themselves as being physically unhealthy, would more likely react with exaggerated anxiety.

Finally, a shared vulnerability has been tested examining whether panic and cigarette smoking share genetic or environmental liability factors.

On the basis of these hypotheses and the above mentioned studies conducted on alcohol and panic, it seemed interesting to evaluate if even the relationship between nicotine and panic may be explained by pharmacological mechanisms.

Accordingly, chapter five contains a study on the acute effect of transdermally administered nicotine on healthy non smokers. Compared to the placebo condition, nicotine did not affect the $35 \% \mathrm{CO}_{2}$ challenge response but induced an aspecific response prior to the challenge. Thus, nicotine did not seem to specifically elicit panic but to trigger an aspecific autonomic activation.

These findings may cast some doubts on the validity of the hypothesis for which smoking has a calming effect. On the other hand, they support the possibility that nicotine contributes in inducing panic via an aspecific noradrenergic system stimulation.

The study, however, seemed to have some limitations. First of all, nicotine was acutely administered. In real life smokers are chronically or sub-acutely exposed to nicotine and this may imply a different pharmacological effect of the substance. Second, the effect of nicotine was evaluated in healthy volunteers. They may have different response to nicotine if compared to psychologically vulnerable individuals such as patients with PD or with a high level of anxiety sensitivity or a strong fear of suffocation. In fact, nicotine's sympathetic arousal induces effects that could easily be interpreted by psychologically vulnerable individuals as dangerous and initiate a panic-like reaction to the $\mathrm{CO}_{2}$ challenge.

Because of these possible limitations, a second study was performed administering the $35 \% \mathrm{CO}_{2}$ challenge to panic disorder smokers and panic disorder non smokers. The study is presented in chapter six. The aim was to test whether cigarette smoking, used as a proxy of chronic exposure to nicotine, has 
an influence on laboratory elicited panic in PD patients. Smokers and non smokers did not differ for baseline clinical characteristics of panic and for pre challenge level of anxiety. Smokers had a significantly higher response to the challenge than non smokers considering both PSL and VAAS score. They also had a higher rate of $\mathrm{CO}_{2}$ elicited panic attacks than non smokers.

In this frame, cigarette smoking, used as a proxy of chronic exposure to nicotine, increases the response to the $35 \% \mathrm{CO}_{2}$ challenge in PD patients. These findings confirm that nicotine, or at least cigarette smoking, may have a specific panicogenic effect.

According to these studies, nicotine and panic might be linked via a causal relationship. Nicotine has an aspecific pharmacological anxiogenic effects when it is acutely administered to healthy no vulnerable volunteers. On the contrary, it has a specific panicogenic effect in vulnerable PD patients chronically exposed to cigarette smoking.

While the association between cigarette smoking and anxiety as well as between cigarette smoking and affective disorders has been well documented, an increasing literature focuses on the relationship between smoking and negative affectivity.

Besides a high prevalence of anxious and depressive symptoms has been observed in smokers (Lagrue et al 2002) and in smokers attending smoking cessation clinics (Fakhfakh et al 2003), it seemed interesting to further evaluate if the occurrence of this sub threshold negative affectivity could complicate smoking dependence and/or lead to the request of specialised centres to quit.

Chapter seven is a study in which negative affectivity was evaluated in smokers applying for smoking cessation clinics and in smokers of the general population. Applicants had anxious and depressive symptoms more frequently than smokers from the general population.

According to these findings, the occurrence of anxious and/or depressive symptoms seems to complicate cigarette smoking in smokers who ask for a specialised intervention to quit.

This phenomenon may have important implications in clinical practice. An evaluation of the level of negative affectivity at first visit would give a more detailed psychopathological picture of the patient. A psychological or pharmacological support could be proposed with the aim to reduce those negative affective symptoms. Strategies of this kind may increase the rate of success in quitting or the duration of smoking abstinence.

However, besides sub threshold symptoms are relevant in determining the severity of smoking dependence and the clinical approach to use, other factors should be taken into account. 
Nicotine dependence, psychological distress and personality characteristics, for instance, are claimed to have a key role in triggering (Malouff et al 2006), maintaining smoking or failing in quitting (Chatkin et al 2004; Doran et al 2004; Hooten et al 2005).

Chapter eight contains a pharmacological study, evaluating the relationship between personality characteristics, psychological distress, nicotine dependence and the risk to fail in quitting smoking in smokers under an eighteen - week treatment with nicotine replacement therapy or placebo. Outcome was evaluated after twelve, twenty six and fifty two weeks of follow up. Smokers who succeeded in quitting were compared with those who failed.

The level of baseline nicotine dependence, measured by means of the Fagerström Tolerance Questionnaire, and Psycoticism, measured by means of the Eysenck Personality Inventory, were the strongest predictors of quitting failures. No statistically significant results were found for psychological distress.

The results show that nicotine dependence influences the medium long term outcome as a possible result of physical and psychological dependence. Moreover, psychoticism seems to influence the risk of quitting failure as it implies personality traits which may favour nicotine dependence and discourage in persisting a task such as quitting smoking. 


\section{REFERENCES}

American Psychiatric Association (1980). DSM IIII: diagnostic and statistical manual of mental disorders. Washington, DC: American Psychiatric Association.

American Psychiatric Association (1987). DSM IIIR: diagnostic and statistical manual of mental disorders. Washington, DC: American Psychiatric Association.

American Psychiatric Association (1994). DSM IV: diagnostic and statistical manual of mental disorders. Washington, DC: American Psychiatric Association.

American Psychiatric Association (2000). DSM IV-T-R: diagnostic and statistical manual of mental disorders. Washington, DC: American Psychiatric Association.

Amering M, Bankier B, Berger P, Griengl H, Windhaber J, Katschnig H (1999). Panic disorder and cigarette smoking behaviour. Compr Psychiatry 40;35-8.

Arch JJ, Craske MG, Stein MB, Sherbourne CD, Roy-Byrne PP (2006). Correlates of alcohol use among anxious and depressed primary care patients. Gen Hosp Psychiatry 28(1);37-42.

Boyle P (1997). Cancer, cigarette smoking and premature death in Europe: a review including the Recommendations of European Cancer Experts Consensus Meeting. Helsinki, October 1996.

Breslau N (1995). Psychiatric comorbidity of smoking and nicotine dependence. Behav Genet 25;95-101.

Breslau N, Klein D F (1999). Smoking and panic attacks. Arch Gen Psychiatry 56;1141-7.

Breslau N, Kilbey M, Andresti P (1991). Nicotine dependence, major depression, and anxiety in young adults. Arch Gen Psychiatry 48(12);1069-1074.

Burns L, Teesson M (2002). Alcohol use disorders comorbid with anxiety, depression and drug use disorders. Findings from the Australian National Survey of Mental Health and Well Being. Drug Alcohol Depend 68(3);299-307.

Cadoret R, Winokur G (1974). Depression in alcoholism. Ann NY Acad Sci 233;34-9.

Chatkin JM, Mariante de Abreu C, Haggstram FM, Wagner MB, Fritscher CC (2004). Abstinence rates and predictors of outcome for smoking cessation: do Brazilian smokers need special strategies? Addiction 99(6);778-84.

Degenhardt L, Hall W, Lynskey M (2001). Alcohol, cannabis and tobacco use among Australians: a comparison of their associations with other drug use and use disorders, affective and anxiety disorders, and psychosis. Addiction 96(11);1603-14.

Dilsaver SC (1987). Nicotine and panic attacks. Am J Psychiatry 144;1245-6. 
Doran N, Spring B, McChargue D, Pergadia M, Richmond M (2004). Impulsivity and smoking relapse. Nicotine Tob Res 6(4);641-7.

Edwards G, Gross MM (1976). Alcohol dependence: provisional description of a clinical syndrome. $\mathrm{Br}$ Med J 1;1058-61.

Fakhfakh R, Aouina H, Gharbi L, Hsairi H, Achour N, Langrue G, Bouacha H (2003). Dependence tabagique te troubles anxio-depressifs chez le fumeur tunisien. Rev Mal Respir 20;850-7.

Gonzalez-Pinto A, Gutierrez M, Ezcurra J, Aizpuru F, Mosquera F, Lopez P, de Leon J (1998). Tobacco smoking and bipolar disorder. J Clin Psychiatry 59;225-8.

Himle JA, Thyer BA, Fischer DJ (1988). Prevalence of smoking among anxious outpatients. Phobia Practice and Research Journal 1;25-31.

Holbrook JB (1983). Tobacco smoking. In Petersdorf RG, Adams RD, Braunwald E, Isselbacher KJ, Martin JB, Wilson D eds. Harrison's Principles of Internal Medicine. New York, NY: McGrawHill.

Hooten WM, Ames SC, Vickers KS, Hays JT, Wolter TD, Hurt RD, Offord KP (2005). Personality correlates related to tobacco abstinence following treatment. Int J Psych Med 35(1);59-74.

Jellinek EM (1952). Phases of alcohol addiction. Q J Stud Alcohol 13; 673-84.

Johnson JG, Cohen P, Pine DS, Klein DF, Kasen S, Brook JS (2000). Association between cigarette smoking and anxiety disorder during adolescence and early adulthood. JAMA 284;2348-51.

Kandel DB, Huang FY, Davies M (2001). Comorbidity between patterns of substance use dependence and psychiatric syndromes. Drug Alcohol Depend 64(2);233-41.

Kessler RC, Crum RM, Warner LA, Nelson CB, Schulenberg J, Anthony JC (1997). Lifetime cooccurrence of DSM IIIR alcohol abuse and dependence with other psychiatric disorders in the National Comorbidity Survey. Arch Gen Psychiatry 54;313-21.

Klein DF (1993). False suffocation alarms, spontaneous panics, and related conditions: an integrative hypothesis. Arch Gen Psychiatry 50;306-17.

Klein DF (1994). Testing the suffocation false alarm theory of panic disorder. Anxiety 1;1-7.

Kushner M, Abrams K, Thuras P, Hanson KL, Brekke M, Sletten S. (2005). A follow-up study of anxiety disorder and alcoholism dependence in co-morbid alcoholism treatment patients. Alcohol Clin Exp Res 29(8);1432-43.

Kushner MG, SHer KJ, Beitmen BD (1990). The relation between alcohol problems and the anxiety 
disorders. Am J Psychiatry 147;685-95.

Kushner MG, Sher KJ, Erickson DJ (1999). Prospective analysis of the relation between DSM-III anxiety disorders and alcohol use disorders. Am J Psychiatry 156(5);723-32.

LaBounty LP, Hatsukami D, Morgan SF, Nelson L (1992). Relapse among alcoholics with phobic and panic symptoms. Addict Behav 17;9-15.

Lagrue G, Dupont P, Fakhfakh R (2002). Anxiety and depressive disorders in tobacco dependence. Encephale 28(4);374-7.

Lasser K, Boyd JW, Woolhandler S, Himmelstein DU, McCormick D, Bor DH (2000). Smoking and mental illness: A population-based prevalence study. JAMA 284(20);2606-10.

Levine HG (1978). The discovery of addiction: changing conceptions habitual drunkenness in American history. J Stud Alcohol 39;143-74.

Malouff JM, Thorsteinsson EB, Schutte NS (2006). The five-factor model of personality and smoking: a meta-analysis. J Drug Educ 36(1);47-58.

Midanik L, Greenfield TK (2000). Trends in social consequences and dependence symptoms in the United States: the National Alcohol Surveys, 1994-95. Am J Public Health 90;53-6.

Ojehagen A, Berglund M, Appel C, Nilsson B, Skjaerris A (1990). Psychiatric symptoms in alcoholics attending outpatient treatment. Alcohol Clin Exp Res 15;640-6.

Pohl R, Yeragani VK, Balon R, Lycaki H, McBride R (1992). Smoking in patients with panic disorder. Psychiatry Res 43;253-62.

Regier DA, Farmer ME, Rue DS, Locke BZ, Keith SJ, Judd LL, Goodwin FK (1990). Comorbidity of mental disorders with alcohol and other drug abuse: results from the Epidemiological Catchment Area (CA) Study. J Am Med Association 246;2511-8.

Rohde P, Kahler CW, Lewinsohn PM, Brown RA (2004). Psychiatric disorders, familial factors, and cigarette smoking: III. Associations with cessation by young adulthood among daily smokers. Nicotine Tob Res 6(3);509-22.

Royal College of Physicians of London (1962). Smoking and health; summary and report, on smoking in the relation to cancer of the lung and other diseases. New York: Pitman Publishing Corporation.

Saunders JB, Lee NK (2000). Hazardous alcohol use: its delineation as a subthreshold disorder, and approaches to its diagnosis and management. Compr Psychiatry 41(2 Suppl 1);95-103.

Schuckit MA (1986). Genetic and clinical implications of alcoholism and affective disorder. Am J 
Psychiatry 143;140-7.

Sonntag H, Wittchen HU, Hofler M, Kessler RC, Stein MB (2000). Are social fears and DSM IV social anxiety disorder associated with smoking and nicotine dependence in adolescents and young adults? Eur Psychiatry 15: 67-74.

Surgeon General's Advisory Committee on Smoking and Health (1964). Smoking and health. Report of the Advisory Committee to the Surgeon General of the Public Health Service, PHS Publication $n^{\circ}$ 1103. Washington, DC: US Department of Health, Education, and Welfare, Public Health Service.

Tomasson K, Vaglum P (1996). Psychopathology and alcohol consumption among treatment-seeking alcoholics: a prospective study. Addiction 91;1019-30.

Upadhyaya HP, Deas D, Brady KT, Kruesi M (2002). Cigarette smoking and psychiatric comorbidity in children and adolescents. J Am Acad Child Adolesc Psychiatry 41(11);1294-305.

Weissman MM, Myers JK (1980). Clinical depression in alcoholism. Am J Psychiatry 137;372-3.

World Health Organization (1992). The ICD 10 classification of mental and behavioural disorders. Geneva: World Health Organization.

World Health Organization (1997). Tobacco or health: a global status report. Geneva: World Health Organization.

Zvolensky MJ, Feldner MT, Leen-Feldner EW, McLeish AC (2005). Smoking and panic attacks, panic disorder, and agoraphobia: a review of the empirical literature. Clin Psychol Review 25;761-89.

Zvolensky MJ, Schmidt NB, McCreary BT (2003). The impact of smoking on panic disorder: an initial investigation of a pathoplastic relationship. J Anxiety Disord 17(4);447-60. 


\section{Chapter 2}

\section{Alcohol use disorders and panic disorder: a review of the evidence of a direct relationship}

\section{Abstract}

Objective. It is generally agreed that alcohol use disorders and panic disorder with or without agoraphobia $[\mathrm{PD}(\mathrm{A})]$ tend to occur within the same individual. However, the cause of this comorbidity remains controversial. Three main explanations are that (1) $\mathrm{PD}(\mathrm{A})$ promotes pathological alcohol use as self-medication, (2) chronic alcohol use and alcohol withdrawal induce changes in the neurochemical system that promote panic, and (3) a third factor, such as familial transmission, promotes both conditions. The aim of this review was to survey the literature in order to determine the validity of these explanatory models.

Data sources. A review of epidemiological, family, and laboratory studies was performed. Studies were identified using MEDLINE (English language articles published from 1960 to April 2006, key words: 'alcohol and panic').

Study selection. Twenty studies were reviewed and selected according to the following criteria: PD(A) and alcohol abuse/dependence diagnosed according to the DSM, no additional comorbidity, use of adult samples, comparison with a non-clinical control group, or application of a cross-over design.

Data extraction. Non-significant results or trends only were reported as 'no difference'. Data on 'anxiety disorders' or 'substance abuse' in general were not included.

Data synthesis. In $\mathrm{PD}(\mathrm{A})$, alcohol lessens anxious apprehension, thereby decreasing the likelihood of panic. In alcohol use disorders, alcohol increases $\mathrm{CO}_{2}$ sensitivity and may thereby promote panic. In both cases, a significant familial transmission contributes to the co-occurrence.

Conclusion. Findings would seem to indicate that $\mathrm{PD}(\mathrm{A})$ and alcohol use disorders can both serve to initiate the other via independent mechanisms. Further studies are warranted. 


\section{Introduction}

Substances like cocaine, marijuana, and alcohol may precipitate anxiety and, more specifically, panic (Cowley et al 1992; Katerndahl et al 1999; Deacon et al 2000). As far as alcohol is concerned, accumulating evidence supports the view that there is a close link between panic disorder with or without agoraphobia [PD(A)] and alcohol abuse or dependence. In fact, some studies (Dick et al 1994) show that subjects with $\mathrm{PD}(\mathrm{A})$ have a higher than expected prevalence of alcohol use disorders; other studies show that alcoholics have a higher than expected prevalence of panic.

One explanation for the etiology of such a comorbidity is that $\mathrm{PD}(\mathrm{A})$ directly promotes alcohol use disorders. The hypothesis that expresses this general view has been referred to as the 'self-medication hypothesis' (Quitkin et al 1972). It suggests that alcohol may decrease aversive panic-like symptoms, thereby promoting persistent and escalating use via negative reinforcement. This view has been most often supported by anxiety researchers who tend to consider alcohol use disorders as a complication of $\mathrm{PD}(\mathrm{A})$.

In contrast, alcoholism researchers consider panic symptoms to be a consequence of chronic alcohol use, especially in cases of strong dependence or withdrawal syndrome. According to this latter view, changes in neurochemical systems induced by alcohol use or alcohol withdrawal may be responsible for the onset of $\mathrm{PD}(\mathrm{A})$ (George et al 1990). In this regard, it is worth noting that researchers' backgrounds may shift the point of view from which the phenomenon is studied and influence the observation itself.

There is an alternative hypothesis that, rather than there being a direct causal relationship, both comorbid conditions may be promoted by a third factor. On the basis of the strong familial component observed in $\mathrm{PD}(\mathrm{A})$ and alcoholism, some authors have suggested that this third causal factor may run in the family (Merikangas et al 1998).

Finally, the illusion of a relationship between $\mathrm{PD}(\mathrm{A})$ and alcoholism may be due to an over representation of patients with both disorders according to Berkson's bias. However, this applies only to clinical studies and not to the ones conducted in community samples.

The present article briefly reviews the existing data on the comorbidity between alcoholism and panic. It focuses on epidemiological surveys, family studies, and experimental research. The aim is to get a broader perspective on the relationship between $\operatorname{PD}(\mathrm{A})$ and alcohol abuse/dependence and to identify the possible underlying etiological mechanisms. 


\section{Methods}

A computerized search was carried out (PUBMED 1960-2006) using the key words: 'alcohol and panic'. In addition, the reference lists from existing reviews and from the articles retrieved were inspected. Only English language articles published in peer-reviewed journals were included.

Drawing conclusions on the basis of the results of poorly designed studies is of questionable value. To proceed in the most conservative fashion, only studies performed according to specific criteria were included in the review.. The diagnosis of PD with (PDA) or without agoraphobia (PD) and alcohol abuse/dependence had to be made according to the Diagnostic and Statistical Manual of Mental Disorders. Moreover, no additional comorbid psychiatric disorders were allowed to be present at the time of participation in the study, and the study had to include adult samples. Except in the case of epidemiological surveys conducted in the general population, a non-clinical control group or a cross over design was required.

In order to work with an approach as conservative as possible, non- significant results or trends only were reported as 'no difference'. Also, studies were excluded when the data referred to 'anxiety disorders' or 'substance abuse' in general and when the comorbid disorders were not specifically limited to $P D(A)$ and alcohol use disorders.

\section{Results}

Twenty articles met our inclusion criteria. What follows is, first, an overview of studies estimating the prevalence of comorbidity in epidemiological studies in the general population, on the one hand, and in clinical samples, on the other hand. Then, the family studies looking at psychopathology in the families of probands with one of the two disorders will be reviewed. Finally, experimental studies analyzing the interaction between panic and alcohol, using panic provocation in the laboratory, will be considered.

\section{Studies on the prevalence of comorbidity}

In 1998, Swendsen et al (1998) aggregated and weighted the data of four major epidemiological surveys 
and showed the lifetime risk of $\operatorname{PD}(A)$ for patients with alcohol abuse/dependence compared with that of non-alcohol abuse/dependence samples (i.e., odds ratio, OR) after accounting for age, gender, and education. The OR was $3.82(95 \% \mathrm{Cl}=3.75-3.90)$ in the Epidemiologic Catchment Area (ECA) survey (Regier et al 1990), $2.09(95 \% \mathrm{Cl}=1.41-3.10)$ in the National Comorbidity Survey (NCS) (Kessler et al 1997), 0.97 (95\% Cl = 0.41-2.58) in the Puerto Rico study (Canino et al 1987), and $1.96(95 \% \mathrm{Cl}=0.93-$ 4.13) in the Zurich study (Angst et al 1984). The ORs of having alcohol abuse/dependence comorbid with PD over the past 12 months were $4.06(95 \% \mathrm{Cl}=3.90-4.22)$ in the $\mathrm{ECA}, 1.21(95 \% \mathrm{Cl}=0.77-1.90)$ in the NCS, $0.40(95 \% \mathrm{Cl}=0.49-12.68)$ in Puerto Rico, and $4.08(95 \% \mathrm{Cl}=0.79-21.18)$ in the Zurich study.

In Edmonton (Alberta, Canada), a random sample of 3,258 adult household residents was interviewed. The OR of alcohol abuse/dependence in those with $\mathrm{PD}(\mathrm{A})$ compared with all other subjects was 3.1 (Dick et al 1994). Lifetime comorbidity was also measured in the Ontario, Canada population aged 15-64 years by means of a survey of a representative household sample. The OR of PD in the case of alcohol dependence was $2.2(95 \% \mathrm{Cl}=1.1-4.3)$ (Ross 1995).

Finally, in the National Survey of Mental Health and Well-Being, a cross-sectional survey of 10,641 Australian adults, the $\mathrm{OR}(95 \% \mathrm{Cl})$ for the association between alcohol abuse/dependence and panic was 3.9 (2.3-6.7) (Burns et al 2002).

In sum, according to the results of the literature, the risk of $\mathrm{PD}(\mathrm{A})$ in cases of alcohol abuse/dependence is between two and four times higher than in cases of no alcohol abuse/dependence, the only exception being in the Puerto Rico (Canino et al 1987). This exception may be due to some characteristics of the study and of the Puerto Rican population: 1. subjects over age 64 years were not included, thus reducing the possibility of seeing a lifetime prevalence rate increase due to age; 2 . subjects had a low socioeconomic status as Puerto Rico is part of the developing and third world countries; 3 . least educated inhabitants and those living in urban areas were underrepresented, since they had higher rates of disorders for several diagnoses; thus, the overall rate of psychiatric disorder on the island may be slightly higher than what was reported; 4. Puerto Ricans may have different cultures and customs regarding disclosure of psychopathology and alcohol consumption; and 5. in Puerto Rico a translated and adapted version of the Diagnostic Interview Schedule (DIS) was used. The interview was changed as what concerns the computer algorithms and modified adding items according to diagnostic or cultural considerations. Moreover, fewer schedules were included because the survey was conducted by the Ministry of Health, and in this context the full DIS appeared likely to lead to respondent fatigue. Finally, 
the authors suggested that Puerto Ricans may have singular coping styles or social support networks that protect them from mental disorders.

Some epidemiological studies also examined the temporal relationship between panic and alcohol use/dependence, which is a relevant element in clarifying the etiologic mechanisms of such a comorbidity. Krystal et al (1992) used data from the first wave of interviews from five communities of the ECA project to examine the comorbidity of alcohol use and panic in relation to age. Alcoholism was negatively associated with age $(p<0.01)$. Among men, PD declined to $0 / 100$ by age 54 for individuals reporting recent alcohol abuse and by age 45 for individuals with a past, but not recent, alcoholism history (no alcohol abuse for greater than 6 months). Among women, PD rates declined to 0/100 by age 64 for individuals reporting recent alcohol abuse and by age 55 for women with a past, but not recent, alcoholism history. Thus, PD prevalence declined earlier in subjects with a past history of alcoholism than in subjects with a recent history of alcoholism. However, when the order of onset of reported symptoms of panic and alcoholism was examined among those who met criteria for both disorders at some point in their lives, $60 \%$ had symptoms of alcoholism at least 1 year earlier than symptoms of panic, $6 \%$ reported the onset of both symptoms within the same year, and $33 \%$ reported symptoms of panic at least 1 year earlier than those of alcoholism. Although the onset of alcohol abuse or dependence was almost twice as likely to occur prior to the onset of PD, this did not reach statistical significance $(p=0.11)$.

Finally, according to Swendsen et al (1998), alcohol abuse/dependence occurred prior to the onset of PD in $44.5 \%$ of subjects in the ECA, in $32.7 \%$ of those in the NCS, and in $50 \%$ of those in the Puerto Rico study. On the other hand, $\mathrm{PD}(\mathrm{A})$ was prior to alcohol abuse/dependence in $45.2 \%, 62.3 \%$, and $33.3 \%$ of cases, respectively.

The overall impression is that the temporal relationship between panic and alcohol use/dependence is still a matter of debate, with the literature showing quite heterogeneous results.

In recent decades, various publications have investigated the comorbidity of $\operatorname{PD}(\mathrm{A})$ and alcohol abuse/dependence in clinical samples. Some have addressed $\operatorname{PD}(A)$ subjects, and others have addressed alcoholic samples. Unfortunately, the large majority of those studies did not include a healthy control group or did not use DSM diagnostic criteria. Consequently, we reviewed only a small part of the literature.

Pollard et al (1990) compared 79 patients with alcohol dependence with 70 hospital employees and found that $10 \%$ versus $0 \%$, respectively, had a diagnosis of PD and that $22 \%$ versus $7 \%$ had a diagnosis of 
PDA.

Schuckit et al (1997) evaluated 2,713 alcohol dependent subjects and 919 controls and found that 4.2\% of alcoholics had panic disorder versus $1 \%$ of controls $(p<.001)$. More recently, Sbrana et al (2005) evaluated 50 consecutive $\operatorname{PD}(A)$ inpatients and outpatients presenting for treatment at their clinic and 50 healthy controls. They found that $4 \%(n=2)$ of the $\operatorname{PD}(A)$ patients and $6 \%(n=3)$ of the controls had an alcohol use disorder. In all cases, the rate of co-occurrence was surprisingly low when compared with that found in epidemiological surveys. However, before concluding that clinical samples may not be representative of the general population, additional methodologically sound research should be conducted and taken into account. Especially considering that the rates of $P D(A)$ documented in uncontrolled samples of alcohol dependent patients seeking treatment are between 13 and 25\% according to the studies (Johannessen et al 1989; Segui et al 2001).

There is also interesting literature on treatment of panic among alcohol dependent patients.

This topic has high interest today for several reasons. First, baseline comorbid panic disorder has been shown to be, among anxiety disorders, the single best predictor of a relapse to alcohol dependence after treatment (Kushner et al 2005). Second, it would be important to clarify if a specific antipanic treatment should be postponed to 3-6 months of sobriety, as suggested by clinical guidelines in 1990s (Cowley 1992); proposed as early treatment of panic in alcoholics; or integrated into the standard treatment for alcoholism. Besides representing an important future research direction, the studies on this topic are to our knowledge still a small number and not always including controls. Up to now, favourable results have been observed with administration of imipramine to depressed PD alcoholics in an open label trial (Nunes et al 1993) and clonazepam to three alcoholics in a case series (Baron et al 1990). According to these results, early pharmacotherapy for panic in alcoholics may be indicated.

Non pharmacological interventions showed controversial results. Bowen et al (2000) administered the regular alcoholism program with or without cognitive-behavioural treatment (CBT) specific for panic to alcoholic inpatients with $\mathrm{PD}(\mathrm{A})$ according to a case control design. No statistically significant differences were found between the two programs. On the other hand, Kushner et al (in press) reviewed the conduct and preliminary findings of a clinical trial of an integrated CBT program for alcoholism treatment patients with comorbid panic disorder.

The data overviewed indicated that this program was effective in reducing panic attacks and, more importantly, serious alcohol relapses following treatment. 
In brief, treatment research on panic and alcoholism is growing but still apparently not exhaustive to solve the clinical practice dilemma of which serial or integrated comorbidity treatment approach to use.

\section{Family studies}

Since the 1980s, several studies have investigated the possibility of genetic liability or clustering in families of $\mathrm{PD}(\mathrm{A})$ and alcohol abuse/dependence. Some studies have shown that family members of individuals with $\operatorname{PD}(\mathrm{A})$ are at an increased risk of alcoholism; others have found that family members of individuals with alcohol abuse/dependence are at an increased risk of panic.

Crowe et al (1983) collected data on 278 first-degree relatives of 41 probands with PD and on 262 relatives of 41 control probands. The morbidity risk for alcoholism was $6.1 \%$ in the first group and $3.8 \%$ in the second. Similar results were found by Noyes et al (1986), who observed that $6.6 \%$ of PD relatives and $4.4 \%$ of control relatives had a diagnosis of alcohol abuse/dependence $(p=0.01)$. Once again, Goodwin et al (2006) compared rates of alcohol use disorders in the relatives of 3 proband groups (PD with lifetime alcohol use disorders, PD without lifetime alcohol use disorders, and not-ill controls). They found a significantly higher rate (12\%) of alcohol use disorders among the relatives of PD probands compared with relatives of controls $(5 \%)$, and anxiety symptoms were more frequent among the male relatives of panic probands who received an alcohol diagnosis, compared with those who did not have alcohol use disorders.

In contrast, Merikangas et al (1998) evaluated 42 alcoholic probands and 61 controls and found an OR for having PD of $2.7(95 \% \mathrm{Cl}=1.2-5.8)$ when comparing relatives of alcoholic probands to relatives of controls. Similarly, Nurnberger et al (2004) conducted a study on a large sample of 8,296 relatives of alcoholic probands and of 1,654 controls, finding a relative risk of $2.15(95 \% \mathrm{Cl}=1.31-3.52)$. Adjusting for sex, ethnicity, ascertainment site, cohort effect, and comorbidity, the relative risk decreased to 1.90 (1.03-3.51).

Two additional studies should be noted as they refer to adult offspring of alcoholics. Mathew et al (1993) observed 408 adult children of alcoholics and 1,477 controls and found that $2.7 \%$ and $0.7 \%$, respectively, had a diagnosis of PD ( $p<0.001)$ with an OR of 4.06 ( $p \leq 0.01)$. Bidaut-Russell et al (1994) studied 74 adult offspring of mothers clinically diagnosed with alcoholism and 978 control subjects. They observed in male offspring of alcoholic mothers a more than twofold increased risk of panic occurrence when 
compared with male offspring of controls $(\mathrm{OR}=2.86,95 \% \mathrm{Cl}=0.31-26.52)$. Thus, the risk of one of the two disorders occurring in first-degree relatives of patients is almost doubled when compared with that of first-degree relatives of controls. The elevated risk of panic in relatives of alcoholics, and viceversa, seems to be confirmed also by studies on offspring.

However, family data sets also should be examined according to the pattern of co-occurrence. It might be worth clarifying if panic disorder and alcoholism co-occur in same families as an apparent phenotype (i.e. probands with $\mathrm{PD}(\mathrm{A})$ and alcoholism have relatives with $\mathrm{PD}(\mathrm{A})$ and alcoholism) or if the disorders tend to co-occur in isolation in relatives. The latter would suggest alternative phenotypic expressions of the same underlying vulnerability. This sort of analysis has already been used to make inferences about the relationship between depression and alcoholism in family studies. Moreover, this may be a starting point to strengthen the research on co-aggregation of multiple disorders as suggested by Nurnberger et al (2004). They found that rates of specific substance dependence were markedly increased in relatives of alcohol-dependent probands for cocaine, marijuana, opiates, sedatives, stimulants, and tobacco. Aggregation was also seen for panic disorder, obsessive-compulsive disorder, posttraumatic stress disorder, and major depression. These data suggest that new phenotypes for molecular genetic studies may exist as well as alternative strategies for studying the heterogeneity of alcohol dependence.

\section{Experimental studies}

Epidemiological and family studies highlight the possibility of a significant causal relationship between panic and alcohol abuse/dependence. Most studies suggest that panic may promote alcohol use disorders while other studies show that heavy drinking may induce the onset or worsening of panic. This suggests a potential complex causal link that needs to be clarified.

Experimental research may contribute to our understanding of this link as panic attacks, the core phenomenon of $\mathrm{PD}(\mathrm{A})$, are reproduced under controlled laboratory conditions by the administration of provocative agents (i.e., sodium lactate, carbon dioxide, cholecystokinin, yohimbine, etc.). These challenges also allow the direct observation of the effects of alcohol use on the panic-like response to a provocative agent.

Lactate infusion and $\mathrm{CO}_{2}$ inhalation are the challenges specifically used in studying the comorbidity between $\mathrm{PD}(\mathrm{A})$ and alcohol use disorders. George et al (1989) administered lactate to abstinent alcoholic 
patients with PD, non-alcoholics with PD, and control subjects. They found that alcoholic patients had fewer panic attacks in response to lactate infusion than non-alcoholic patients $(p<0.05)$ with no differences in baseline anxiety. The authors suggested that the pathophysiology of $P D(A)$ in alcoholics is different from that in non-alcoholics. It may be argued that even past alcohol use can protect against panic attacks or at least that alcoholics with $\mathrm{PD}$ are resistant to $\mathrm{CO}_{2}$.

On the other hand, Cowley et al (1989) studied the response to sodium lactate infusion in alcoholics with a history of panic attacks, alcoholics without a history of panic attacks, and non-alcoholics with PD. The rate of lactate-induced panic was significantly higher in alcoholics with panic attacks than in alcoholics without panic attacks $(p<0.02)$. Non-alcoholic patients with $\operatorname{PD}(A)$ and alcoholics with panic attacks did not differ significantly in their lactate response. The authors suggested that panic attacks in alcoholics resemble those in non-alcoholics.

Kushner et al (1996) tested the acute effect of alcohol on panic symptoms by administering either alcohol or placebo to subjects with PD and then administering a $35 \% \mathrm{CO}_{2}$ challenge. State anxiety scores were significantly lower in the alcohol group at both the pre- and post-challenge assessment $(p<0.01$ and $p<$ 0.05 , respectively). Subjects in the placebo group showed a greater increase over baseline on the postchallenge Acute Panic Inventory score than did subjects in the alcohol group $(p<0.01)$. No difference was found with regard to the number of panic attacks although they occurred in $50 \%$ of the subjects in the placebo group and in $25 \%$ of the subjects in the alcohol group $(p=0.15)$. The authors concluded that alcohol may attenuate panicky responses in patients with PD, perhaps by acting upon gamma-amino butyric acid (GABA) receptors. These results seem to contradict the previous ones obtained using lactate infusion as a challenge (George et al 1989). In reality, studies with lactate on the one hand and the ones with $\mathrm{CO}_{2}$ on the other address different questions and do not really contradict. The first (George et al 1989; Cowley et al 1989)evaluate "panicogen in alcoholics", and the second (Kushner et al 1996) are about "panicogen and alcohol administration". Thus, the first evaluate the acute effect of a panicogenic agent in subjects chronically exposed or not exposed to alcohol. The second evaluate the acute effects of panicogen plus alcohol or placebo in subjects chronically exposed to panic. Considering that lactate infusion and $\mathrm{CO}_{2}$ challenge have comparable efficacy in inducing panic under controlled laboratory conditions (Nutt 2001), different previous chronic exposures may imply a different sensitivity to the panicogenic agent. For this reason, studies with lactate infusion and studies with $\mathrm{CO}_{2}$ inhalation should be considered complementary. 
Lehman et al (2002) examined the effects of alcohol outcome expectancy, subjective anxiety, and anticipatory anxiety on panic symptoms induced by a $35 \% \mathrm{CO}_{2}$ challenge in PDA patients after consuming either an alcoholic or placebo beverage. Participants with greater positive alcohol expectancies reported fewer panic symptoms, participants who drank alcohol reported less anxiety after the challenge, and individuals with greater anticipatory anxiety reported greater post-challenge anxiety. The authors concluded that anticipatory anxiety mediates the relationship between alcohol use and selfreported anxiety as alcohol lessens anxious apprehension, possibly decreasing the likelihood of having a panic attack.

More recently, Rassovsky et al (2004) compared 22 detoxified, alcohol-dependent individuals with 32 healthy controls on two biological challenges (a breath-holding challenge and the $5 \% \mathrm{CO}_{2}$ re-breathing challenge). The alcoholic group had significantly higher $\mathrm{CO}_{2}$ sensitivity than controls in response to both challenges, while no differences were found in the number of laboratory-induced panic attacks. The authors concluded that alcohol withdrawal may lead to $\mathrm{CO}_{2}$ hypersensitivity and that this could be an important causal factor for comorbidity between alcohol abuse/dependence and panic. A proposed explanation is that $\mathrm{CO}_{2}$ hypersensitivity, resulting from chronic suppression of medullary chemoreceptors by alcohol, may lead to hyperventilation during the alcohol withdrawal syndrome and that this, in turn, may promote the onset and maintenance of panic. Alternatively, acute alcohol withdrawal could lead to a pathologically dysregulated $\mathrm{CO}_{2}$ chemosensory state, and $\mathrm{CO}_{2}$ hypersensitivity could thus generate false suffocation alarms and trigger panic attacks, according to Klein's (1993) theory.

\section{Discussion}

Perhaps the strongest conclusion that can be drawn from this review is that both $\operatorname{PD}(\mathrm{A})$ and alcohol use disorders appear to have the capacity to serve as a causal factor/facilitator in the development of the other. Epidemiological studies show a direct relationship between $\operatorname{PD}(\mathrm{A})$ and alcohol abuse/dependence. The lifetime risk of $\mathrm{PD}(\mathrm{A})$ occurrence in alcoholics ranges from 4.08 in the Zurich study to 1.21 in the NCS (United States), with the Puerto Rico study being the only exception ( $\mathrm{OR}=0.97)$.

As for the temporal pattern, panic onset occurs prior to alcohol abuse/dependence more frequently than the opposite pattern (Swendsen et al 1998; Krystal et al 1992). Yet, these two studies are the only ones 
suggesting this sequence pattern. The temporal pattern becomes even more complex if we consider that a past history of alcoholism has been found to be associated with an earlier decline in $\operatorname{PD}(A)$ prevalence compared with a recent history of alcoholism. Theoretically, this phenomenon may be differently explained. First, a successful self-medication can be considered. As an alternative, a biological degenerative process triggered by age, alcohol neurotoxicity, or alcohol withdrawal damage could be hypothesized. A natural age-related decline in panic prevalence and incidence in later life may be yet another explanation (Flint et al 1996). Finally, it could merely be a matter of under-reporting of symptoms by elderly subjects. The first explanation seems to be an argument in favour of the self-medication theory. In the second case, the hypothesis that alcohol triggers panic would be supported. In the third case, an independent factor, like the natural history of panic, would be the explanation. In the latter case, it would be a matter of methodological biases.

Clinical studies (Pollard et al 1990; Schuckit et al 1997; Sbrana et al 2005) further support a direct relationship between the two disorders but do not suggest an order of causality.

There is a clear familial aggregation between panic and alcohol use disorders since both occur in firstdegree relatives. However, the situation in offspring is not as clear. We were unable to find studies that met our criteria in offspring of $\mathrm{PD}(\mathrm{A})$ patients. In offspring of alcoholics, one study (Mathew et al 1993) found a higher risk of PD, but the other (Bidaut-Russell et al 1994) found this only in males.

Experimental research provides more substantial insight. Although lactate research is somewhat contradictory (Cowley et al 1989; George et al 1989), studies using $\mathrm{CO}_{2}$ challenge have yielded crucial results. These studies suggest that alcohol does not directly influence the likelihood of panic attack (Kushner et al 1996; Lehman et al 2002). Rather, in PD(A) patients, it seems to decrease the level of anticipatory anxiety (Kushner et al 1996; Lehman et al 2002). In alcoholics, however, it appears to increase the $\mathrm{CO}_{2}$ sensitivity (Rassovsky et al 2004). The effect of alcohol in the two subpopulations would, therefore, appear to be opposite. In PD patients, alcohol lessens anxious apprehension and thus decreases the likelihood of a panic attack. In alcoholics, alcohol increases $\mathrm{CO}_{2}$ sensitivity and promotes panic.

As far as $\operatorname{PD}(A)$ patients are concerned, the self-medication hypothesis appears to be valid. In the case of alcoholic patients, the hypothesis that alcohol may trigger the onset of panic is most likely. 


\section{Conclusions}

Findings from the present review support the higher than expected rate of co-occurrence of $\operatorname{PD}(A)$ and alcohol use disorders, and document a familial aggregation and a familial transmission. The findings also suggest that when panic onset is prior to alcohol use disorder, the use of alcohol is an attempt to selfmedicate. At the same time, the findings suggest that when alcohol use disorders occur prior to $\operatorname{PD}(A)$, panic follows as a consequence of hypersensitivization.

We started with two opposite hypotheses of causality that were apparently mutually exclusive. The first depicted alcohol use disorders as a complication of panic, thus supporting the self-medication theory. The other suggested that panic is a complication of alcohol use disorders.

We propose that these two hypotheses are opposite, but not mutually exclusive. The first may explain the mechanism of the comorbidity when panic occurs prior to alcohol use, the latter when alcohol use disorders are temporally prior to panic.

However, the issues proposed in the present review require further clarification. In fact, we found only 20 studies that met our strict inclusion criteria over a time span of about 20 years. What is needed are additional studies using well-standardized methods, followed by reliable replications.

Moreover, studies clarifying the temporal occurrence of the two disorders are warranted. They could have interesting clinical implications and solve the dilemma on how to treat dually diagnosed patients. If $\mathrm{PD}(\mathrm{A})$ occurs first, a specific psycho-pharmacological anti-panic treatment could be applied early. If alcohol abuse occurs first, the biochemical process of hypersensitization should be addressed early preventing, withdrawals and promoting sobriety. Alternatively, a parallel treatment approach or an integrated treatment program could be useful.

In this frame, treatment research should be encouraged to define the pharmacological/non pharmacological program to apply when panic and alcoholism co-occur. It also would be interesting to establish if the treatment of panic has an impact on drinking habits, for instance reducing alcohol consumption or improving withdrawal symptoms, and if this activates a virtuous circle further improving panic symptoms.

Finally, to draw a more complete picture, it would be interesting to verify if the hypotheses proposed in the present review can be applied to the relationship between panic and other substances of abuse. In fact, it is widely accepted that panic may begin or be exacerbated by the use of drugs such as marijuana, 
cocaine, and amphetamines and that in sedative/hypnotic abusers there is an increasing rate of panic. In practice, it would be interesting to verify the temporal relationship between panic and abuse of other substances and, once again, identify the proper treatment for dually disordered patients. This would imply addressing the substance dependence as well as using pharmacological/non pharmacological treatments for panic.

In general, increasing the knowledge on panic and substance abuse should guarantee that more instruments are used in clinical practice to treat patients, prevent complications, and improve their quality of life.

\section{Acknowledgments}

The present project was not supported by any grants and was not previously presented. 


\section{REFERENCES}

Angst J, Dobler-Mikola A, Binder J (1984). The Zurich study--a prospective epidemiological study of depressive, neurotic and psychosomatic syndromes. I. Problem, methodology. Eur Arch Psychiatry Neurol Sci 234(1);13-20.

Baron DH, Sands BF, Ciraulo DA, Shader RI (1990). The diagnosis and treatment of panic disorder in alcoholics: three cases. Am J Drug Alcohol Abuse 16(3-4);287-95.

Bidaut-Russell M, Bradford SE, Smith EM (1994). Prevalence of mental illnesses in adult offspring of alcoholic mothers. Drug Alcohol Depend 35;81-90.

Bowen RC, D'Arcy C, Keegan D, Senthilselvan A (2000). A controlled trial of cognitive behavioral treatment of panic in alcoholic inpatients with comorbid panic disorder. Addict Behav. 25(4);593-7.

Burns L, Teesson M (2002). Alcohol use disorders comorbid with anxiety, depression and drug use disorders. Findings from the Australian National Survey of Mental Health and Well Being. Drug Alcohol Depend 68;299-307.

Canino G, Bird H, Shrout P, Rubio-Stipec M, Bravo M, Martinez R, Sesman M, Guevara LM. (1987). The prevalence of specific psychiatric disorders in Puerto Rico. Arch Gen Psychiatry 44;727-35.

Cowley DS, Jensen CF, Johannessen D, Parker L, Dager SR, Walker RD (1989). Response to sodium lactate infusion in alcoholics with panic attacks. Am J Psychiatry 146;1479-83.

Cowley DS (1992). Alcohol abuse, substance abuse, and panic disorder. Am J Med 92 (Suppl 1A);1S$41 S$.

Crowe RR, Noyes R, Pauls DL, Slyman D (1983). A family study of panic disorder. Arch Gen Psychiatry 40;1065-9.

Deacon BJ, Valentiner DP (2000). Substance use and non-clinical panic attacks in a young adult sample. J Subst Abuse 11(1);7-15.

Dick CL, Bland RC, Newman SC (1994). Epidemiology of Psychiatric Disorders in Edmonton: Panic disorder. Acta Psych Scand 376(Suppl);45-53.

Flint AJ, Cook JM, Rabins PV (1996). Why is panic disorder less frequent in late life? Am J Geriatr Psychiatry 4;96-109.

George DT, Nutt DJ, Waxman RP, Linnoila M (1989). Panic response to lactate administration in alcoholic and nonalcoholic patients with panic disorder. Am J Psychiatry 146;1161-5. 
George DT, Nutt DJ, Dwyer BA, Linnoila M (1990). Alcoholism and panic disorder; is the comorbidity more than a coincidence? Acta Psychiatr Scand 81;97-107.

Goodwin RD, Lipsitz JD, Chapman TF, Mannuzza S, Klein DF, Fyer AJ (2006). Alcohol use disorders in relatives of patients with panic disorder. Compr Psychiatry 47(2);88-90.

Johannessen DJ, Cowley DS, Walker RD, Jensen CF, Parker L (1989). Prevalence, onset, and clinical recognition of panic states in hospitalized male alcoholics. Am J Psychiatry 146(9);1201-3.

Katerndahl DA, Realini JP (1999). Relationship between substance abuse and panic attacks. Addict Behav 24 (Suppl 5);731-6.

Kessler RC, Crum RM, Warner LA, Nelson CB, Schulenberg J, Anthony JC (1997). Lifetime cooccurrence of DSM III R alcohol abuse and dependence with other psychiatric disorders in the National Comorbidity Survey. Arch Gen Psychiatry 1997;54:313-321.

Klein DF (1993). False suffocation alarms, spontaneous panics, and related conditions. Arch Gen Psychiatry 50;306-17.

Krystal JH, Leaf PJ, Bruce ML, Charney DS (1992). Effects of age and alcoholism on the prevalence of panic disorder. Acta Psychiatr Scand 85(Suppl 1);77-82.

Kushner M, Abrams K, Thuras P, Hanson KL, Brekke M, Sletten S (2005). Follow-up study of anxiety disorder and alcoholism dependence in co-morbid alcoholism treatment patients. Alcohol Clin Exp Res 29(8);1432-43.

Kushner MG, Donahue C, Sletten S, Thuras P, Abrams K, Peterson J, Frye B (in press). Cognitive Behavioral Treatment of Comorbid Anxiety Disorder in Alcoholism Treatment Patients: Presentation of a Prototype Program and Future Directions. Int J Ment Health.

Kushner MG, Mackenzie TB, Fiszdon J, Valentiner DP, Foa E, Anderson N, Wangensteen D (1996). The effects of alcohol consumption on laboratory-induced panic and state anxiety. Arch Gen Psychiatry 53;264-70.

Lehman CL, Brown TA, Palfai T, Barlow DH (2002). The effects of alcohol outcome expectancy on a carbon dioxide challenge in patients with panic disorder. Behavior Therapy 33;447-63.

Mathew RJ, Wilson WH, Blazer DG, George Lk (1993). Psychiatric disorders in adult children of alcoholics: data from the Epidemiologic Catchment Area project. Am J Psychiatry 150(Suppl 5);793-800.

Merikangas KR, Stevens DE, Fenton B, Stolar M, O'Malley, Woods SW, Risch N (1998). Comorbidity 
and familial aggregation of alcoholism and anxiety disorders. Psychol Med 28;773-88.

Noyes R, Crowe RR, Harris EL, Hamra BJ, McChesney CM, Chaudhry DR (1986). Relationship between panic disorder and agoraphobia. Arch Gen Psychiatry 43;227-32.

Nunes EV, McGrath PJ, Quitkin FM, Stewart JP, Harrison W, Tricamo E, Ocepek-Welikson K (1993). Imipramine treatment of alcoholism with comorbid depression. Am J Psychiatry 150;963-5.

Nurnberger JI, Wiegand R, Bucholz K, O'Connor S, Meyer ET, Reich T, Rice J, Schuckit M, King L, Petti T, Bierut L, Hinrichs AL, Kuperman S, Hesselbrock V, Porjesz B (2004). A family study of alcohol dependence: coaggregation of multiple disorders in relatives of alcohol-dependent probands. Arch Gen Psychiatry 61;1246-56.

Nutt DJ (2001). The pharmacology of human anxiety. In: Griez EJL, Faravelli C, Nutt D, Zohar J, eds. Anxiety disorders. An introduction to clinical management and research. New York: Md John Wiley \& Sons. pp. 309-24.

Pollard CA, Detrick P, Flynn T, Frank M (1990). Panic attacks and related disorders in alcoholdependent, depressed, and nonclinical samples. J Nerv Ment Dis 178(Suppl 3);180-5.

Quitkin FM, Rifkin A, Kaplan J, Klein DF (1972). Phobic anxiety syndrome complicated by drug dependence and addiction. Arch Gen Psychiatry 27;159-62.

Rassovsky Y, Hurliman E, Abrams K, Kushner MG (2004). $\mathrm{CO}_{2}$ hypersensitivity in recently abstinent alcohol dependent individuals: a possible mechanism underlying the high risk for anxiety disorder among alcoholics. J Anxiety Disord 18;159-76.

Regier D, Farmer M, Rae D, Locke BZ, Keith SJ, Judd LL, Goodwin FK (1990). Comorbidity of mental disorders with alcohol and other drug abuse: results from the Epidemiologic Catchment Area (ECA) study. JAMA 264;2511-8.

Ross HE (1995). DSM IIIR alcohol abuse and dependence and psychiatric comorbidity in Ontario: results from the Mental Health Supplement to the Ontario Health Survey. Drug Alcohol Depend $39 ; 111-28$.

Sbrana A, Bizzari JV, Rucci P, Gonnelli C, Doria MR, Spagnolli S, Ravani L, Raimondi F, Dell'Osso LO, Cassano GB (2005). The spectrum of substance use in mood an anxiety disorders. Compr Psychiatry 46;6-13.

Schuckit MA, Tipp JE, Bucholz KK, Nurnberger JI Jr, Hesselbrock VM, Crowe RR, Kramer J (1997). The life-time rates of three major mood disorders and four major anxiety disorders in alcoholics and 
controls. Addiction 92(10);1289-304.

Segui J, Marquez M, Canet J, Cascio A, Garcia L, Ortiz M (2001). Panic disorder in a Spanish sample of 89 patients with pure alcohol dependence. Drug Alcohol Depend 63(2);117-21.

Swendsen JD, Merikangas KR, Canino GJ, Kessler RC, Rubio-Stipec M, Angst J (1998). The comorbidity of alcoholism with anxiety and depressive disorders in four geographic communities. Compr Psychiatry 39(Suppl 4);176-84. 


\section{Chapter 3}

\section{The influence of alcohol oral intake on the effects of $35 \% \mathrm{CO}_{2}$ challenge. A study in healthy volunteers}

\section{Abstract}

Objective. Alcohol use disorders and panic disorder co-occur at a rate that exceeds chance significantly. The underlying mechanism of alcoholism associated to anxiety has been rarely examined using experimental methodologies.

The present study tested in healthy volunteers whether alcohol consumption reduces anxiety associated with a panic-challenge procedure $\left(35 \% \mathrm{CO}_{2}\right.$ challenge).

Methods. Placebo-controlled, double-blind, randomised study design. Eight healthy volunteers were enrolled; all subjects had an alcohol and a placebo oral intake according to a cross-over design. After each consumption the subjects underwent the $35 \% \mathrm{CO}_{2}$ challenge and a series of anxiety symptom assessments.

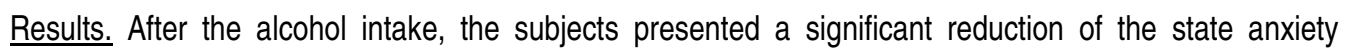
associated with the challenge procedure. The Panic Symptom List score is significantly lower after alcohol intake ( $p=0.032$ ), if compared with the placebo, and the Visual Analogous Anxiety Scale shows a trend to be lower after alcoholic drinking $(p=0.111)$.

Conclusions. Moderate doses of alcohol acutely decrease the response to a $35 \% \mathrm{CO}_{2}$ challenge in healthy volunteers. These results lend support to the pharmacological anxiolytic effect of alcohol and suggest that this property may reinforce the drinking behaviour among those with high levels of anxiety.

\section{Introduction}

Alcohol use disorders co-occur with panic disorder (PD) at a rate that exceeds chance significantly (Himle et al 1991; Kessler et al 1997). 
The reason of this comorbidity is unclear and may be explained by the "self-medication hypothesis" (Quitkin et al 1972), the genetic load (Maier et al 1993) or by the pharmacological anxiolytic effect of alcohol (Liljequist et al 1984; St Clair 1991).

Although such a comorbidity has been widely evaluated, only a small number of studies referred to experimental methodologies, able to induce panic attacks in a controlled laboratory environment (Dager et al 1987, Griez et al 1990, Verburg et al 2001). George et al (1989) and Cowley et al (1989) found that alcoholic patients had fewer panic attacks in response to lactate infusion than the non alcoholic subjects. On the other hand, Kushner et al (1996) showed that alcohol intake significantly decreases panic response to $\mathrm{COO}_{2}$ challenge and the state anxiety surrounding the challenge.

These results may be consistent with a direct pharmacological activity of alcohol on panic. However, in Kushner et al.'s study, subjects achieved relatively high alcohol blood levels corresponding in clinical signs of alcohol intoxication which may have biased the probants' reaction to the challenge.

The present study is aimed to replicate Kushner and co-workers using a smaller dosage of alcohol in a sample of healthy volunteers.

\section{Methods}

Eight healthy volunteers were enrolled, 5 males and 3 females with a mean age of 36.63 years. They had a medical history inventory, a physical examination and an evaluation through the Mini International Neuropsychiatric Interview (MINI) (Sheehan et al. 1998) to exclude past or present history of psychiatric disorders. They provided written informed consent and were paid to participate.

According to a placebo-controlled, double-blind, randomised, cross-over design, each subject underwent a $35 \% \mathrm{CO}_{2}$ challenge, after intake of a moderate dose of alcohol on one test day and placebo on another test day with an interval between the two days of at least 48 hours.

All appointments had been scheduled for the morning and females were tested during the first two weeks of the menstrual cycle (Jones 1974, Jones et al 1976). Subjects had been instructed: a) not to drink alcohol for 24 hours preceding each test, b) to refrain from caffeinated products and eating 4 hours prior to their appointment, c) not to drive to the laboratory and to stay for at least one hour after each experiment. 
Targeting a Blood Alcohol Concentration (BAC) of $50 \mathrm{mg} / \mathrm{dl}$ (Fisher et al 1987), females received $20 \mathrm{~g}$ of pure alcohol $(0.29 \mathrm{~g} / \mathrm{Kg})$ and males $28 \mathrm{~g}(0.34 \mathrm{~g} / \mathrm{Kg})$ (Watson et al 1981, Centraal Bureau Voor de Statistiek 2001) corresponding to 51 and $71 \mathrm{ml}$ of 80-proof vodka poured into grapefruit juice.

Placebo drink consisted of grapefruit juice plus water, squirted on the top with $4 \mathrm{ml}$ of vodka (Levenson et al 1987) and matched the volume of the alcoholic drink.

Placebo and alcoholic drink were pre-tested in 8 healthy non alcoholic subjects, no difference were found concerning the taste. Moreover, subjects gurgled with $10 \mathrm{cc}$ of mouth water before each oral intake to attenuate the taste acuity (DeBoer et al 1994).

Subjects had 10 minutes to consume the drinks and 20 minutes to rest to allow for alcohol absorption (Levenson et al 1987).

Then, $\mathrm{BAC}$ was assessed using a breath analyzer and they underwent a $35 \% \mathrm{CO}_{2}$ challenge, taking one vital capacity inhalation of $35 \% \mathrm{CO}_{2}-65 \% \mathrm{O}_{2}$ mixture via a self administration mask (Verburg et al 2001). Before entering the entire procedure, subjects completed a baseline assessment using the State Trait Anxiety Inventory, state form (STAI-1) (Spielberger et al 1970), the Zung Self rating Scale for Anxiety (SAS) (Zung 1971). Before and after the $\mathrm{CO}_{2}$ challenge, anxiety was assessed by means of the Visual Analogue Anxiety Scale (VAAS) (range 0-100), and the occurrence of panic symptoms by means of the Panic Symptom List (PSL) consisting of 13 panic symptoms listed in the DSM IV (APA 1994), each being rated between 0 (absent) and 4 (severe).

\section{Results}

There was not statistically significant difference concerning descriptive variables, biological parameters (blood pressure, heart rate, air inhaled) and rating scales scores measured at the baseline during the two test days.

The difference between pre- and post-challenge scores of the two main scales used (PSL and VAAS) shown a significant decrease of the PSL score after alcohol intake $(p=0.032)$ and a trend to a decrease of the VAAS score after alcohol assumption $(p=0.111)$ (table 1 ).

No statistically significant differences were found for the pre-challenge score of the two scales.

No subjects presented panic attacks during the $\mathrm{CO}_{2}$ challenge. 
Table 1. Paired t-test.

\begin{tabular}{|l|c|c|c|c|c|c|}
\hline & N & mean & SD & t & df & p \\
\hline PSL score & 8 & 3,500 & 3,546 & 2,67 & 7 & 0,032 \\
\hline With alcohol & 8 & 6,625 & 4,596 & & & \\
\hline With placebo & 8 & & & \\
\hline VAAS score & 8 & 3,250 & 6,964 & 1,82 & 7 & 0,111 \\
\hline With alcohol & 8 & 10,750 & 12,000 & & & \\
\hline With placebo & 8
\end{tabular}

\section{Comment}

Moderate doses of ethanol decreased the response to the $35 \% \mathrm{CO}_{2}$ challenge in healthy volunteers. These results confirm previous findings (George et al. 1989, Cowley et al. 1989, Kushner et al. 1996) and support the hypothesis that alcohol has an anxiolytic effect in cases with panic-like symptoms.

The present study has some obvious limitations. The sample size is small and consists of healthy volunteers, therefore any conclusion refers only inferentially to PD patients. Moreover, the subjects received alcohol orally which does not eliminate the bias linked to the drinking behaviour (Hull 1981).

Besides this, the present results have some advantages. In order to prevent sedation affecting cognitive performance and baseline anxiety before the $\mathrm{CO}_{2}$ challenge, low doses of alcohol were used referring to a BAC of $50 \mathrm{mg} / \mathrm{dl}$ (Kissin 1997). This means that the alcohol blood levels did not influence the subjects' cognitive performance (Tagawa et al 2000, Howland et al 2001) conferring a good reliability to their self ratings. Moreover, as ascertained by the pre-test assessments, such a dose did not produce any noticeable sedation that could have interfered with the reaction to the $\mathrm{CO}_{2}$ challenge. This means that the blunted response to $\mathrm{CO}_{2}$ observed after alcohol intake cannot be merely related to a decrease in anticipatory anxiety, but rather to a specific direct inhibitory action of ethanol on experimental panic (Liljequist et al 1984). 


\section{REFERENCES}

American Psychiatric Association (APA) (1994). Diagnostic and statistical manual of mental disorders (edition 4). Washington, D.C. American Psychiatric Association.

Centraal Bureau Voor de Statistiek www.cbs.nl 2001. Index N. 4: Jeugd, Thema Kortjes, 14.

Cowley DS, Jensen CF, Johannessen D, Parker L, Dager SR, Walker RD (1989). Response tosodium lactate infusion in alcoholics with panic attacks. Am J Psychiatry 146;1479-83.

Dager SR, Cowley DS, Dunner DL (1987). Biological markers in panic states: lactate-induced panic and mitral valve prolapse. Biol Psychiatry 22;339-59.

DeBoer MC, Schippers GM, VanderStaak CPF (1994). The effect of alcohol, expectancy, and alcohol beliefs on anxiety and self-disclosure in women: do beliefs moderate alcohol effects? Addict Behav 53;541-5.

Fisher HR, Simpson RI, Kupur BM (1987). Calculation of blood alcohol concentration (BAC) by sex, weight, number of drinks and time. Can J Public Health 78;300-4.

George DT, Nutt DJ, Waxman RP, Linnoila M (1989). Panic response to lactate administration in alcoholic and nonalcoholic patients with panic disorder. Am J Psychiatry 146;1161-5.

Griez E, de Loof C, Pols H, Zandbergen J, Lousberg H (1990). Specific sensitivity of patients with panic attacks to carbon dioxide inhalation. Psychiatry Res 31;193-9.

Himle JA, Hill EM (1991). Alcohol abuse and the anxiety disorders: evidence from the Epidemiologic Catchment Area Survey. J Anxiety Disord 5;237-45.

Howland J, Rohsenow DJ, Cote J, Gomez B, Mangione TW, Laramie AK (2001). Effects of low-dose alcohol exposure on simulated merchant ship piloting by maritime cadets. Accid Anal Prev 33(2);257-65.

Hull $\mathrm{J}$ (1981). A Self-awareness model of the causes and effects of alcohol consumption. $J$ Abnorm Psychol 90;586-600.

Jones BM (1974). Circadian variation in the effect of alcohol on cognitive performance. Q J Study Alcohol 35;1212-9.

Jones BM, Jones MK (1976). Alcohol effects in women during the menstrual cycle. Ann N Y Acad Sci 273:576-87.

Kessler RC, Crum RM, Warner LA, Nelson CB, Schunlenberg J, Anthony LC (1997). Lifetime cooccurrence of DSM IIIR alcohol abuse and dependence with other psychiatric disorders in the 
National Comorbidity Survey. Arch Gen Psychiatry 54;313-21.

Kissin B (1997). Alcoolismo e abuso di alcool. In: Bennett JC, Plum F (eds). Cecil Trattato di Medicina Interna. 20tesima edizione. Verduci, Roma. p. 55.

Kushner MG, Mackenzie TB, Fiszdon J, Valentiner DP, Foa E, Anderson N, Wangensteen D (1996). The effects of alcohol consumption on laboratory-induced panic and state anxiety. Arch Gen Psychiatry 53;264-70.

Levenson RW, Oyama ON, Meek PS (1987). Greater reinforcement from alcohol for those risk, personality risk, and sex. J Abnorm Psychol 96;242-53.

Liljequist S, Engel JA (1984). The effects of GABA and benzodiazepine receptor antagonists on the anticonflict actions of diazepam or ethanol. Pharmacol Biochem Behav 21(4);521-5.

Maier W, Minges J, Lichtermann D (1993). Alcoholism and panic disorder: co-occurence and cotransmission in families. Eur Arch Psychiatry Clin Neurosci 243(3-4);205-11.

Quitkin FM, Rifkin A, Kaplan J, Klein DF (1972). Phobic anxiety syndrome complicated by drug dependence and addiction. Arch Gen Psychiatry 27;159-62.

Sheehan DV, Lecrubier Y, Sheenan KH, Amorim P, Janavs J, Weiller E, Hergueta T, Baker R, Dunbar GC (1998). The Mini-International Neuropsychiatric Interview (M.I.N.I.) the development and validation of a structured diagnostic psychiatric interview for DSM-IV and ICD-10. J Clin Psychiatry 59(20);22-33.

Spielberger CD, Gorsuch RL, Lusene RE (1970). STAI Manual for the State-trait Anxiety Inventory. Palo Alto, CA: Consulting Psychologists Press.

St Clair HR (1991). Recognizing alcoholism and its effects. A mini-guide. Basel: Karger AG.

Tagawa M, Kano M, Okamura N, Itoh M, Sakurai E, Watanabe T, Yanai K (2000). Relationship between effects of alcohol on psychomotor performance and blood alcohol concentrations. Jpn J Pharmacol 83(3);253-60.

Verburg K, Perna G, Griez EJL (2001). A case study of the $35 \% \mathrm{CO}_{2}$ challenge. In: Griez EJL, Faravelli $\mathrm{C}$, Nutt D, Zohar J (eds). Anxiety disorders. An introduction to clinical management and research.. John Wiley \& sons, LTD. pp. 341-357.

Watson PE, Watson ID, Batt RD (1981). Prediction of blood alcohol concentration in human subjects. J Stud Alcohol 42;547-56.

Zung WWK (1971). A rating instrument for anxiety disorders. Psychosomatics 12;371-7. 


\title{
Chapter 4
}

\section{The influence of ethanol infusion on the effects of $35 \% \mathrm{CO}_{2}$ challenge. A study in panic disorder patients and healthy volunteers}

\author{
Abstract \\ Alcohol and panic disorders co-occur at a rate that exceeds chance significantly. Early experimental work \\ suggests that alcoholic subjects, compared to non alcoholics, are less sensitive to sodium lactate and \\ that alcohol intake reduces the response to a $35 \% \mathrm{CO}_{2}$ challenge in Panic Disorder patients. The present \\ study documents the direct pharmacological effect of ethanol infusion on $\mathrm{CO}_{2}$ induced panic. \\ Methods. According to a placebo-controlled, double-blind, randomized, cross-over design 10 drug free \\ panic disorder patients and 16 healthy volunteers underwent a $35 \% \mathrm{CO}_{2}$ challenge after intravenous \\ infusion of a moderate dose of ethanol on one test day and of placebo on another test day. \\ Results. Compared to the placebo condition, the effect of the $\mathrm{CO}_{2}$ challenge was significantly smaller \\ after ethanol infusion $(p=0.041)$. \\ Discussion. A moderate dose of ethanol decreased the response to a $35 \% \mathrm{CO}_{2}$ without inducing pre \\ challenge sedation. \\ Conclusion. The results comfort earlier findings of a direct pharmacological effect of ethanol on panic.
}

\section{Introduction}

Although alcohol use and panic disorders (PD) do co-occur at a rate that exceeds chance (Segui et al 2001), the exact mechanisms underlying this high co morbidity remain a matter of discussion. Some authors posit that those with PD use alcohol as a self administered medication to cope with their anxiety (Quitkin et al 1972). There is evidence that alcohol acts on gamma-aminobutyric acid (GABA) receptors in a similar way to benzodiazepines (Liljequist et al 1984) resulting in an anxiolytic effect. However, there has been conflicting evidence on the exact role of the GABA-benzodiazepine complex in the 
pathophysiology of panic (Nutt et al 1990; Strohle et al 1999). As a consequence, the issue of a specific pharmacological action of alcohol on panic is still a matter of debate.

Early experimental work with provocative laboratory challenges has suggested that alcoholic PD subjects have fewer panic attacks in response to sodium lactate infusion than non alcoholic individuals (Cowley et al 1989; George et al 1989). Kushner and co-workers (1996) showed that relative to a placebo, oral alcohol intake reduced the response to a $35 \% \mathrm{CO}_{2}$ challenge in $\mathrm{PD}$ patients. However, in this particular study both baseline and post test anxiety were affected, and it could therefore not be excluded that the blunted response to $\mathrm{CO}_{2}$ was the result of a general sedative effect of ethanol. Moreover, when the authors applied conservative criteria, the specific $\mathrm{CO}_{2}$ triggered panic response failed to reach statistical significance.

The present study aims at clarifying the effect of alcohol on $\mathrm{CO}_{2}$ induced panic. In an attempt to prevent any sedative action of alcohol on pre-test anxiety, only moderate doses were used and in order to minimize outcome expectancies linked to the very act of drinking (Hull 1981), both alcohol and placebo were administered by intravenous (IV) infusion.

The effect of the challenge was expected to be smaller after ethanol than after placebo, under conditions of strictly comparable pre test anxiety. Such results would lend support for the idea of a direct pharmacological effect of alcohol on panic.

\section{Subjects and methods}

\section{$\underline{\text { Subjects }}$}

The sample consisted of 10 drug free PD patients, 5 males and 5 females with a mean age of 42.10 years, and 16 healthy volunteers, 9 males and 7 females with a mean age of 39.00 years.

Patients were recruited among those applying for treatment at the Academic Anxiety Centre (Maastricht, The Netherlands) and by means of newspapers' advertisements. A trained research assistant prescreened them by telephone on basis of the following inclusion criteria: good physical health; no current psychiatric disorder in co-morbidity with PD; not being pregnant, lactating or alcohol naïve; no current use of psychotropic medication, beta-, alphaz-blockers or diuretic. 
All participant patients were then screened by an experienced psychiatrist. This screening comprised a complete medical history, a physical examination, a psychiatric evaluation to confirm the PD diagnosis according to the DSM IV criteria (APA 1994) and using the Mini International Neuropsychiatric Interview (MINI) (Sheehan et al 1998) to support the diagnosis. Following participation, the patients received appropriate treatment.

Healthy volunteers were recruited among hospital employees and their acquaintances and matched on gender and age with the patients. They were pre-screened by a trained research assistant according to the previous exclusion criteria; they had a complete medical history, a physical examination and an evaluation on basis of the MINI [25] to exclude life time history of mental illness. To prevent any reluctance to disclose a psychiatric disorder, the psychiatric interview was administered by a physician who did not personally know the volunteers and was not involved in the management of the hospital staff. Healthy volunteers were paid to participate in the study. All participants provided written informed consent. The study was approved by the local Medical Ethics Committee.

\section{Procedure}

The study was conducted according to a placebo-controlled, double- blind, randomized, cross-over design. Each subject underwent a $35 \% \mathrm{CO}_{2}$ challenge after an IV infusion of a moderate dose of ethanol on one test day and a placebo infusion on another test day. The order of ethanol versus placebo over the two-day study was counterbalanced with subjects assigned randomly to ethanol or placebo first. The interval between the two test days was minimal 4 and maximal 10 days.

All appointments were scheduled for the morning and females were tested during the first two weeks of the menstrual cycle (Jones 1974; Jones et al 1976). Subjects were instructed not to drink alcohol for 24 hours preceding each test day, and to refrain from caffeinated products and eating 4 hours prior to their appointment. They were also instructed not to drive to the laboratory and to stay for at least one hour after each experiment.

Subjects received ethanol $5 \% \mathrm{w} / \mathrm{v}$ in $0.9 \% \mathrm{NaCl}$ solution by IV infusion targeting a Blood Alcohol Concentration (BAC) of $50 \mathrm{mg} / \mathrm{dl}$ (Fisher et al 1987). Females received 18.19 grams of ethanol (IV) and males 26.09 grams of ethanol (IV). The dose was calculated, according to Watson et al (1981) and referring to biometric tables published by the Dutch office for statistics for height and weight (Centraal 
Bureau Voor de Statistiek 2001). Female subjects were infused (5\% w/v) $375 \mathrm{ml}$ during 30 minutes and males $500 \mathrm{ml}$ during 40 minutes. Placebo infusion consisted of a physiological solution $(0.9 \% \mathrm{NaCl})$ at a constant rate, in matched time duration. Subjects knew they would be infused with one type of solution on one day and the other one on the second day.

After the infusion, BAC was assessed using a breath analyzer, which was set to read BAC directly. Subjects then underwent a $35 \% \mathrm{CO}_{2}$ challenge.

The $35 \% \mathrm{CO}_{2}$ challenge is a standard procedure satisfying the criteria for a laboratory model of panic (Verburg et al 2001). The procedure runs as follows: using a self-administration mask, the subject takes one single breath of a gas mixture of $35 \% \mathrm{CO}_{2}$ and $65 \% \mathrm{O}_{2}$. After having inhaled, the subject holds his breath for 4 seconds in deep inspiration, to enhance alveolar gas exchange. A respirometer is used to measure the gas volume delivered at each inhalation. The test is considered valid if the subject inhales at least $80 \%$ of his vital capacity.

On their test days, subjects completed a general baseline assessment upon arrival at the laboratory. This included the State Trait Anxiety Inventory, state form (STAl-1) (Spielberger et al 1970), the Zung Self rating Scale for Anxiety (SAS) (Zung 1971), a Visual Analogue Anxiety Scale (VAAS) ranging from 0 ("no anxiety at all") to 100 ("worst imaginable anxiety"), and a Panic Symptom List (PSL), consisting of the 13 panic symptoms listed in the DSM IV (APA 1994), each being rated between 0 (absent) and 4 (severe). Subjects then received the infusion, followed by the $\mathrm{CO}_{2}$ challenge. To evaluate $\mathrm{CO}_{2}$ elicited symptoms, a VAAS and a PSL assessment were repeated just before and immediately after the inhalation.

\section{Data analysis}

Student's t-test was used for data with a normal distribution (age, height, weight, liters inhaled). Due to the non-normal distribution of the scores of the rating scales (STAl, SAS, VAAS, PSL), non-parametric tests were used (Wilcoxon signed ranks test for dependent samples, Mann-Whitney $U$ test for independent samples).

Significance levels were set at $p<0.05$ (two-tailed). Main outcome measures were the $\mathrm{CO}_{2}$ induced changes (deltas) in VAAS and PSL scores on basis of the immediate pre- and post-inhalation assessments. 
Chapter 4

\section{Results}

There were no significant differences between patients and controls in age $(42.10 \pm 9.66$ years for patients; $39.00 \pm 11.82$ years for volunteers; $t=0.695)$, height $(173.70 \pm 8.03 \mathrm{~cm}$ for patients; $175.81 \pm$ 9.90 for volunteers; $t=-0.567)$ or weight $(75.80 \pm 11.67 \mathrm{Kg}$ for patients; $73.50 \pm 15.73$ for volunteers; $t=$ 0.398).

The BAC was $48 \pm 23 \mathrm{mg} / \mathrm{dl}$ after ethanol infusion and $0.00 \pm 0.00 \mathrm{mg} / \mathrm{dl}$ after placebo infusion in the group of patients, and $54 \pm 37 \mathrm{mg} / \mathrm{dl}$ after ethanol infusion and $0.00 \pm 0.00 \mathrm{mg} / \mathrm{dl}$ after placebo infusion in the group of controls.

The volume inhaled during each challenge was $3.56 \pm 0.57$ liters after ethanol infusion versus $3.68 \pm$ 0.64 after placebo infusion in the patients sample $(t=-1.118, n s)$, and $4.25 \pm 0.93$ liters after the ethanol infusion versus $4.10 \pm 0.902$ after placebo infusion in the healthy volunteers sample $(t=0.902, n s)$.

The baseline scores (STAI, SAS, PSL and VAAS) were comparable between the two test days both in patients and controls. Likewise, there were no differences in immediate pre-challenge values (VAAS and PSL) between the ethanol and the placebo test day, excepting for the pre-test PSL score in healthy controls, which was higher in the ethanol condition $(Z=-2.687, p=0.007)$ (table 1$)$.

Figures 1 and 2 represent the $35 \% \mathrm{CO}_{2}$ induced increases (post minus pre $\mathrm{CO}_{2}$ scores) for patients and controls under ethanol and placebo condition. In the PD group, increases in both PSL and VAAS scores were blunted after ethanol infusion $(Z=-2.405 p=0.016 ; Z=-2.040 p=0.041)$. On the other hand, in controls only a trend was observed towards blunted changes in PSL scores $(Z=-1.885 p=0.059)$.

\section{Discussion}

We found that moderate doses of ethanol decreased the response to a $35 \% \mathrm{CO}_{2}$ challenge in $\mathrm{PD}$ patients and tended to decrease such a response in healthy volunteers.

The ethanol effect was achieved with BAC below $50 \mathrm{mg} / \mathrm{dl}$ and in the absence of any noticeable influence on pre-test state anxiety as measured with the VAAS. In addition, the infusion method used instead of oral intake eliminated the possibility that psychological factors linked to the very act of drinking (Holroyd 1978; Hull 1981) may have played a role in the present experiment. However, even our cautious 
methodology failed to exclude all cognitive biases. Despite the double blind design and the low doses of ethanol, when asked at the debriefing whether they had received alcohol or placebo, nine out of ten subjects, though not being sure, made a guess that proved correct. Such a type of bias cannot be easily eliminated and is widely represented in pharmacological trials, both patients and clinicians being perfectly able to guess correctly whether the subject is receiving an active drug or placebo (Faravelli 1994).

Although in this particular experiment the effect failed to reach statistical significance, in the healthy volunteers there was a clear trend $(p=0.059)$ towards an ethanol induced decrease on the PSL. The modest effects of ethanol on $\mathrm{CO}_{2}$ induced symptomatology in healthy persons is not surprising, as $\mathrm{CO}_{2}$ triggered symptoms in non-panic subjects are modest anyway, particularly on the VAAS dimension (Griez et al 1998). Therefore, with the $35 \% \mathrm{CO}_{2}$ paradigm in normal subjects, a frank disclosure of statistical significance may be difficult, particularly in small samples. It is worth noting that in a previous study, we did observe a significant effect of ethanol on $35 \% \mathrm{CO}_{2}$ induced symptoms in normal subjects (Cosci et al in press). With these considerations in mind, the present results might be interpreted as an instance of stress response dampening by ethanol (Cappell et al 1994).

The results in PD patients seem to confirm earlier findings of ethanol blunting experimental panic (Kushner et al 1996) and add to the suspicion that the pharmacological effects of alcohol may serve as reinforcement for drinking behavior among those with PD.

In order to prevent any sedation affecting both cognitive performance and baseline anxiety before the $\mathrm{CO}_{2}$ challenge, the present research used low doses of ethanol. Low doses were defined by reference to a BAC of $50 \mathrm{mg} / \mathrm{dl}$ as a threshold for evident symptoms of alcohol intoxication (Hobbs et al 1996, Kissin 1996). This means that the alcohol blood levels did not reach the point of marked effects on the subjects' cognitive performance (Howland et al 2001; Tagawa et al 2000) which conferred a good reliability to their self ratings. Compared to the placebo condition, neither PSL nor VAAS scores were decreased on the ethanol test day. This indicates that the doses used in this study failed to induce any noticeable sedation that could have interfered with the reaction to the $\mathrm{CO}_{2}$ challenge. Therefore the blunted response to $\mathrm{CO}_{2}$ observed after ethanol infusion cannot be merely related to a decrease in anticipatory anxiety. Rather a specific direct inhibitory action of ethanol on experimental panic is suggested. Some authors have previously argued that challenge responding may confound panic with non-panic anxiety distress and that ethanol may diminish the non-panic elements of the challenge response only (Sanderson et al 1990). The present results, on the contrary, suggest that alcohol may affect state anxiety and panic itself through 
separate processes. With the low doses used in this study, blunting of the $\mathrm{CO}_{2}$ response was marginal in normal subjects, who are not prone to (experimental) panic. Only PD patients were clearly affected, and this effect occurred in the absence of a decrease in state anxiety preceding the $\mathrm{CO}_{2}$ challenge.

While the distinction between the panic and non panic elements of the response did not clearly appear from the results of Kushner et al (1996), the present data suggest that state anxiety and panic may be modulated independently.

The idea of a specific link between panic and ethanol is in line with epidemiological findings. Co-morbidity between alcoholism and anxiety disorders usually shows phobic anxiety to precede the onset of alcoholism, while no systematic pattern is observed for panic (Swendsen et al 1998). In phobic anxiety, beliefs and expectations appear to play a crucial role in mediating the effects of alcohol on anxiety (Himle et al 1999). On the contrary, community sample studies evidenced that alcoholism directly influences the symptoms of panic (Swendsen et al 1998). The pattern of co-aggregation of alcohol and anxiety disorders in families also differ depending on the type of anxiety: elements of a true shared diathesis seem to be present in the case of PD only (Merikangas et al 1998).

An obvious limitation of the present study is the relative small sample size. Though in PD patients, ethanol inhibited apparently the effects of the panicogenic challenge without affecting pretest anxiety, there tended to be an effect in healthy controls as well. We interpreted the marginal effect in normals as an instance of stress dampening, and the results in patients as indicative of a specific link between ethanol and panic. Admittedly, only a clear cut difference in effect between PD patients and normals would have provided an unambiguous demonstration of specificity between alcohol and panic. Seeing the results in healthy volunteers, the above data call for further studies in larger samples.

\section{Conclusion}

Bearing in mind some reservations, the present findings may be consistent with the idea that ethanol acts on specific panic pathways.

Although the issue was not addressed directly, our results fit the view that those with panic may seek alcohol to obtain a pharmacological relief of their panic attacks. If true, effective panicolytic treatment should remove an important factor in the development of alcoholism amongst PD patients. 
Table 1. rating scales scores at baseline, pre challenge and post challenge assessment. Ethanol test day versus placebo test day in panic disorder patients and healthy volunteers.

\begin{tabular}{|c|c|c|c|c|c|c|}
\hline & & \multicolumn{2}{|c|}{ ethanol } & \multicolumn{2}{|c|}{ placebo } & \multirow{2}{*}{$\frac{\text { analysis }}{Z}$} \\
\hline & $\mathrm{N}$ & mean & SD & mean & SD & \\
\hline \multicolumn{7}{|c|}{ Baseline } \\
\hline \multicolumn{7}{|c|}{ patients } \\
\hline SAS & 10 & 38.30 & 12.71 & 37.50 & 11.45 & -0.421 \\
\hline STAI & 10 & 40.00 & 15.80 & 41.10 & 16.06 & -0.059 \\
\hline PSL & 10 & 7.10 & 10.17 & 6.30 & 9.29 & -0.702 \\
\hline VAAS & 10 & 20.30 & 29.77 & 19.40 & 27.31 & -0.119 \\
\hline \multicolumn{7}{|c|}{ volunteers } \\
\hline SAS & 16 & 26.13 & 3.44 & 25.88 & 4.32 & -0.284 \\
\hline STAI & 16 & 27.63 & 5.51 & 28.00 & 6.55 & -0.317 \\
\hline PSL & 16 & 0.31 & 0.70 & 0.63 & 1.09 & -0.850 \\
\hline VAAS & 16 & 4.06 & 5.25 & 3.87 & 5.25 & -0.458 \\
\hline \multicolumn{7}{|c|}{ Pre challenge } \\
\hline \multicolumn{7}{|c|}{ patients } \\
\hline PSL & 10 & 5.30 & 5.755 & 4.40 & 5.985 & -1.054 \\
\hline VAAS & 10 & 18.05 & 28.480 & 13.70 & 22.642 & -1.262 \\
\hline \multicolumn{7}{|c|}{ volunteers } \\
\hline PSL 1 & 16 & 1.56 & 1.711 & 0.19 & 0.403 & -2.687 \\
\hline VAAS & 16 & 3.75 & 4.824 & 3.06 & 4.312 & -0.388 \\
\hline \multicolumn{7}{|c|}{ Post challenge } \\
\hline \multicolumn{7}{|c|}{ patients } \\
\hline PSL & 10 & 10.90 & 7.866 & 14.20 & 9.283 & -1.127 \\
\hline VAAS & 10 & 36.80 & 34.797 & 55.30 & 36.237 & -1.785 \\
\hline \multicolumn{7}{|c|}{ volunteers } \\
\hline PSL & 16 & 6.12 & 4.395 & 8.63 & 8.294 & -0.944 \\
\hline VAAS & 16 & 12.06 & 13.005 & 19.94 & 27.908 & -0.196 \\
\hline
\end{tabular}

SAS: Zung Self rating Scale for Anxiety; STAl: State Trait Anxiety Inventory, state form; PSL: Panic Symptom List; VAAS: Visual Analogue Anxiety Scale.

${ }^{1} p<0.01$ 
Figure 1. $35 \% \mathrm{CO}_{2}$ induced increase in subjective anxiety measured by the Visual Analogue Anxiety Scale (VAAS). Panic disorder patients versus healthy volunteers

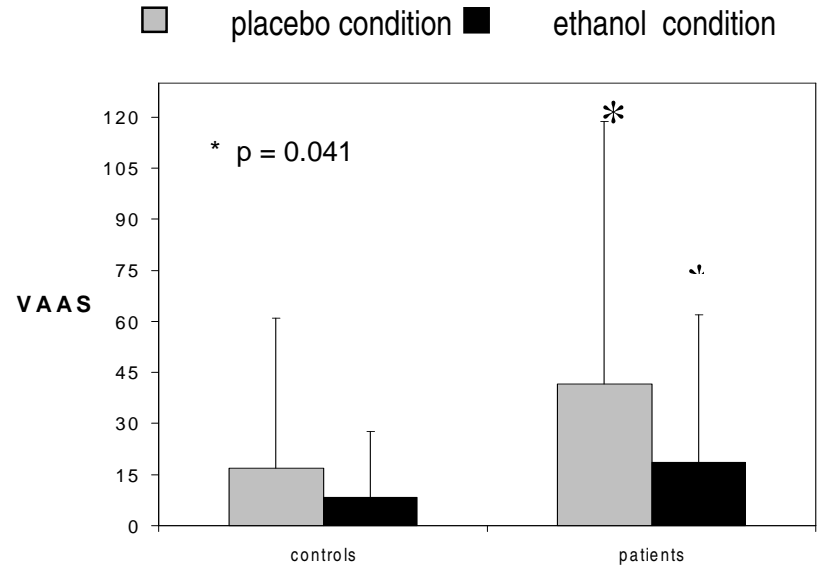

Figure 2. 35\% $\mathrm{CO}_{2}$ induced increase in panic symptomatology measured by the Panic Symptom List (PSL). Panic disorder patients versus healthy volunteers

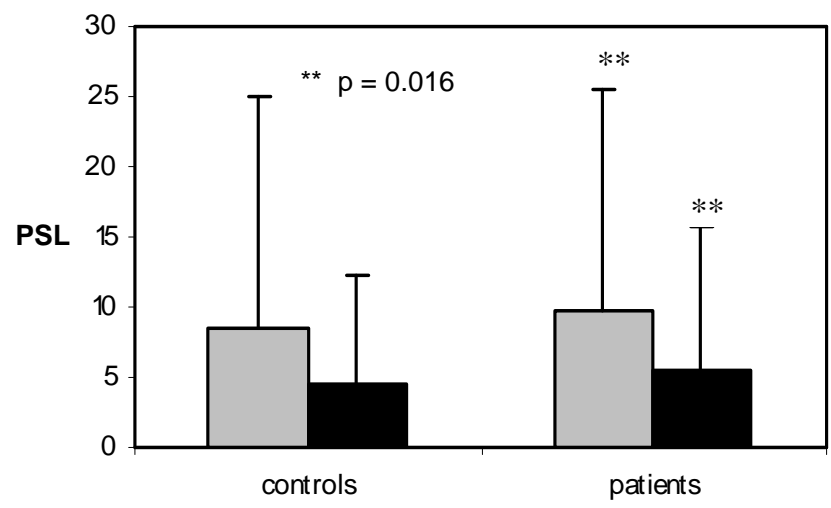




\section{REFERENCES}

American Psychiatric Association (1994). Diagnostic and statistical manual of mental disorders. $4^{\text {th }} \mathrm{ed}$. Washington, DC. American Psychiatric Association.

Cappell H, Greeley J (1994). Alcohol and tension reduction: an update on research and theory. In: Blane HT, Leonard KE (eds). Psychological Theories of Drinking and Alcoholism. New York: The Guilford Press. pp. 90-8.

Centraal Bureau Voor de Statistiek www.cbs.nl. Index N. 4: Jeugd, Thema Kortjes; 2001.

Cosci F, Schruers K, Faravelli C, Griez E (in press). The influence of alcohol oral intake on the effects of $35 \% \mathrm{CO}_{2}$ challenge. A study in healthy volunteers. Acta Neuropsychiatrica.

Cowley DS, Jensen CF, Johannessen D, Parker L, Dager SR, Walker RD (1989). Response to sodium lactate infusion in alcoholics with panic attacks. Am J Psychiatry 146;1479-83.

Faravelli C (1994). Che cosa non funziona nelle sperimentazioni cliniche controllate. In: Maj M, Racagni $G$ (eds). La sperimentazione dei nuovi farmaci in psichiatria. Milano: Masson. pp. 81-90.

Fisher HR, Simpson Rl, Kupur BM (1987). Calculation of blood alcohol concentration (BAC) by sex, weight, number of drinks and time. Can J Public Health 78;300-4.

George DT, Nutt DJ, Waxman RP, Linnoila M (1989). Panic response to lactate administration in alcoholic and nonalcoholic patients with panic disorder. Am J Psychiatry 146;1161-5.

Griez E, Schruers K (1998). Experimental pathophysiology of panic. J Psychosom Res 45(6);493-503.

Himle JA, Abelson JL, Haghightgou H, Hill EM, Nesse RM, Curtis GC (1999). Effect of alcohol on social phobic anxiety. Am J Psychiatry 156(8);1237-43.

Hobbs WR, Rall TW, Verdon TA (1996). Hypnotics and sedatives; ethanol. In: Hardman JG, Limbird LE, Goodman Gilman A, Molinoff PB, Ruddon RW (eds). Goodman \& Gilman's The pharmacological basis of therapeutics ninth edition. New York: McGraw-Hill Health Profession Division Inc. pp. 361-96.

Holroyd KA (1978). Effects of social anxiety and social evaluation on beer consumption and social interaction. J Stud Alcohol 39(5);737-44.

Howland J, Rohsenow DJ, Cote J, Gomez B, Mangione TW, Laramie AK (2001). Effects of low-dose alcohol exposure on simulated merchant ship piloting by maritime cadets. Accid Anal Prev 33(2);257-65.

Hull J (1981). A Self-awareness model of the causes and effects of alcohol consumption. J Abnorm 
Psychol 90;586-600.

Jones BM (1974). Circadian variation in the effect of alcohol on cognitive performance. Q J Study Alcohol $35 ; 1212-9$.

Jones BM, Jones MK (1976). Alcohol effects in women during the menstrual cycle. Ann N Y Acad Sci 273;576-87.

Kissin B (1996). Alcoholism and alcohol abuse. In: Bennett JC, Plum F (eds). Cecil Textbook of Medicine. $20^{\text {th }}$ edition. WB Saunders. pp. 55.

Kushner MG, Mackenzie TB, Fiszdon J, Valentiner DP, Foa E, Anderson N, Wangensteen D (1996). The effects of alcohol consumption on laboratory-induced panic and state anxiety. Arch Gen Psychiatry 53;264-70.

Liljequist S, Engel JA (1984). The effects of GABA and benzodiazepine receptor antagonists on the anticonflict actions of diazepam or ethanol. Pharmacol Biochem Behav 21(4);521- 5.

Merikangas KR, Stevens DE, Fenton B, Stolar M, O'Malley S, Woods SW, Risch N (1998). Co-morbidity and familial aggregation of alcoholism and anxiety disorders. Psychol Med 28(4);773-88.

Nutt DJ, Glue P, Lawson C, Wilson S (1990). Flumazenil provocation of panic attacks. Evidence for altered benzodiazepine receptor sensitivity in panic disorder. Arch Gen Psychiatry 47(10);91725.

Quitkin FM, Rifkin A, Kaplan J, Klein DF (1972). Phobic anxiety syndrome complicated by drug dependence and addiction. Arch Gen Psychiatry 27;159-62.

Sanderson WC, Wetzler S (1990). Five percent carbon dioxide challenge: valid analogue and marker of panic disorder? Biol Psychiatry 27;689-701.

Segui J, Marquez M, Canet J, Cascio A, Garcia L, Ortiz M (2001). Panic disorder in a Spanish sample of 89 patients with pure alcohol dependence. Drug Alcohol Depend 63;118-21.

Sheehan DV, Lecrubier Y, Sheenan KH, Amorim P, Janavs J, Weiller E, Herguenta T, Baker R, Dunbar GC (1998).The Mini-International Neuropsychiatric Interview (M.I.N.I.) the development and validation of a structured diagnostic psychiatric interview for DSM-IV and ICD-10. J Clin Psychiatry 59(20);22-33.

Spielberger CD, Gorsuch RL, Lusene RE (1970). STAI Manual for the State-trait Anxiety Inventory. Palo Alto, CA: Consulting Psychologists Press.

Strohle A, Kellner M, Holsboer F, Wiedemann K (1999). Behavioral, neuroendocrine, and cardiovascular 
response to flumazenil: no evidence for an altered benzodiazepine receptor sensitivity in panic disorder. Biol Psychiatry 45(3);321-6.

Swendsen JD, Merikangas KR, Canino GJ, Kessler RC, Rubio-Stipec M, Angst J (1998). The comorbidity of alcoholism with anxiety and depressive disorders in four geographic communities. Compr Psychiatry 39(4);176-84.

Tagawa M, Kano M, Okamura N, Itoh M, Sakurai E, Watanabe T, Yanai K (2000). Relationship between effects of alcohol on psychomotor performance and blood alcohol concentrations. Jpn J Pharmacol 83(3);253-60.

Verburg K, Perna G, Griez EJL (2001). A case study of the $35 \% \mathrm{CO}_{2}$ challenge. In: Griez EJL, Faravelli C, Nutt DJ, Zohar J (eds). Anxiety disorders. An introduction to clinical management and research.. Chichester: John Wiley \& sons, LTD. pp. 341-57.

Watson PE, Watson ID, Batt RD (1981). Prediction of blood alcohol concentration in human subjects. J Stud Alcohol 42;547-56.

Zung WWK (1971). A rating instrument for anxiety disorders. Psychosomatics 12;371-7. 


\section{CHAPTER 5}

\section{Effect of nicotine on $35 \% \mathrm{CO}_{2}$ induced anxiety. A study in healthy volunteers}

\section{Abstract}

Panic Disorder and cigarette smoking co-occur at a rate that exceeds what would be expected by chance. Theoretically, cigarette smoking may: a) attenuate panicky symptoms via cognitive factors or pharmacological action; b) contribute to the development of panic disorder; or c) share an etiologic vulnerability with panic. The present study was aimed at testing whether nicotine has a direct influence on laboratory-elicited panic.

Methods. In a placebo-controlled, double-blind, randomized, cross-over study, 33 healthy nonsmokers underwent a $35 \% \mathrm{CO}_{2}$ challenge after transdermal administration of a nicotine patch on one test day and a placebo patch on another test day. Physiological measures (blood pressure, heart rate) and rating scale scores (Panic Symptom List [PSL], Visual Analogue Scale of Anxiety, State-Trait Anxiety Inventory) were assessed.

Results. Compared with the placebo condition, nicotine increased diastolic blood pressure $(p<.1)$, heart rate $(p<.001)$ and PSL scores $(p<.005)$ prior to the $\mathrm{CO}_{2}$ challenge but did not affect responding to the $\mathrm{CO}_{2}$ challenge itself.

Discussion. Results are consistent with the notion that nicotine promotes autonomic activation. However, the present study did not provide direct evidence that nicotine elicits panic in healthy volunteers. Replication in a clinical sample is warranted.

\section{Introduction}

Panic Disorder (PD) and cigarette smoking co-occur more frequently than would be expected by chance. A disproportionate number of persons with PD smoke cigarettes compared with the general population (Breslau et al 1991; Amering et al 1999) or individuals with other anxiety disorders (Himle et al 1988; 
Johnson et al 2000).

Three types of hypothesis have been advanced to account for the association between smoking and panic. One hypothesis is that panic disorder patients smoke to self-medicate (prevent or treat) their symptoms (Breslau et al 1991; Pohl et al 1992; Kassel et al 1997). The possible underlying mechanisms include: a) the direct effect of nicotine, given that in healthy volunteers smoking mitigates subjective anxiety induced by stressful anagrams (Jarvik et al 1989); and b) a cognitive mediation, in that smoking would narrow the focus of attention and reduce anxiety by facilitating distraction from stressful cognitions (Kassel et al 1997).

Another hypothesis is that cigarette smoking contributes to the development of anxiety disorders, and particularly to $\mathrm{PD}$. Several studies have indicated that cigarette smoking precipitates panic attacks among individuals with panic disorder (Breslau et al 1991; Pohl et al 1992; West et al 1997; Amering et al 1999; Johnson et al 2000; De Graaf et al 2002; McCabe et al 2004) and that daily smoking increases the risk for first occurrence of panic attack and disorder (Breslau et al 1999). In addition, Breslau \& Klein (1999) found an increased lifetime prevalence of panic attacks in smokers who reported lung disease. On the basis of the false suffocation alarm theory (Klein 1993) and the association between lung disease and panic attacks among non smokers (Yellowlees et al 1987; Yellowlees et al 1988; Yellowlees et al 1990; Caldirola et al 2004), Breslau \& Klein (1999) suggested that by increasing the risk for lung disease, smoking might increase the risk to overreact to suffocation signals and indirectly the risk for panic attacks. However, the small proportion of smokers reporting lung disease and the increasing incidence of panic attacks or panic disorder in smokers with no history of lung disease suggest the possibility of other pathways from smoking to panic. For instance, Dilsaver (1987) proposed that nicotine produces physiological effects characteristics of panic attacks promoting the release of epinephrine and norepinephrine.

The aforementioned hypotheses have received some support from animal studies (File et al 2000; Paterson et al 2000; Slawecki et al 2003).

A third hypothesis proposes a shared etiological vulnerability linking cigarette smoking to panic (Sontag et al 2000; Goodwin et al 2002). Zvolensky et al (2003), for instance, suggested that smoking may modify the expression of PD by exacerbating affective disturbances and negative health processes. Smoking may increase the production of potentially fear-producing bodily sensation (because of medical disorders, autonomic sensations, smoking related withdrawal symptoms) and individuals with PD, who usually 
perceive themselves as being physically unhealthy, are more likely to react to them with exaggerated anxiety.

The above evidence might suggest that there is a causal relationship between smoking and panic; however, things may not be that clear-cut. The majority of studies on the relationship between nicotine and affective pathology are either epidemiological surveys in humans or of experimental studies in animals.

Few truly experimental investigations have been conducted on this topic in human subjects.

In this context, the present study was designed to test experimentally whether nicotine has a direct influence on laboratory elicited panic in human volunteers. We hypothesized that nicotine facilitates the emergence of panic. We administered nicotine and examined its acute effect on $35 \% \mathrm{CO}_{2}$ response in healthy non-smokers.

\section{Methods}

\section{Subject}

Volunteers, aged between 18 and 65 years, were recruited from the Maastricht, Netherlands area, through advertisements and flyers. All participants had to be non-smokers (less than 10 cigarettes in their lifetime and none in the last 5 years) and were screened and received the Mini-International Neuropsychiatric Interview (MINI 5.0 - Sheehan et al 1998) to exclude a history of psychiatric disorders. Subjects were excluded if they met diagnostic criteria for a current mood, anxiety, eating or substance use disorder or if a first-degree relative had been diagnosed with Panic Disorder. Additionally, advertisement respondents with a medical history contraindicating $\mathrm{CO}_{2}$ administration (e.g. pregnancy or lactating, hypertension, cardiovascular diseases, seizures, heart problems, pulmonary diseases, history of coma or cerebral aneurysm) or who were currently taking daily psychiatric medications or $\alpha_{2-}, \beta$ blockers were excluded.

Briefly, 43 subjects were screened and 36 were enrolled. Of the seven not enrolled, five had a medical history contraindicating $\mathrm{CO}_{2}$ administration and two refused to participate. Of the 36 non-smoking volunteers, 33 ( 7 males and 26 females) completed the study and 3 dropped out (2 for severe side 
effects, 1 retracted informed consent).

Approval for this study was granted by Maastricht University's Medical Ethics Review Board.

\section{Procedures}

The study was conducted using a double-blind, placebo-controlled, cross-over design. All subjects were identically tested on two separate days, except that a nicotine patch was used on one day and a placebo patch was used on the other. The order of patch administration was counterbalanced. On each day, testing occurred both in the morning (from 8.00 to 11.00 a.m.) and in the afternoon (from 2.30 to 5.30 p.m.). Each subject was tested at the same times on the two test days.

At least 7 days elapsed between the two sessions to ensure complete metabolism of any nicotine received and to prevent desensitization to the $\mathrm{CO}_{2}$ challenge (Verburg et al 2001).

The two research days for female subjects were scheduled exclusively during the same phase of their menstrual cycle because of hormonal effects on drug metabolism (Jones 1976) and $\mathrm{CO}_{2}$ sensitivity (Brambilla et al 2003).

Subjects were instructed not to drink alcohol for 24 hours preceding the study, consume caffeinated products for 4 hours prior to the study (Parsons et al 1978), eat for 2 hours preceding the study, or take psychotropic medications in the period between the initial screening and the second test day.

\section{Morning sessions}

On the mornings of testing days, a patch was applied to the upper back of participants and covered with a bandage. Each participant received a nicotine patch on one occasion and a placebo patch on the other, in a random, counter-balanced fashion. Nicotine was administered via over-the-counter 10-mg Novartis nicotine patches (Nicotinell 10®). Placebo patches were similar in size and shape but contained no active substances. Participants and primary investigators were blind to the treatment condition.

Immediately before the patch application, blood pressure and heart rate were measured. Additionally, anxiety level was measured by means of the Visual Analogue Scale of Anxiety (electronic version eVAAS), the Panic Symptom List (PSL) and the State-Trait Anxiety Inventory - State form (STAI-S; Spielberger et al 1970). 
Scores on the VAAS range from 0 (no anxiety at all) to 100 (worst anxiety imaginable). The PSL consists of the 13 panic symptoms of a panic attack, as described by DSM IV (APA 1994), on a scale from 0 (absent) to 4 (very intensive). Both scales have been used previously to assess experimental anxiety (Verburg et al 1995; Pols et al 1999; Schruers et al 2000).

\section{Afternoon sessions}

Participants returned to the laboratory in the afternoon on both testing days and, after having their patch removed, engaged in the $\mathrm{CO}_{2}$ challenge.

The duration from patch application to $\mathrm{CO}_{2}$ challenge was 7 hours (i.e., when plasma nicotine levels would be expected to have reached a plateau) (Chan et al 1990).

The experimenter applied the $35 \% \mathrm{CO}_{2}$ challenge procedure after informing the participant that shortlived discomfort might be experienced during the challenge, ranging from a few physical symptoms to a definite sensation of anxiety. However, the words "panic" or "panic attack" were not mentioned.

The challenge used is standard and satisfies the criteria for a laboratory model of panic (Verburg et al 2001). The procedure runs as follows.

First, the vital capacity of the subject is measured. The subject is informed that this practice would be used as the basis for his/her $\mathrm{CO}_{2}$ breath. Then, the subject exhales as much as possible, and deeply inhales a single breath of room air through a self-administration facemask connected to a respirometer. The facemask completely covers the mouth and nose. The respirometer provides an indication of the subject vital capacity.

Next, the self administration mask is connected to a $35 \% \mathrm{CO}_{2} / 65 \% \mathrm{O}_{2}$ gas source. The subject takes the mask, exhales as deeply as possible, presses the mask firmly against his/her face to prevent any leaks, inhales deeply one single breath of the mixture, and holds his/her breath while the experimenter counts aloud 4 seconds to enhance alveolar gas exchange.

The procedure requires the experimenter to check that the subject's tidal volume is at least $80 \%$ of the vital capacity so that the inhalation can be declared valid.

An assessment package consisting of the PSL, STAI-S, eVAAS as well as measurement of blood pressure and heart rate was administered just prior to the $\mathrm{CO}_{2}$ challenge and immediately afterward.

Additionally, saliva samples were collected 5 minutes after the $\mathrm{CO}_{2}$ challenge using Salivette $($ (Sarsedt) 
cotton strips to measure cotinine, the main metabolite of nicotine (Jarvis et al 2003).

\section{Check of participant blindness}

At the conclusion of the second testing day, participants were given a brief questionnaire designed to check their blindness with respect to which week they received the nicotine and placebo patches. Participants selected the testing day on which they thought they received the patch and their confidence level regarding this selection.

\section{Data analysis}

Results were analyzed based on data collected on both nicotine and placebo-patch days at:

1) "baseline" (i.e., in the morning before applying the patch);

2) "post patch" (i.e., in the afternoon immediately after removing the patch and immediately before the $\mathrm{CO}_{2}$ challenge, to measure the pure effect of nicotine on anxiety);

3) "post challenge" (i.e., immediately after the $35 \% \mathrm{CO}_{2}$ challenge, to measure the effect of nicotine on the $35 \% \mathrm{CO}_{2}$ challenge response).

Means were compared using the Student's t-test for data with a normal distribution (e.g. age, liters inhaled) and the Wilcoxon signed ranks test for dependent samples for data with non-normal distribution (STAI, eVAAS, PSL).

Repeated measure analysis of variance was performed using the two-way ANOVA for correlated samples (Tukey option) for data with a normal distribution and Friedman's two-way analysis of variance for correlated samples for non parametric data.

Significance levels were set at $p<0.05$ (two-tailed). Main outcome measures were the $\mathrm{CO}_{2}$ induced changes (deltas) in eVAAS and PSL scores on basis of the immediate pre- and post-inhalation assessments.

Correlations were tested by Pearson's and Spearman's formulas. Results were considered statistically significant at the $5 \%$ level. 


\section{Results}

\section{Descriptive, physiological and psychological variables}

A total of 33 non smoking healthy volunteers completed the two test days; 7 subjects were male and 26 female, with a mean age of $26.3 \pm 9.8$ years.

The salivary cotinine concentration was $0.8 \pm 0.9 \mathrm{ng} / \mathrm{ml}$ after placebo administration and $34.8 \pm 15.6$ $\mathrm{ng} / \mathrm{ml}$ after nicotine administration $(t=11.980, p<0.001)$.

The volume inhaled during each challenge was $3.6 \pm 1.1$ liters after placebo administration and $3.5 \pm 1.0$ after nicotine administration ( $t=-0.257, \mathrm{~ns})$.

Table 1 reports "baseline", "post patch" and "post challenge" values of systolic and diastolic blood pressure, heart rate, STAI, PSL and eVAAS scores.

\section{$\underline{\text { Nicotine effects }}$}

Table 2 reports the values of systolic and diastolic blood pressure, heart rate, STAI, PSL and eVAAS scores as differences between "post patch" and "baseline". The findings reflect the pure effect of nicotine. Diastolic blood pressure showed a trend to an increase with nicotine $(p<.1)$; heart rate and PSL showed a statistically significant increase with nicotine, compared with placebo $(p<0.001$ and $p<.005$ respectively).

\section{Nicotine effect on $\mathrm{CO}_{2}$ challenge reaction}

Table 3 reports the repeated measures ("baseline", "post patch" and "post challenge") analysis of variance of physiological variables and rating scale scores under nicotine and placebo effect, adjusted by gender and age. As with our previous analysis, we found no statistical significant results.

Table 4 analyzes blood pressure, heart rate and rating scale scores expressed as differences between "post challenge" and "post patch". This is the so called DELTA which gives a measure of increase in anxiety related to the challenge test (Verburg, Perna, \& Griez, 2001). Under the nicotine condition, we found a trend for diastolic blood pressure to increase, compared to the placebo condition $(p<.1)$. 
No significant correlation was found between salivary cotinine and delta STAI, delta PSL, or delta eVAAS under nicotine conditions.

\section{$\underline{\text { Participants blindness }}$}

Most $(66.7 \%, \mathrm{n}=22)$ of the subjects were right in selecting the test day on which they received the nicotine patch, when asked at the end of the two test days. Of them $31.8 \%(n=7)$ were not confident at all, $18.2 \%(n=4)$ were mildly confident, $31.8 \%(n=7)$ were moderately confident and $18.2 \%(n=4)$ were completely confident. We found no statistically significant linear correlation between being right in the above selection and the change in STAI, PSL or eVAAS score already mentioned.

\section{Discussion}

We administered nicotine to healthy non smokers and evaluated the effect of this intervention on response to a $35 \% \mathrm{CO}_{2}$ challenge. Nicotine induced an increase in the PSL score as well as an increase in heart rate and tended to increase diastolic blood pressure. Nicotine on the other hand did not appear to have a clear-cut effect on the $35 \% \mathrm{CO}_{2}$ challenge response.

Although the literature reports gender differences in cognitive and hemodynamic responses to nicotine (Girdler et al 1997; Fallon et al 2005), we refrained from performing the comparison between males and females because of the small sample size.

More specifically, the acute effect of nicotine evaluated before the $\mathrm{CO}_{2}$ challenge administration did not significantly affect psychological variables (STAI, eVAAS) but tended to increase diastolic blood pressure and significantly increased heart rate and PSL, compared to placebo (respectively $p<.1, p<.001$ and $p$ $<.005)$.

The increases in blood pressure and heart rate are likely related to nicotine induced autonomic activation. Nicotine may mobilize adrenergic mechanisms causing increased heart rate and blood pressure. Further, nicotine activates aortic and carotid body chemo-receptors resulting in reflex vasoconstriction, tachycardia and increased blood pressure (Dilsaver, 1987). However, it is well known that nicotine influences heart rate more than blood pressure (Perkins et al 1991), which apparently is the case in the 
present study.

The PSL score increase seemed mainly linked to the sympathetic arousal, given that nicotine's autonomic side effects may be felt by the participants as panic like symptoms listed in the PSL.

Concerning the effect of nicotine on the $35 \% \mathrm{CO}_{2}$ challenge response, we found no statistically significant modifications of blood pressure, heart rate and psychological variables (STAl, eVAAS). The lack of significant physiological reactivity to the $\mathrm{CO}_{2}$ challenge under the placebo condition may be attributed to our use of a single breath inhalation and a subsequent single assessment. Greater physiological reactivity occurs during extended $\mathrm{CO}_{2}$ re-breathing. Moreover, in studies of a $35 \% \mathrm{CO}_{2}$ single breath inhalation, increases in systolic blood pressure have been observed 30 seconds after the challenge, although this effect tends to dissipate within 60-90 seconds, as apparently occurred in our study as well (Griez et al 1983).

The present findings do not seem to support the original hypothesis that nicotine increases panic like symptoms induced by the $35 \% \mathrm{CO}_{2}$ challenge in healthy non smokers.

The lack of an effect may have a variety of explanations. First, the dose of nicotine administered may have been too low. However, according to the SRNT Subcommittee on Biochemical Verification (2002) a cut off of $15 \mathrm{ng} / \mathrm{ml}$ of salivary cotinine is used to differentiate smokers from non smokers. The mean value of $34.833 \mathrm{ng} / \mathrm{ml}$ of salivary cotinine reached in the present study corresponds to the dose of cotinine assumed by a regular smoker. Moreover, the dose administered was chosen according to ethical and methodological limitations. An earlier pilot study on 6 healthy non smokers used a higher dose of nicotine (Nicotinell 20®). Five of the six volunteers had severe side effects (nausea, vomiting, dizziness) and dropped out. We used a lower dosage of nicotine (Nicotinell 10®) to avoid these severe side effects and maintaining double blindness.

Second, the findings could have been influenced by the timing of the nicotine patch application and $35 \%$ $\mathrm{CO}_{2}$ challenge administration. According to the kinetics of Nicotinell $10 \AA$, a $10 \mathrm{~cm}^{2}$ system designed to deliver nicotine base at $72 \mu \mathrm{g} / \mathrm{cm}^{2} / \mathrm{h}$ reaches a peak level of $15.2 \mathrm{ng} / \mathrm{ml}$ after a median of 6 hours and thereafter reaches a plateau (Chan et al 1990). Therefore, the challenge was applied when plasma nicotine levels would be expected to have reached the plateau. The present findings refer strictly to the acute effect of nicotine on $35 \% \mathrm{CO}_{2}$ challenge response.

Moreover, to prevent further sources of bias nicotine was: (1) administered transdermally to avoid any interference due to the act of smoking and the concomitant influence of $\mathrm{CO}_{\text {and }} \mathrm{CO}_{2}$; (2) administered 
according to a double blind scheme to minimize the impact of demand characteristics and experimenter bias; (3) administered in a single dose in non smokers in order to avoid the interference of dependence or withdrawal symptoms.

Our hypothesis was not supported in this sample of healthy volunteers. Results might be different in psychologically vulnerable individuals such as non smokers with PD or in non smokers with high level of anxiety sensitivity or strong fear of suffocation. In fact, nicotine's sympathetic arousal induces effects that could be easily interpreted by psychologically vulnerable individuals as dangerous and initiate a panic-like reaction to the $\mathrm{CO}_{2}$ challenge.

Moreover, the sub-acute or chronic effect of nicotine should be evaluated, as in real life individuals smoke more than once and panic does not develop within hours after the first cigarette. Because chronic administration of nicotine to non smokers would not be ethical, such an evaluation could focus on $\mathrm{CO}_{2}$ challenge responses of regular smokers, exposed to a natural chronic nicotine administration, versus non smokers. Our research group is conducting an investigation into this topic.

\section{Acknowledgments}

The present project was not grant-supported. 
Table 1. Biological variables and rating scale scores.

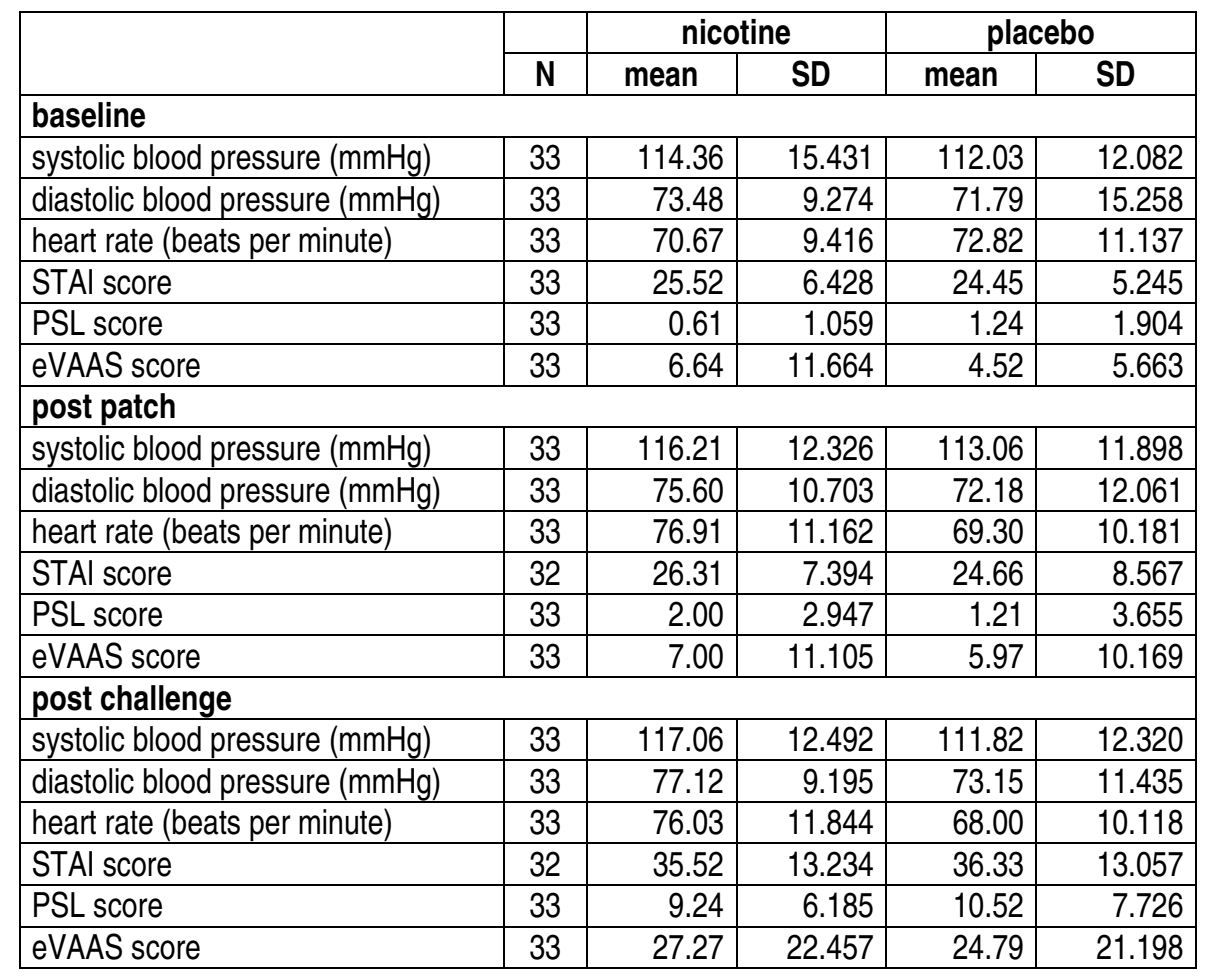


Table 2. "post patch" minus "baseline" values of physiological variables and rating scale scores. Nicotine test day versus placebo test day. T-test for dependent samples was applied to physiological variables, Wilcoxon Signed Ranks Test was applied to rating scale scores.

\begin{tabular}{|l|c|r|r|r|r|c|}
\hline & & \multicolumn{2}{|c|}{ Nicotine } & \multicolumn{2}{c|}{ placebo } & analysis \\
\cline { 2 - 7 } & $\mathbf{N}$ & mean & \multicolumn{1}{c|}{ SD } & mean & \multicolumn{1}{c|}{ SD } & \multicolumn{1}{c|}{$\boldsymbol{p}$} \\
\hline $\begin{array}{l}\text { systolic blood pressure } \\
\text { (mmHg) }\end{array}$ & 33 & 1.848 & 12.597 & 1.030 & 11.148 & .623 \\
\hline $\begin{array}{l}\text { diastolic blood pressure } \\
\text { (mmHg) }\end{array}$ & 33 & 2.272 & 6.520 & 0.393 & 15.959 & .053 \\
\hline $\begin{array}{l}\text { heart rate } \\
\text { (beats per minute) }\end{array}$ & 33 & 6.242 & 7.168 & -3.515 & 11.364 & .000 \\
\hline STAl score & 33 & 0.813 & 5.468 & 0.343 & 6.429 & .514 \\
\hline PSL score & 33 & 1.393 & 2.249 & -0.030 & 3.450 & .003 \\
\hline eVAAS score & 33 & 0.812 & 5.468 & 1.454 & 7.425 & .627 \\
\hline
\end{tabular}


Table 3. Repeated measures ("baseline", "post patch", "post challenge") analysis of variance of physiological variables and rating scale scores. Nicotine test day versus placebo test day. Two-way ANOVA for correlated samples was applied to physiological variables, Friedman's non parametric twoway analysis of variance for correlated samples was applied to rating scale scores.

\begin{tabular}{|l|c|r|r|r|r|c|}
\hline & & \multicolumn{2}{|c|}{ nicotine } & \multicolumn{2}{c|}{ placebo } & analysis \\
\cline { 2 - 7 } & $\mathbf{N}$ & LS means & SE & \multicolumn{1}{c|}{$\begin{array}{c}\text { LS } \\
\text { means }\end{array}$} & SE & $\boldsymbol{p}$ \\
\hline $\begin{array}{l}\text { systolic blood pressure } \\
\text { (mmHg) }\end{array}$ & 33 & 116.44 & 1.263 & 113.94 & 1.239 & .1091 \\
\hline $\begin{array}{l}\text { diastolic blood pressure } \\
\text { (mmHg) }\end{array}$ & 33 & 77.14 & 1.155 & 75.79 & 1.587 & .3520 \\
\hline $\begin{array}{l}\text { heart rate (beats per } \\
\text { minute) }\end{array}$ & 33 & 72.79 & 1.232 & 71.46 & 1.264 & .4289 \\
\hline STAl score & 33 & 35.03 & 2.37 & 37.60 & 2.38 & .4405 \\
\hline PSL score & 33 & 9.29 & 1.19 & 9.91 & 1.23 & .2770 \\
\hline eVAAS score & 33 & 24.09 & 3.93 & 22.04 & 3.79 & .6947 \\
\hline
\end{tabular}


Table 4. "post challenge" minus "post patch" scores of physiological variables and rating scale scores (i.e. DELTA). Nicotine test day versus placebo test day. T-test for dependent samples was applied to physiological variables, Wilcoxon Signed Ranks Test was applied to rating scale scores.

\begin{tabular}{|l|c|r|r|r|r|c|}
\hline & \multicolumn{2}{|c|}{ nicotine } & \multicolumn{2}{c|}{ placebo } & analysis \\
\hline & \multicolumn{1}{|c|}{$\mathbf{~}$ mean } & \multicolumn{1}{c|}{ SD } & \multicolumn{1}{c|}{ mean } & \multicolumn{1}{c|}{ SD } & \multicolumn{1}{c|}{$\boldsymbol{p}$} \\
\hline $\begin{array}{l}\text { systolic blood } \\
\text { pressure (mmHg) }\end{array}$ & 33 & -1.303 & 4.660 & -0.879 & 7.300 & .778 \\
\hline $\begin{array}{l}\text { diastolic blood } \\
\text { pressure (mmHg) }\end{array}$ & 33 & 0.969 & 7.908 & 1.364 & 5.378 & .083 \\
\hline $\begin{array}{l}\text { heart rate } \\
\text { (beats per minute) }\end{array}$ & 33 & -1.242 & 7.562 & 0.848 & 5.540 & .248 \\
\hline STAl score & 33 & 9.500 & 11.656 & 11.969 & 11.613 & .514 \\
\hline PSL score & 33 & 7.242 & 5.523 & 9.303 & 6.957 & .036 \\
\hline eVAAS score & 33 & 20.273 & 19.631 & 18.818 & 19.068 & .632 \\
\hline
\end{tabular}




\section{REFERENCES}

American Psychiatric Association (1994). Diagnostic and statistical manual of mental disorders. $4^{\text {the }}$. Washington, DC. American Psychiatric Association.

Amering M, Bankler B, Berger P, Griengl H, Windhaber J, Katsching H (1999). Panic disorder and cigarette smoking behavior. Compr Psychiatry 40;35-8.

Brambilla F, Biggio G, Pisu MG, Bellodi L, Perna G, Bogdanovich-Djukic V, Purdy RH, Serra M (2003). Neurosteroid secretion in panic disorder. Psychiatry Res 118(2);107-16.

Breslau N, Kilbey M, Andresti P (1991). Nicotine dependence, major depression, and anxiety in young adults. Arch Gen Psychiatry 48(12);1069-1074.

Breslau N, Klein DF (1999). Smoking and panic attacks: an epidemiologic investigation. Arch Gen Psychiatry 56(12);1141-7.

Caldirola D, Bellodi L, Cammino S, Perna G (2004). Smoking and respiratory irregularity in panic disorder. Biol Psychiatry 56;393-8.

Chan KKH, Ross HD, Berner B, Piratino AJ, John VA (1990). Pharmakokinetics of a single transdermal dose of nicotine in healthy smokers. J Control Release 14 (Suppl 2);145-51.

De Graaf R, Bijl RV, Smit F, Volebergh WA, Spijker J (2002). Risk factors for 12-month comorbidity of mood, anxiety, and substance use disorders: findings from The Netherlands mental health survey and incidence study. Am J Psychiatry 159;620-9.

Dilsaver SC (1987). Nicotine and panic attacks. Am J Psychiatry 144;1245-6.

Fallon JH, Keator DB, Mbogori J, Taylor D, Potkin SG (2005). Gender: a major determinant of brain response to nicotine. International J Neuropsychopharmacol 8(1);17-26.

File SE, Cheeta S, Kenny PJ (2000). Neurobiological mechanisms by which nicotine mediates different types of anxiety. Eur J Pharmacol 393;231-6.

Girdler SS, Jamner LD, Jarvik M, Soles JR, Shapiro D. (1997). Smoking status and nicotine administration differentially modify hemodynamic stress reactivity in men and women. Psychosom Med 59(3);294-306.

Goodwin R, Hamilton SP (2002). Cigarette smoking and panic: the role of neuroticism. Am J Psychiatry 159;1208-13.

Griez E, Van den Hout MA (1983). Carbon dioxide and anxiety: cardiovascular effects of a single inhalation. J Behav Ther Exp Psychiatry 14(4);297-304. 
Himle J, Thyer BA, Fischer DJ (1988). Prevalence of smoking among anxious outpatients. Phobia Practice Research Journal 1;25-31.

Jarvik ME, Caskey NH, Rose JE, Herskovic JE, Sadeghpour M (1989). Anxiolytic effect of smoking associated with four stressors. Addict Behav 14(4);379-86.

Jarvis MJ, Primatesta P, Erens B, Feyerabend C, Bryant A (2003). Measuring nicotine intake in population surveys: comparability of saliva and plasma cotinine estimates. Nicotine Tob Res 5;349-55.

Johnson JG, Cohen P, Pine DS, Klein DF, Kasen S, Brook JS (2000). Association between cigarette smoking and anxiety disorders during adolescence and early adulthood. JAMA 284;2348-51.

Jones BM, Jones MK (1976). Alcohol effects in women during the menstrual cycle. Ann N Y Acad Sci 273;576-87.

Kassel JD, Shiffman S (1997). Attentional mediation of cigarette smoking's effect on anxiety. Health Psychol 16;359-68.

Klein DF (1993). False suffocation alarms, spontaneous panics, and related conditions: an integrative hypothesis. Arch Gen Psychiatry 50;306-17.

McCabe RE, Chudzik SM, Antony MM, Young L, Swinson RP, Zolvensky MJ (2004). Smoking behaviors across anxiety disorders. J Anxiety Disord 18;7-18.

Parsons WD, Neims AH (1978). Effect of smoking on caffeine clearance. Clin Pharmacol Ther 24(1);405.

Paterson D, Nordberg A (2000). Neuronal nicotine receptors in the human brain. Prog Neurobiol 61;75111.

Perkins KA, Stiller RL, Jennings JR (1991). Acute tolerance to the cardiovascular effects of nicotine. Drug Alcohol Depend 29(1);77-85.

Pohl R, Yeragani VK, Balon R, Lycaki H, McBride R (1992). Smoking in patients with panic disorder. Psychiatry Res 43;253-62.

Pols H, Griez E, Bourin M, Schruers K (1999). Effect of CCK-4 on a 35\% carbon dioxide challenge in healthy volunteers. Prog Neuropsychopharmacol Biol Psychiatry 23(8);1345-50.

Schruers K, Pols H, Overbeek T, Griez E (2000). 10 microg CCK-4 premedication and 35\% $\mathrm{CO}_{2}$ challenge in healthy volunteers. Prog Neuropsychopharmacol Biol Psychiatry 24(3);409-18.

Sheehan DV, Lecrubier Y, Sheehan KH, Amorim P, Janavs J, Weiller E, Herguenta T, Baker R, Dunbar 
GC (1998). The Mini-International Neuropsychiatric Interview (M.I.N.I.) the development and validation of a structured diagnostic psychiatric interview for DSM-IV and ICD-10. J Clin Psychiatry 59(Suppl 20);22-33.

Slawecki CJ, Gilder A, Roth J, Ehlers CL. (2003). Increased anxiety-like behaviour in adult rats exposed to nicotine as adolescents. Pharmacol Biochem Behav 75;355-61.

Sontag H, Wittchen HU, Hofler M, Kessler RC, Stein MB (2000). Are social fears and DSM IV social anxiety disorder associated with smoking and nicotine dependence in adolescents and young adults? Eur Psychiatry 15;67-74.

Spielberger CD, Gorsuch RL, Lusene RE (1970). STAI Manual for the State-trait Anxiety Inventory. Palo Alto, CA: Consulting Psychologists Press.

SRNT Subcommittee on Biochemical Verification (2002). Biochemical verification of tobacco use and cessation. Nicotine Tob Res 4;149-59.

Verburg K, Griez E, Meijer J, Pols H (1995). Discrimination between panic disorder and generalized anxiety disorder by 35\% carbon dioxide challenge. Am J Psychiatry 152(7);1081-3.

Verburg K, Perna G, Griez EJL (2001). A case study of the $35 \% \mathrm{CO}_{2}$ challenge. In: E. J. L. Griez, C. Faravelli, D. J. Nutt, \& J. Zohar (eds.), Anxiety disorders. An introduction to clinical management and research. Chichester: John Wiley \& sons, LTD. pp. 341-57.

West R, Hajek P (1997). What happens to anxiety levels on giving up smoking? Am J Psychiatry $154 ; 1589-92$.

Yellowlees P, Alpers JH, Bowden JJ, Bryant GD, Ruffin RE (1987). Psychiatric morbidity in patients with chronic airflow obstruction. Med J Aust 97;305-7.

Yellowlees P, Haynes S, Potts N, Ruffin RE (1988). Psychiatric morbidity in patients with life-threatening asthma: initial report of controlled study. Med J Aust 149;246-9.

Yellowlees P, Kaluci RS (1990). Psychological aspects of asthma and the consequent research implications. Chest 97;628-34.

Zvolensky MJ, Schmidt NB, Stewart SH (2003). Panic disorder and smoking. Clin Psychol (New York) 10;29-51. 


\section{Chapter 6}

\section{Cigarette smoking and $35 \% \mathrm{CO}_{2}$ induced panic in panic disorder patients}

\section{Abstract}

Background. Clinical and experimental data suggest that cigarette smoking increases the risk for emergence of panic disorder (PD). Several explanations for such a relationship have been proposed. One hypothesis is that PD patients smoke as means of self-medicating their symptoms. Another hypothesis is that cigarette smoking contributes to the development of panic. A third one refers to a shared vulnerability.

The present study wants to test whether cigarette smoking, that is chronic exposure to nicotine, has an influence on laboratory elicited panic in PD patients.

Methods. 25 PD smokers and 25 PD non smokers, matched for gender and age, were compared. All subjects received a clinical baseline assessment (Panic Associated Symptom Scale, Fear Questionnaire) and underwent a $35 \% \mathrm{CO}_{2}$ challenge. Response to the challenge was evaluated via the Panic Symptom List and the Visual Analogue Anxiety Scale.

Results. The two samples did not differ on clinical baseline features of PD or for anxiety level preceding the $35 \% \mathrm{CO}_{2}$ challenge. Smokers had a significantly higher increase in panic symptoms in response to the challenge than non smokers and also tended to react more subjective anxiety. Smokers had a higher probability to experience a $35 \% \mathrm{CO}_{2}$ induced panic attack than non smokers.

Conclusions. The present findings are consistent with the idea that nicotine acts on specific panic pathways triggering panic attacks in PD subjects. This may have clinical implications as quitting smoking could become one of the relevant steps in the treatment of PD patients. 


\section{Introduction}

Clinical and experimental data suggest that cigarette smoking increases the risk for emergence of certain anxiety disorders and in particular of panic disorder (PD) (Morissette et al 2006). A disproportionate number of persons with panic smoke cigarettes compared to people in the general population (Breslau et al 1991; Amering et al 1999) and individuals with other anxiety disorders (Johnson et al 2000).

Panic has been strongly associated with occasional and regular smoking and nicotine dependence. For example, a recent epidemiological study (Isensee et al 2003) found smokers significantly more apt to have a history of panic attacks or panic disorder (odds ratio range, 3.0-28.0) compared to non smokers. And, Breslau et al (2004) confirmed that the onset of PD was associated with pre-existing daily smoking (OR 2.6). These findings are consistent with other epidemiological data (Breslau et al 1991, De Graaf et al 2002) and with studies using samples from treatment clinics (Himle et al 1988; Hayward et al 1989).

Several explanations for the relationship between panic and smoking have been proposed. One hypothesis is that PD patients smoke as means of self-medicating their symptoms (Breslau et al 1991; Pohl et al 1992), either due to anxiolytic effects of nicotine (Jarvik et al 1989) or behavioural mechanisms (Kassel et al 1997).

Another hypothesis is that cigarette smoking contributes to the development of PD precipitating panic attacks (PAs) among individuals with PD (Johnson et al 2000; De Graaf et al 2002; Zvolensky et al 2003a; McCabe et al 2004) or increasing the risk for first occurrence of panic (Breslau et al 1999). Cigarette smoking might lead to the onset of panic by inducing respiratory abnormalities (Pine et al 2000; Gorman et al 2001; Caldirola et al 2004) or changes in respiratory function. In particular, Breslau \& Klein (1999) observed an increased lifetime prevalence of panic attacks in smokers who reported lung disease. On the basis of the false suffocation alarm theory (Klein 1993) and the association between lung disease and panic attacks among non smokers (Yellowlees et al 1990), the authors suggested that by increasing the risk for lung disease, smoking might increase the risk to overreact to suffocation signals and indirectly the risk for panic attacks.

However, the small proportion of smokers reporting lung disease and the increasing incidence of panic attack/disorder in smokers with no history of lung disease suggest the possibility of other pathways from smoking to panic. For instance, Dilsaver (1987) proposed that nicotine produces physiological effects characteristic of panic attacks promoting the release of epinephrine and norepinephrine. Alternatively, 
Zvolensky et al (2003b) suggested that smoking may modify the expression of PD by increasing potentially fear-producing bodily sensation. Thus, individuals with PD, who usually perceive themselves as being physically unhealthy, would more likely react with exaggerated anxiety.

Finally, the hypothesis of a shared vulnerability has been tested examining whether panic and cigarette smoking share genetic or environmental liability factors. Reichborn-Kjennerud et al (2004) used data of 3,172 female-female twins to calculate the correlation between genetic factors and between environmental factors that influence lifetime measures of panic attacks and daily smoking. Genetic factors were uncorrelated. Shared or familial environmental factors were strongly correlated (75\%) and influenced the two phenotypes identically.

Goodwin et al (2005) did not reach the same conclusions. Adjusting for parental anxiety disorder and parental smoking, the association between cigarette smoking and panic attack was not statistically significant (OR 2.0; 95\% 0.9 - 4.5), as opposed to the association with PD (OR 3.7; 95\% Cl 1.6 - 8.9).

A shared vulnerability has been studied also focussing on personality, which seems responsible for the co-occurrence of cigarette smoking and panic attack rather than a direct causal link (Goodwin et al 2002). The above evidence might suggest that there is a causal relationship between smoking and panic. However, since things may not be that clear-cut and the majority of existing studies have been conducted in naturalistic settings, laboratory based test can be a useful additional research step.

Zvolensky et al (2004) evaluated smokers with or without PD, and non smokers with PD who completed a voluntary hyperventilation procedure, which elicits panic-relevant bodily sensations. Smokers with PD reported greater levels of anxiety and bodily distress than smokers without PD and than non smokers with PD at the post-challenge assessment and recovery period. No differences in autonomic responding were evident during the challenge or in the recovery phase. The authors suggest that smoking does not increase anxious responding to elicited bodily sensations by producing more autonomic sensations but via cognitive-affective variables. However, they consider that the lack of differences in autonomic responding could be an artefact due to the relatively young age of the sample, a ceiling effect of the challenge or methodological factors.

In this frame, the effect of the acute administration of nicotine under controlled laboratory conditions was evaluated in 33 healthy non smokers volunteers in our lab. They received transdermal nicotine and underwent a $35 \% \mathrm{CO}_{2}$ challenge. Compared with placebo, nicotine increased diastolic blood pressure, heart rate and Panic Symptom List score prior to the challenge but did not affect anxiety at baseline or 
response to the $35 \% \mathrm{CO}_{2}$ challenge itself. Nicotine seemed to promote autonomic activation but not to facilitate panic in healthy volunteers (Cosci et al 2006). Once again, results may have been influenced by factors such as the evaluation of healthy volunteers rather than psychologically vulnerable individuals or the acute administration of nicotine used as a proxy of cigarette smoking.

Considering the heterogeneity of the methods and the results proposed as well as the limitations exposed, we designed a study to test whether cigarette smoking, that is a chronic exposure to nicotine, has an influence on laboratory elicited panic in panic disorder patients. Because chronic administration of nicotine to non smokers would be unethical, we administered $35 \% \mathrm{CO}_{2}$ challenge to regular PD smokers (as a proxy of chronic exposure to nicotine) and compared them to PD non smokers. We hypothesized that cigarette smoking facilitates the emergence of panic.

\section{Methods}

\section{$\underline{\text { Subject }}$}

The sample consisted of 50 outpatients with panic disorder with or without agoraphobia (agoraphobia was diagnosed in about $70 \%$ of the sample). Twenty five of them were smokers and 25 were non smokers. Smokers and non smokers were matched for age and gender.

All the participants were screened by experienced psychiatrists. This screening comprised a complete medical history, a physical examination, a psychiatric evaluation to formulate the PD diagnosis according to the DSM IV criteria and using the Mini-International Neuropsychiatric Interview-Plus (Sheehan et al 1994).

The exclusion criteria for all subjects were the presence of significant concurrent cardiovascular or respiratory disease, significant hypertension (systolic blood pressure greater than $80 \mathrm{mmHg}$, diastolic blood pressure greater than $100 \mathrm{~mm} \mathrm{Hg}$ ), pregnancy or epilepsy, according to a direct physical examination and a medical history, as well as concurrent psychiatric disorders, except specific phobia. Subjects who were currently taking daily psychiatric medications or $\alpha_{2}-, \beta$-blockers were also excluded. All participants gave their informed consent after a detailed explanation of the entire procedure. 


\section{Procedures}

The study was conducted on two separate days. Before the $\mathrm{CO}_{2}$ challenge, the subjects had to have been without all psychotropic medications for at least 2 weeks. None of the patients had taken fluoxetine in the 6 months before testing. Because many substances can affect the $35 \% \mathrm{CO}_{2}$ challenge response, subjects were instructed not to drink alcohol or take nonsteroid anti-inflammatory drugs for at least 36 hours preceding the second test day, consume caffeinated products for 8 hours prior to the study, eat or smoke for 2 hours preceding the test.

First day. Experienced psychiatrists screened the patients by means of a complete medical history, a physical examination, and a psychiatric evaluation to make the PD diagnosis according to the DSM IV criteria (APA 1994) and using the Mini-International Neuropsychiatric Interview-Plus (Sheehan et al 1994) to support the diagnosis.

Second day. Subjects who met the inclusion criteria received a baseline assessment and thereafter underwent the $35 \% \mathrm{CO}_{2}$ challenge.

As part of the baseline assessment, subjects were evaluated about smoking habits. Age of onset of smoking, defined as the age at which the subjects started to smoke daily for at least 4 weeks (Breslau et al 1999; Sonntag et al 2000; Isensee et al 2003), and number of cigarettes daily smoked were asked.

Non smokers were defined as those who declared they had never used cigarettes or other tobacco products in their lifetime. Current smokers were defined as those who were smokers at the time of the assessment, had an active tobacco use on daily basis for a period of at least 4 weeks continually (Breslau et al 1999; Sonntag et al 2000; Isensee et al 2003) and did not quit smoking for a period longer than 6 continuous months in their lifetime (Caldirola et al 2004).

Clinical assessment of symptoms of panic was performed using two scales. The Panic Associated Symptom Scale (PASS) is an interviewer administered scale which measures the severity of the core symptoms of panic disorder. It assesses the frequency of panic attacks, the level of anticipatory anxiety, and phobic avoidance. These yield a global score (PASS-tot) and sub scores for panic attacks (PASSPA), anticipatory anxiety (PASS-AA), and phobic avoidance (PASS-AV) (Argyle et al 1991). The Fear Questionnaire is a self administered scale which assesses agoraphobia, blood injury phobia, and social phobia. It produces a global score (FQ-tot) and sub scores for agoraphobia (FQ-AGO), blood-injury phobia (FQ-BI) and social phobia (FQ-SOC) (Marks et al 1979). 
mmediately before the $35 \% \mathrm{CO}_{2}$ challenge anxiety level was measured by means of the Visual Analogue Scale of Anxiety, the Panic Symptom List (PSL) and the State-Trait Anxiety Inventory - State form (STAIS; Spielberger et al 1970).

Scores on the VAAS range from 0 (no anxiety at all) to 100 (worst anxiety imaginable). The PSL consists of the 13 panic symptoms of a panic attack, as described by DSM IV (APA 1994), on a scale from 0 (absent) to 4 (very intensive). Both scales have been used previously to assess experimental anxiety (Verburg et al 1995; Pols et al 1999; Schruers et al 2000).

Then, subjects underwent a $35 \% \mathrm{CO}_{2}$ challenge which was immediately followed by a reassessment of anxiety (PSL and VAAS).

The experimenter applied the $35 \% \mathrm{CO}_{2}$ challenge procedure after informing the participant that shortlived discomfort might be experienced during the challenge, ranging from a few physical symptoms to a definite sensation of anxiety. However, the words "panic" or "panic attack" were not mentioned.

The challenge used is standard, and satisfies the criteria for a laboratory model of panic (Verburg et al 2001). The procedure runs as follows. First, the subject deeply inhales a single breath of room air through a self-administration face mask connected to a respirometer which provides an indication of the subject vital capacity. Next, the subject inhales deeply one single breath of the $35 \% \mathrm{CO}_{2} / 65 \% \mathrm{O}_{2}$ gas mixture, and holds his breath while the experimenter counts aloud 4 seconds to enhance alveolar gas exchange. The procedure requires the experimenter to check that the subject's tidal volume is at least $80 \%$ of the vital capacity in order to declare that the inhalation was valid. According to the scales described and DSM-IV criteria defining a panic attack, the reaction to the $35 \% \mathrm{CO}_{2}$ challenge was considered to be an induced panic attack if it included a sensation of fear or panic with at least delta visual analogue scale for anxiety score more than $25 \mathrm{~mm}$, and an increment of at least four symptoms on the PSL. Delta visual analogue scale for anxiety score is a measure of global anxiety reactivity and is calculated as the post challenge minus the pre challenge VAAS scores.

\section{Data analysis}

Chi square test was used for categorical variables (gender, occurrence of challenge induced panic attack).

Student's t-test was used for non categorical data with a normal distribution (age, age of PD onset). Due 
to the non-normal distribution of the scores of the rating scales (STAI, VAAS, PSL, PAAS, FQ), nonparametric test were used (Mann-Whitney $\mathrm{U}$ test for independent samples).

Significance levels were set at $p<0.05$ (two tailed).

Main outcome measures were the $\mathrm{CO}_{2}$ induced changes (deltas) in VAAS and PSL scores on the basis of the immediate pre- and post-inhalation assessments. Deltas are calculated as $35 \% \mathrm{CO}_{2}$ post challenge minus $35 \% \mathrm{CO}_{2}$ pre challenge scores.

\section{Results}

Twenty five smokers and 25 non smokers with a diagnosis of panic disorder were evaluated. The two samples were individually matched for gender (13 males and 12 females in each group) and group matched for age (32.33 \pm 11.488 years in cases and $34.40 \pm 10.595$ years in controls; $p=0.6958$ ).

Among smokers, the mean age of onset of the smoking habit was $17.38 \pm 4.117$ years $(n=21)$ and the mean daily consumption of cigarettes was $14.30 \pm 9.171(n=20)$. Sixty eight percent $(n=17)$ of PD smokers smoke $1-10$ cigarettes per day, $24 \%(n=6)$ smoke $11-20$ cigarettes per day, and $8 \%(n=2)$ more than 30 cigarettes per day.

The two samples did not differ in age of PD onset $(26.17 \pm 7.927$ years in cases and $29.09 \pm 10.137$ years in controls; $p=0.2526$ ), as well as for clinical characteristics and severity of panic disorder as evaluated at baseline by means of the PASS and the FQ. The only exception was situational panic attacks which tended to occur significantly more often in smokers if compared to non smokers $(p=$ 0.0501) (table 1).

Smokers and non smokers did not differ for STAI, VAAS and PSL pre challenge scores, as well as for VAAS and PSL post challenge scores. On the other hand, the two samples differed in terms of deltas of VAAS and PSL (table 2).

Smokers had a significantly higher increase in PSL in response to the $35 \% \mathrm{CO}_{2}$ challenge than non smokers and a strong trend to an increase in the VAAS score.

According to the two scales, smokers had lower scores immediately before the challenge and reached higher scores immediately after.

Finally, smokers had a higher probability to experience a $35 \% \mathrm{CO}_{2}$ induced panic attack. Sixty four 
percent (16/25) of smokers versus thirty six percent (9/25) of non smokers had an induced panic attack $(p=.0477)$, defined as a sensation of fear or panic with at least delta visual analogue scale for anxiety score greater than $25 \mathrm{~mm}$, and an increment of at least four symptoms on the PSL.

\section{Discussion}

The present study shows that PD smokers had a stronger response to the $35 \% \mathrm{CO}_{2}$ challenge, according to the VAAS and the PSL scores, when compared to PD non smokers. Additionally, PD smokers had a higher probability to experience $\mathrm{CO}_{2}$ induced panic attacks.

Together, the results indicate that smokers were more affected by the $35 \% \mathrm{CO}_{2}$ challenge than nonsmokers.

The effects of cigarette smoking on $\mathrm{CO}_{2}$ induced symptomatology nicely fit with the literature according to which panic is strongly related to regular smoking and nicotine dependence (Isensee et al 2003; Breslau et al 2004). The findings support the hypothesis that cigarette smoking may contribute to the development of PD, at least precipitating panic attacks in PD patients (Johnson et al 2000; De Graaf et al 2002; Zvolensky et al 2003a; McCabe et al 2004). They are also consistent with the finding of Zvolensky and co-workers (2004) that smokers with PD had greater levels of anxiety and bodily distress than non smokers with $\mathrm{PD}$ at the post-challenge assessment and recovery period.

A previous study by our group (Cosci et al 2006) in healthy volunteers did not show any effect of nicotine to facilitate panic. There was, however, an increase in autonomic activation due to nicotine. It is well known that healthy volunteers are less affected by a $35 \% \mathrm{CO}_{2}$ challenge than PD patients (Verburg et al 1995). It is therefore conceivable that nicotine may only elicit aspecific autonomic activation in healthy subjects but promote panic in psychologically vulnerable individuals by interacting with specific underlying mechanisms related to panic disorder. This phenomenon is not unexpected as it has been already observed for alcohol (Cosci et al 2004; Cosci et al 2005).

The lack of difference between PD smokers and PD non smokers in the pre challenge state anxiety is consistent with Zvolensky et al (2004) and rules out that smokers had a stronger reaction to the challenge because of a higher baseline anxiety. In fact, smokers and non smokers had comparables scores, both on PASS and FQ scales, the only exception pertaining to the occurrence of situational PAs 
which tended to be more frequent in smokers than non smokers.

In brief, cigarette smoking increases the $\mathrm{CO}_{2}$ challenge response in PD patients, without affecting pre challenge state anxiety.

The issue of the mechanisms by which smoking subjects with $\mathrm{PD}$ are more affected by a $35 \% \mathrm{CO}_{2}$ challenge than non smoking PDs is not explicitly addressed in this work. One hypothesis, amongst others, could be that smoking increases anxious responding to elicited bodily sensations by producing more autonomic sensations (Dilsaver 1987). Alternative hypotheses could refer to the role of cognitiveaffective variables (Zvolensky et al 2004). Obviously, various direct pharmacological influences of nicotine on panic pathways should be taken into consideration as well.

Some can argue that using cigarette smoking as a proxy of chronic exposure to nicotine may introduce a bias. In fact, it is well known that tobacco includes more than four thousand different constituents (Burns 1991). However, the effect of cigarette smoking at least on the central nervous system has been mainly attributed to the pharmacological action of nicotine (Dilsaver 1987).

In this frame, the pure effect of nicotine could be studied chronically administering nicotine to PD patients, which does not seem to be the case for ethical reasons.

An other possible limitation is the relatively small sample of smokers and non smokers evaluated. This may be the reason why the increase of VAAS score induced by the challenge just failed to reach statistical significance. Additional work on larger PD patient samples may be welcome on basis of the present preliminary results.

\section{Conclusions}

The present findings seem consistent with the idea that nicotine acts on specific panic pathways. Our results fit the view that nicotine may trigger panic attacks in PD subjects. If confirmed, this may have interesting clinical implications. Quitting smoking, for instance, should be encouraged and considered one of the relevant steps in the treatment of PD patients.

Similar studies should be conducted in patients with different anxiety disorders. This may clarify if nicotine acts via a common pathway in all psychologically vulnerable subjects.

Moreover, it would be interesting to replicate the present observation comparing healthy smokers with 
| Chapter 6

healthy non smokers. This may add information to the effects of nicotine chronic exposure in non vulnerable subjects. 
Table 1. Comparison of PD smokers and PD non smokers on clinical characteristics and severity of panic disorder as assessed at baseline. Mann Whitney test for independent samples.

\begin{tabular}{|l|c|r|r|r|r|r|r|}
\hline & \multicolumn{3}{|c|}{ smokers } & \multicolumn{3}{c|}{ non smokers } & \\
\hline & $\mathrm{N}$ & \multicolumn{1}{|c|}{ mean } & \multicolumn{1}{c|}{ SD } & N & \multicolumn{1}{c|}{ mean } & \multicolumn{1}{c|}{ SD } & p \\
\hline $\begin{array}{l}\text { PASS, situational } \\
\text { panic attacks }\end{array}$ & 21 & 1.48 & 1.778 & 22 & 0.54 & 1.224 & 0.0501 \\
\hline $\begin{array}{l}\text { PASS, spontaneous } \\
\text { panic attacks }\end{array}$ & 21 & 0.95 & 1.564 & 22 & 1.00 & 1.573 & 0.8815 \\
\hline $\begin{array}{l}\text { PASS, sub- } \\
\text { threshold panic } \\
\text { attacks }\end{array}$ & 21 & 1,86 & 1.682 & 22 & 1.64 & 0.953 & 0.9005 \\
\hline $\begin{array}{l}\text { PASS, anticipatory } \\
\text { anxiety (PASS-AA) }\end{array}$ & 21 & 3.24 & 1.921 & 22 & 2.59 & 1.817 & 0.3361 \\
\hline $\begin{array}{l}\text { PASS, phobic } \\
\text { avoidance (PASS- } \\
\text { AV) }\end{array}$ & 21 & 0.67 & 1.016 & 20 & 0.70 & 0.923 & 0.7703 \\
\hline $\begin{array}{l}\text { PASS total score } \\
\text { (PASS-tot) }\end{array}$ & 21 & 8.19 & 4.600 & 20 & 6.40 & 3.016 & 0.2202 \\
\hline $\begin{array}{l}\text { FQ, agoraphobia } \\
\text { (FQ-AGO) }\end{array}$ & 23 & 12.26 & 9.588 & 23 & 15.39 & 14.963 & 0.8008 \\
\hline $\begin{array}{l}\text { FQ, blood phobia } \\
\text { (FQ-BI) }\end{array}$ & 23 & 16.00 & 12.504 & 23 & 18.48 & 10.761 & 0.4262 \\
\hline $\begin{array}{l}\text { FQ, social phobia } \\
\text { (FQ-SOC) }\end{array}$ & 23 & 10.48 & 8.495 & 23 & 11.35 & 6.582 & 0.4515 \\
\hline $\begin{array}{l}\text { FQ total score (FQ- } \\
\text { tot) }\end{array}$ & 23 & 38.74 & 23.586 & 23 & 41.43 & 26.611 & 0.7349 \\
\hline
\end{tabular}


| Chapter 6

Table 2. Comparison of PD smokers with PD non smokers concerning pre and post challenge assessment. Mann Whitney test for independent samples.

\begin{tabular}{|l|r|r|r|r|r|r|r|}
\hline & \multicolumn{3}{|c|}{ smokers } & \multicolumn{3}{c|}{ non smokers } & \\
\hline & $\mathbf{N}$ & \multicolumn{1}{|c|}{ Mean } & \multicolumn{1}{c|}{ SD } & \multicolumn{1}{c|}{$\mathbf{N}$} & \multicolumn{1}{c|}{ Mean } & \multicolumn{1}{c|}{ SD } & \multicolumn{1}{c|}{$\mathbf{p}$} \\
\hline STAl pre challenge & 24 & 44.38 & 10.806 & 24 & 47.17 & 13.796 & 0.5869 \\
\hline PSL pre challenge & 25 & 3.48 & 4.917 & 25 & 5.36 & 5.203 & 0.1212 \\
\hline PSL post challenge & 25 & 14.72 & 8.409 & 25 & 13.12 & 8.017 & 0.6360 \\
\hline Delta PSL & 25 & 11.24 & 6.173 & 25 & 7.76 & 6.267 & $\mathbf{0 . 0 4 5 4}$ \\
\hline $\begin{array}{l}\text { VAAS pre } \\
\text { challenge }\end{array}$ & 25 & 26.88 & 23.463 & 25 & 31.88 & 27.025 & 0.5825 \\
\hline $\begin{array}{l}\text { VAAS post } \\
\text { challenge }\end{array}$ & 25 & 68.84 & 24.277 & 25 & 61.28 & 26.337 & 0.3132 \\
\hline Delta VAAS & 25 & 41.96 & 21.378 & 25 & 29.40 & 22.546 & 0.0522 \\
\hline
\end{tabular}




\section{REFERENCES}

American Psychiatric Association 1994. Diagnostic and statistical manual of mental disorders. $4^{\text {th }} \mathrm{ed}$. Washington, DC: American Psychiatric Association.

Amering M, Bankler B, Berger P, Griengl H, Windhaber J, Katsching H (1999). Panic disorder and cigarette smoking behavior. Compr Psychiatry 40;35-8.

Argyle N, Deltito J, Allerup P, Maier W, Albus M, Nutzinger D, Rasmussen S, Ayuso JL, Bech P (1991). The Panic-Associated Symptom Scale: measuring the severity of panic disorder. Acta Psychiatr Scand 83(1);20-6.

Breslau N, Kilbey M, Andresti P (1991). Nicotine dependence, major depression, and anxiety in young adults. Arch Gen Psychiatry 48(12);1069-74.

Breslau N, Klein DF (1999). Smoking and panic attacks: an epidemiologic investigation. Arch Gen Psychiatry 56(12);1141-7.

Breslau N, Novak SP, Kessler RC (2004). Daily smoking and the subsequent onset of psychiatric disorders. Psychol Med 34(2);323-33.

Burns DM (1991). Cigarettes and cigarette smoking. Clin Chest Med 12(4);631-42.

Caldirola D, Bellodi L, Cammino S, Perna G (2004). Smoking and respiratory irregularity in panic disorder. Biol Psychiatry 56;393-8.

Cosci F, Abrams K, Schruers KR, Rickelt J, Griez EJ (2006). Effect of nicotine on $35 \% \mathrm{CO}_{2}$-induced anxiety: A study in healthy volunteers. Nicotine Tob Res 8(4);511-7.

Cosci F, De Gooyer T, Schruers K, Faravelli C, Griez EJL (2005). The influence of ethanol infusion on the effects of $35 \% \mathrm{CO}_{2}$ challenge. A study in panic disorder patients and healthy volunteers. Eur Psychiatry 20;299-303.

Cosci F, Schruers K, Faravelli C, Griez E (2004). The influence of alcohol oral intake on the effects of $35 \% \mathrm{CO}_{2}$ challenge. A study in healthy volunteers. Acta Neuropsychiatrica 16(2);107-9.

De Graaf R, Bijl RV, Smit F, Volebergh Nicotine Tob ResWA, Spijker J (2002). Risk factors for 12-month comorbidity of mood, anxiety, and substance use disorders: findings from The Netherlands mental health survey and incidence study. Am J Psychiatry 159;620-9.

Dilsaver SC (1987). Nicotine and panic attacks. Am J Psychiatry 144;1245-6.

Goodwin R, Hamilton SP (2002). Cigarette smoking and panic: the role of neuroticism. Am J Psychiatry 159(7);1208-13. 
Goodwin RD, Lewinsohn PM, Seeley JR (2005). Cigarette smoking and panic attacks among young adults in the community: the role of parental smoking and anxiety disorders. Biol Psychiatry 58(9);686-93.

Gorman JM, Kent J, Martinez J, Browne S, Coplan J, Papp LA (2001). Physiological changes during carbon dioxide inhalation in patients with panic disorder, major depression, and premenstrual dysphoric disorder: evidence for a central fear mechanism. Arch Gen Psychiatry 58(2);125-31.

Hayward C, Killen JD, Taylor CB (1989). Panic attacks in young adolescents. Am J Psychiatry 146(8);1061-2.

Himle J, Thyer BA, Fischer DJ (1988). Prevalence of smoking among anxious outpatients. Phobia Practice and Research Journal 1;25-31.

Isensee B, Wittchen HU, Stein MB, Hofler M, Lieb R (2003). Smoking increases the risk of panic: findings from a prospective community study. Arch Gen Psychiatry 60(7);692-700.

Jarvik ME, Caskey NH, Rose JE, Herskovic JE, Sadeghpour M (1989). Anxiolytic effect of smoking associated with four stressors. Addictive Behaviors 14(4);379-86.

Johnson JG, Cohen P, Pine DS, Klein DF, Kasen S, Brook JS (2000). Association between cigarette smoking and anxiety disorders during adolescence and early adulthood. JAMA 284;2348-51.

Kassel JD, Shiffman S (1997). Attentional mediation of cigarette smoking's effect on anxiety. Health Psychol 16;359-68.

Klein DF (1993). False suffocation alarms, spontaneous panics, and related conditions: an integrative hypothesis. Arch Gen Psychiatry 50;306-17.

Marks IM, Mathews AM (1979). Brief standard self-rating for phobic patients. Behav Res Ther. 17(3);2637.

McCabe RE, Chudzik SM, Antony MM, Young L, Swinson RP, Zolvensky MJ (2004). Smoking behaviors across anxiety disorders. J Anxiety Disord 18;7-18.

Morissette SB, Brown TA, Kamholz BW, Gulliver SB (2006). Differences between smokers and nonsmokers with anxiety disorders. J Anxiety Disord.20(5);597-613. Epub 2005 Oct 3.

Pine DS, Klein RG, Coplan JD, Papp LA, Hoven CW, Martinez J, Kovalenko P, Mandell DJ, Moreau D, Klein DF, Gorman JM (2000). Differential carbon dioxide sensitivity in childhood anxiety disorders and nonill comparison group. Arch Gen Psychiatry 57(10);960-7.

Pohl R, Yeragani VK, Balon R, Lycaki H, McBride R (1992). Smoking in patients with panic disorder. 
Psychiatry Res 43;253-62.

Pols H, Griez E, Bourin M, Schruers K (1999). Effect of CCK-4 on a 35\% carbon dioxide challenge in healthy volunteers. Prog Neuropsychopharmacol Biol Psychiatry 23(8);1345-50.

Reichborn-Kjennerud T, Roysamb E, Tambs K, Torgersen S, Kringlen E, Magnus P, Harris JR (2004). Genetic and environmental influences on the association between smoking and panic attacks in females: a population-based twin study. Psychol Med 34(7);1271-7.

Schruers K, Pols H, Overbeek T, Griez E (2000). 10 microg CCK-4 premedication and 35\% $\mathrm{CO}_{2}$ challenge in healthy volunteers. Prog Neuropsychopharmacol Biol Psychiatry 24(3);409-18.

Sheehan DV, Lecrubier Y, Janavs J, Knapp E, Weiler EB, Hergueta T, Sheedan M, Amorim P, Baker R, Sheehan KH, Lepine JP (1994). Mini International Neuropsychiatric Interview: MINI-Plus. Tampa: University of South Florida College of Medicine.

Sonntag H, Wittchen HU, Hofler M, Kessler RC, Stein MB (2000). Are social fears and DSM-IV social anxiety disorder associated with smoking and nicotine dependence in adolescents and young adults? Eur Psychiatry 15(1);67-74.

Spielberger CD, Gorsuch RL, Lusene RE (1970). STAI Manual for the State-trait Anxiety Inventory. Palo Alto, CA: Consulting Psychologists Press.

Verburg K, Griez E, Meijer J, Pols H (1995). Discrimination between panic disorder and generalized anxiety disorder by 35\% carbon dioxide challenge. Am J Psychiatry 152(7);1081-3.

Verburg K, Perna G, Griez E J L (2001). A case study of the $35 \% \mathrm{CO}_{2}$ challenge. In: Griez EJL, Faravelli C, Nutt DJ, Zohar J eds. Anxiety disorders. An introduction to clinical management and research. Chichester: John Wiley \& sons, LTD.

Yellowlees P, Haynes S, Potts N, Ruffin RE (1988). Psychiatric morbidity in patients with life-threatening asthma: initial report of controlled study. Med J Aust 149;246-9.

Zvolensky MJ, Kotov R, Antipova AV, Schmidt NB (2003a). Cross cultural evaluation of smokers risk for panic and anxiety pathology: a test in a Russian epidemiological sample. Behav Res Ther 41(10);1199-215.

Zvolensky MJ, Leen-Feldner EW, Feldner MT, Bonn-Miller MO, Lejuez CW, Kahler CW, Stuart G (2004). Emotional responding to biological challenge as a function of panic disorder and smoking. $\mathrm{J}$ Anxiety Disord 18(1);19-32.

Zvolensky MJ, Schmidt NB, McCreary BT (2003b). The impact of smoking on panic disorder: an initial 
| Chapter 6

investigation of a pathoplastic relationship. J Anxiety Disord 17(4);447-60. 


\section{Chapter 7}

\section{Negative affectivity in individuals applying for smoking cessation clinics. A case control study}

\section{Abstract}

Objective. To assess whether subjects applying for smoking cessation clinics display a higher level of affective symptoms than smokers recruited from the general population.

Methods. The study was conducted according to a case control design. Cases were smokers applying for public smoking cessation clinics for the first visit and controls were smokers enrolled from the general population. Socio-demographic data and clinical information were collected. Self- and heteroadministered rating scales were used to assess anxious and depressive symptoms. Nicotine dependence was measured via a self-administered questionnaire.

Results. Sixty eight cases were recruited, individually matched and compared to controls. Overall, cases had significantly higher scores than controls when the rating scales assessing anxious and depressive symptoms were evaluated.

Conclusions. Smokers applying for smoking cessation clinics for the first visit have a higher level of negative affectivity than smokers from the general population. An evaluation of the level of negative affectivity could be introduced in clinical practice to have a complete assessment of the patient and propose a psychological or pharmacological support as a complement to the smoking cessation programme.

\section{Introduction}

While the association between tobacco dependence and affective disorders has been well documented (Fergusson et al 1996; Black et al 1999; Johnson et al 2000; Grant et al 2004), an increasing literature nowadays focuses on the relationship between smoking and negative affectivity. Negative affectivity 
points to the presence of anxious and depressive symptoms in absence of any formal psychiatric disorder.

As early as in the 1980s it has been observed that female smokers had higher depressive symptoms than female non smokers (Chetwynd et al 1986; Frederick et al 1988). Later on, the results were confirmed for both male and female (Perez-Stable et al 1990). Kick et al (1997) conducted a cross sectional survey on internal medicine outpatients and found a statistically significant higher score on the depression scale in current smokers compared to non smokers. In the same year, Son et al (1997) evaluated 3,933 subjects and found that stratifying for nicotine dependence, in an adjusted comparison between smokers and non smokers, nicotine dependent smokers had higher scores on depression scale than never smokers. The results were confirmed by Brown et al (2000) evaluating 526 patients presenting in the waiting rooms of medicine clinics. In 2002, Ludman and co-workers identified depression score as a risk factor for tobacco dependence in African American low income female smokers if compared to European Americans. Later, Karp et al (2006) confirmed the results in 1,293 students of Montreal secondary schools.

As what concerns anxious symptoms, Williams et al (1982) compared 50 smokers and 50 non-smokers using the MMPI's Manifest Anxiety Scale (MAS). Mean MAS scores for smokers were significantly higher than those for non-smokers. Item analysis revealed that smokers obtained higher scores than nonsmokers on significantly more items in which anxiety is manifested by a physical symptom rather than psychological ones. They finally concluded that physical stimulation by nicotine may contribute to a more ready arousal to anxiety in smokers.

Considering anxious and depressive symptoms together, Lagrue and co-workers (2002) observed a series of 400 heavy smokers and noted subthreshold anxiety and depression in $34 \%$ of them. Thereafter, Tselebis et al (2003) found in a sample of 80 physicians and surgeons that smoking behaviour was more strongly related to anxiety than depression. Dudas et al (2005) evaluated the prevalence of smoking among 215 adolescents in Hungary, administering the Spielberger's State-Trait Anxiety Inventory. Smoking students showed significantly more anxiety and depressive symptoms compared to their nonsmoking peers. Occasional smokers appeared to be more anxious than non-smokers, whereas daily smokers scored higher on the depression inventory.

A high prevalence of anxious and depressive symptoms has been also observed in smokers attending smoking cessation clinic. Fakhfakh et al (2003) found in Tunisia a prevalence of respectively $22.9 \%$ and 
$20 \%$.

Moreover, smokers with anxious or depressive symptoms had higher level of dependence, reduced quitting rate and more withdrawal symptoms than smokers without affective symptoms.

In the light of these findings, there seems to be little doubt that, even in the absence of any formal psychiatric disorder, smokers do report more affective symptomatology than non smokers. It appears that this symptomatology most often amounts to anxiety and depression. The chronic presence of negative affectivity may contribute to poor quality of life which in turn might motivate smokers to apply for a smoking cessation programme.

In the present study we want to further document whether subjects applying for a smoking cessation programme have more affective symptoms than non applicants, as first suggested by Fakhfakh et al (2003).

This would fit the hypothesis that smokers tend to follow a smoking cessation programme at least in part because of a lack of well being due to anxious and/or depressive affectivity. Findings in support of our hypothesis would additionally call for more attention to anxious and depressive symptoms at baseline evaluation in smoking cessation programmes.

For our purpose, a sample of smokers applying for smoking cessation clinics and a sample of habitual smokers of the general population were compared. The aim was to assess whether those applying for a smoking cessation programme display a higher level of affective symptomatology in absence of any formal psychiatric disorder than smokers recruited from the general population.

\section{Materials and methods}

The study was conducted according to a case control design. Cases were smokers applying for public smoking cessation clinics for the first visit. Controls were smokers enrolled from the general population. Sixty eight smokers were recruited from 01/03/2005 to 30/09/2006 among applicants for the first visit to the facilities in Pescia, Pisa and Pistoia (central Tuscany, Italy). Each smoking cessation centre collected the data for a period of 12 months. Smokers were evaluated by fully qualified and trained medical doctors (a psychiatrist and a pneumologist) and psychologists.

Sixty eight control smokers were recruited among the general population of the same area and in the 
same period of time and evaluated by a fully qualified psychiatrist.

The two groups were individually matched for age, gender and level of nicotine dependence.

At first contact at the smoking cessation clinic, subjects were asked about socio-demographic data (age, gender, instruction, working activity) and physical health. Thereafter, they had a complete medical history inventory and a physical examination. Expired air carbon monoxide was measured to have an objective indication of smoking exposure.

Subjects were excluded if they daily used more than 6 coffees (www.sisalimentazione.it/ relazionenews7.pdf), 4 standard alcohol units (www.alcol.net/italiani/Doxa/doxa.asp?anno), psychotropic medications or drugs of abuse. Those substances might in fact influence the occurrence or the severity of anxious or depressive symptoms. Additional exclusion criteria were a poor physical health (that is chronic medical conditions requiring treatment), a lifetime formal psychiatric disorder and, only among controls, the intention to try to quit (either his own, or via a formal cessation programme).

At the first visit the Hospital Anxiety Depression Scale (HADS, Snaith et al 1986), was administered to identify formal affective diagnoses. This is a brief self rating scale investigating anxiety and depression according to two different subscales of 7 items each. If the score is higher than 7 on either the anxiety or the depression subscale, the suspicion of a formal psychiatric disorder is significant.

If one of the HAD subscales scored higher than 7, the Mini International Neuropsychiatric Interview - MINI was administered by a properly qualified medical doctor or clinical psychologist to exclude any lifetime formal psychiatric disorder (Sheehan et al 1998; Kuijpers et al 2003).

Those eligible for the study were asked about smoking behaviours of cohabitants and first degree relatives and evaluated on anxious and depressive symptoms. For this purpose, the Montgomery Asberg Depression Rating Scale (MADRS, Montgomery et al 1979) the Beck Depression Inventory (BDI, Beck et al 1961), the Hamilton Anxiety scale (HAM-A, Hamilton 1959) and the State-trait Anxiety Inventory (STAIS, Spielberger et al 1970) were administered.

The MDRS and the HAM-A were administered by ad hoc trained psychologists and medical doctors, according to the standard procedure. The BDI and STAI were self-administered.

In sum, anxiety and depressive symptoms were investigated using both self- and hetero-administered scales to increase the reliability of the investigation.

The level of nicotine dependence was measured via the Fageström Tolerance Questionnaire (FTQ, Fagerström et al 1978). This is a standardised self-administered questionnaire which counts 8 items with 
a score ranging from 0 to 11 . A total score of 6 or below indicates a low to moderate nicotine dependence, a total score greater or equal than 7 suggests a high nicotine dependence.

Approval for this study was granted by the Medical Ethics Review Board of the Azienda USL3 Pistoia.

\section{Statistics}

Discrete variables (gender, marital status, family history of smoking habits, cohabitant smokers) were evaluated comparing cases and controls via the Chi-square test for independent samples. Continuous variables were analysed using the t-test for independent samples when normally distributed (age) and the Mann-Whitney test for independent samples when non normally distributed (years of school, FTQ, HADS, MADRS, BDI, HAM-A, STAI scores).

HADS, MADRS, BDI, HAM-A and STAI were analysed both considering The subscales of HADS are the anxiety (items $1,3,5,7,9,11,13$ ) and the depression scale (items $2,4,6,8,10,12,14$ ) (Snaith et al 1986). MADRS was analysed according to three factors: dysphoria (item 2, 9, 10), retardation (item 1, 6 , 7,8 ) and vegetative symptoms (item 3, 4, 5) total and subscale scores (Suzuki et al 2005). The somaticaffective factor (item 1, 4, 8, 9, 11, 12, 13) and the cognitive factor (item 2, 3, 5, 6, 7, 10) of BDI were evaluated (Arnau et al 2001). HAM-A subscales concerned somatic anxiety (items 7-13) and psychic anxiety (items 1-6 and 14) (Hamilton 1959). For the STAI two dimensions were considered: mood (item $1-4,6-8,10,13,15,16,19$ ) and worrying dimension (item 5, 9, 11, 12, 14, 17, 18, 20) (Andrade et al 2001).

Significance levels were set at $p<0.05$ (two-tailed).

All the analyses were performed by the statistical package SPSS 11.0.

\section{Results}

Of the thirty six smokers applying for the first visit the smoking cessation clinic in Pistoia from 01/03/2005 to $28 / 02 / 2006$, twenty two met the inclusion criteria to be enrolled in the study $(61.1 \%)$. Of the seventy two applicants from 01/05/2005 to 30/04/2006 in Pescia, twenty one were enrolled (29.2\%). Of the 150 
applicants from 01/10/2005 to 30/09/2006 in Pisa, twenty five were enrolled (16.7\%).

Ninety subjects (34.88\%) (3 in Pistoia, 22 in Pescia, 65 in Pisa) were excluded as they did not meet the inclusion criteria concerning coffee/alcohol habits or were under chronic treatment for poor medical conditions. The remaining ninety five not enrolled subjects (36.82\%) (11 in Pistoia, 29 in Pescia, 55 in Pisa) had a lifetime psychiatric disorder or were currently under psychotropic medications. Five subjects $(1.94 \%)$ were excluded as they expressed the intention not to quit ( $n=3$ in Pisa) or had HADS subscale scores higher that 7 but the MINI was not available ( $n=2$ in Pisa).

In brief, sixty eight smokers applying for the smoking cessation clinics (called 'cases') were compared to sixty eight smokers recruited from the general population (called 'controls'). Subjects were individually matched for gender (39 males and 29 females for each group), age (48.78 $\pm 13.30 \mathrm{yr}$ for cases and $48.19 \pm 12.54 \mathrm{yr}$ for controls, $p=.7912$ ) and level of nicotine dependence as measured via the FTQ ( $6.85 \pm 2.552$ for cases and $6.71 \pm 2.151$ for controls, $p=.7170$ )

Table 1 reports the results concerning discrete variables. Cases had a significantly lower probability to live with smokers than controls $(p<.001)$. Cases and controls did not differ for marital status and family history of smoking habits.

Tables 2 shows the results for continuous variables. Cases and controls did not differ for years of school. As what concerns rating scales the difference was statistically relevant for: HADS total score and anxiety subscale $(p<.01)$; MADRS total scale and subscales (dysphoria, retardation, vegetative symptoms) $(p<$ $.05)$; BDI total score and subscales (somatic and cognitive factors) $(p<.05)$; HAM-A total score and subscales $(p<.0001)$. No statistically significant differences were found for STAI total score or its dimensions.

Stratifying for smoking cessation clinic, no statistically significant differences were found when the above mentioned variables were evaluated. The only exception was the family history of smoking habits.

It resulted positive in $33.33 \%$ of cases in Pescia, in $88.88 \%$ of cases in Pisa and $77.27 \%$ in Pistoia ( $p<$ $0.001)$. 


\section{Discussion}

The present study shows that smokers applying for smoking cessation clinics for the first visit have a higher level of negative affectivity than smokers from the general population, considering anxious as well as depressive symptoms. These findings seem to confirm what has been suggested by Fakhfakh et al (2003), and are consistent with the original hypothesis.

The rates of excluded subjects, despite the appearance, are in line with the present literature.

In fact, a 12-month prevalence of mood disorder as well as of anxiety disorders is expected around $20 \%$ among smokers (Grant et al 2004). This is consistent with our rate of about $37 \%$ of excluded for lifetime history of psychiatric disorders or current psychotropic medication (40.3\% in Pescia, $36.7 \%$ in Pisa, and $30.5 \%$ in Pistoia). Similarly, the proportion of excluded for high consumption of coffee/alcohol or poor medical conditions (43.3\% in Pisa, 30.6\% in Pescia, $8.3 \%$ in Pistoia) is consistent with the findings of the literature (Shiffman et al 2002; Friend et al 2005).

The different location and characteristics of personnel of the three smoking cessation clinics may explain the differences in rates of exclusions.

The smoking cessation clinic in Pisa is located in the University Hospital as part of the Cardio-Thoracic Department. The personnel is constituted by pneumologists with the support of nurses and psychologists. Thus, people who address to this centre may have a high comorbidity with organic illnesses.

The smoking cessation clinic in Pescia, as well as in Pistoia, is within peripheral public health services and the personnel consists of a toxicologist and psychologists. The supply of a tight toxicological and psychological service might explain the high comorbidity with psychiatric disorders of applicants.

Overall, while the centres in Pisa and Pescia are well known in the area and started their activity several years ago, the centre in Pistoia is a small and recently opened facility. There, we can expect to have a fresh recruitment pattern of people motivated and with a low rate of comorbid psychiatric/organic diseases.

Nevertheless, despite the different characteristics of the three centres and the observed differences in the rates of exclusion, the included subjects did not differ as to the variables of interest among the three smoking cessation clinics. Stratifying for smoking cessation clinic, no statistically significant differences were found, with the only exception of the family history of smoking habits.

Regarding anxious symptoms, cases rated higher on anxiety subscale of the $\operatorname{HAD}(p<.005)$ and on the 
HAM-A $(p<.001)$. No differences were found in STAI scores. Although we are not aware of specific studies testing the hypothesis under examination, a number of worthwhile comments should be made about these results.

As appearing from the introduction, several studies have demonstrated a higher prevalence of subthreshold anxiety in smokers compared to non smokers (Williams et al 1982; Lagrue et al 2002; Tselebis et al 2003). We hypothesised that the presence of negative affectivity may be a reason for smokers to apply for cessation programmes. We specifically compared the level of negative affectivity in smokers participating in a cessation programme with a control sample of habitual smokers. Summarizing, the results definitely show a higher level of negative affectivity among those applying for smoking cessation clinics and apparently this supports our hypothesis.

Considering the analysis of subscales, it is interesting that both somatic and psychic anxiety (i.e. the two HAM-A subscales) were relevant in smokers who applied for cessation programmes. This phenomenon has been already reported in the literature. For instance, Williams and co-workers (1982) compared fifty smokers and fifty non smokers using the MMPI's Manifest Anxiety Scale (MAS) and found a Mean MAS scores for smokers significantly higher than for non-smokers. Smokers also obtained higher scores than non-smokers on significantly more items in which anxiety was manifested by a physical symptom rather than a psychological one. Regarding the latter point, we did not find any difference between psychological and physical anxiety. It should however be noted that the present study compared smokers applying for smoking cessation clinics with smokers from the general population while Williams et al merely evaluated smokers and non smokers.

It seems that smokers who apply for smoking cessation clinic suffer of both psychological and physical anxiety. The present findings are consistent with the studies which propose a vulnerability due to the release of epinephrine and norepinephrine or to a high autonomic tone/symptathetic bias (Dilsaver 1987; Yun et al 2005). They are also consistent with the evidence of high level of psychological distress among smokers (Brown et al 2005). The first studies support the occurrence of physical anxiety, the latter of psychological anxious symptoms.

STAI surprisingly failed in discriminating between cases and controls on the dimension of anxiety, contrarily to HADS and HAM-A. However, while for the latter two scales the index period is the latest interview. The STAI may be more strongly influenced by the effect of being under evaluation. A kind of seven days, the official instructions of the STAI refer to symptoms present at the very moment of the 
"white coat effect" could have hidden any difference between cases and controls.

As what concerns depressive symptoms, cases had higher scores than controls when evaluated with the MADRS (including its dysphoria, retardation and vegetative symptom factors) $(p<.01)$ and the BDI (both considering somatic and cognitive symptoms) $(p<.05)$. No differences were found for the HAD depression subscale.

In brief, the present findings highlight a higher level of negative affectivity in smokers applying for smoking cessation clinics for the first visit than smokers from the general population. This is evident for anxious as well as depressive symptoms.

Why some smokers have more negative affectivity than other is not explicitly addressed in the present study. Some people may be more vulnerable because of a different pharmacological sensitivity or an individual predisposition to negative affectivity.

However, according to these data we can say that anxious and depressive symptoms might be important factors in the motivation of smokers to quit. Zvolensky et al (2004) found that anxiety sensitivity is a concurrent and lifetime index of motivation to quit smoking even after controlling for theoretically-relevant smoking (e.g. nicotine dependence) and affect factors (e.g. panic attack history). Moreover, Haukkala et al (2000) observed that higher depression scores are related to greater motivation to quit smoking, at least among female smokers (OR $1.51 ; 95 \% \mathrm{Cl} 1.15-1.97)$.

In this frame, the present results beautifully fit the hypothesis that anxious and depressive symptoms are real motivator in quitting smoking. Thus, a possible explanation of people to apply for smoking cessation clinics may be the presence of anxious or depressive symptoms.

Some would argue that people applying for a smoking cessation programme may report a level of negative affectivity which is strongly situation dependent. A feeling of apprehension and worry may arise in these subjects as the consequence of the perspective of starting the programme. This does not seem the case in our results. The rating scales here used had been validated to assess anxiety and not simply anticipatory anxiety as well as the spectrum of depressive symptoms and not only worry. A further argument in favour of the latter point is the lack of difference of the STAI worrying dimension subscale between smokers attending smoking cessation clinics and smokers from the general population.

A general caveat about the use of rating scales is that, if applied to samples without psychiatric disorders, their mean scores are at the very low end of the scale which may imply a reduced sensitivity. Although HADS, BDI and STAI have been already used in non clinical samples to successfully investigate 
depressive/anxious symptoms (Dudas et al 2005, Desmond et al 2006; Gee et al 2003), it should be considered that these scales have been originally designed in the frame of formal disorders such as anxiety and depression.

Despite a possible lower sensitivity of our assessment tools, we were able to demonstrate a difference between cases and controls which is in favour of the robustness of the results. Moreover, most of the scales were in agreement with each other, and self- and hetero-administered scales yielded reliable results. This support the sensitivity of the used instruments in our sample.

Finally, cases had a significantly lower probability to live with smokers than controls $(p<.005)$. Living with an ex-smoker or never-smoker has been demonstrated to increase the likelihood of quitting, compared to being single or living with a partner who smokes (Monden et al 2003). In this frame, it can be hypothesised that when the self treatment to quit is not efficacious, living with a non-smoker may be a further encouragement or pressure to address specialised centres to find an additional aid.

\section{Conclusions}

Findings from the present paper support the higher than expected rate of negative affectivity in smokers attending smoking cessation clinics if compared to smokers from the general population. Some aspects of our findings may have interesting implications in clinical practice, in particular concerning smoking cessation programmes. In fact, paradoxically higher negative affectivity may motivate people to try to quit smoking but may also work against the successful cessation.

An evaluation of the level of negative affectivity at first visit would give a more detailed clinical picture of the patient. Depending on this evaluation, a psychological or pharmacological support could be proposed to the patients as a complement to the smoking cessation programme itself.

Strategies of this kind may increase the rate of success in quitting or the duration of smoking abstinence. Thus, trial of pharmacological or psychological intervention to treat negative affectivity in smokers attending smoking cessation programmes should be encouraged. 


\section{Acknowledgments}

The authors thank E. Maionchi, F. Innocenti, L. Marini (Centro Antifumo "La Fratta" of Azienda USL 3, Distretto di Pistoia, Italy), V. Pellegrini (Centro Antifumo Valdinievole of Azienda USL 3, Distretto della Valdinievole, Italy), L. Carrozzi (Cardio-Thoracic Department, University

Hospital of Pisa, Italy) for the scientific collaboration. They also thank T. Alfano, M. Fondi (Centro Antifumo Valdinievole of Azienda USL 3, Distretto della Valdinievole, Italy) for data collection.

The present project was not grant-supported. 
| Chapter 7

Table1. Smokers applying for smoking cessation clinics versus smokers from the general population.

Descriptive categorical variables. Chi square test for independent samples.

\begin{tabular}{|c|r|r|r|r|r|}
\hline & \multicolumn{2}{|c|}{ cases } & \multicolumn{2}{c|}{ controls } & statistics \\
\hline & \multicolumn{1}{|c|}{$\mathbf{N}$} & \multicolumn{1}{c|}{$\%$} & \multicolumn{1}{c|}{$\mathbf{N}$} & \multicolumn{1}{c|}{$\%$} & \multicolumn{1}{c|}{$\mathbf{p}$} \\
\hline marital status & & & & & \\
\hline single & 13 & 19.12 & 18 & 26.47 & .3068 \\
\hline married & 47 & 69.12 & 43 & 63.24 & .4685 \\
\hline widower & 1 & 1.47 & 3 & 4.41 & .3101 \\
\hline divorced/separated & 7 & 10.29 & 4 & 5.88 & .3720 \\
\hline cohabitant smokers & 16 & 23.53 & 35 & 51.47 & .0008 \\
\hline first degree smoking relatives & 46 & 67.65 & 54 & 79.41 & .1200 \\
\hline
\end{tabular}


Table 2. Smokers applying for smoking cessation clinics versus smokers from the general population. Rating scale scores evaluating anxious/depressive symptoms. Mann Whitney test for independent samples.

\begin{tabular}{|c|c|c|c|c|c|c|c|}
\hline & & cases & & & controls & & \\
\hline & $\mathrm{N}$ & mean & SD & $\mathrm{N}$ & mean & SD & $p$ \\
\hline years of school & 68 & 10.35 & 4.044 & 68 & 11.23 & 4.587 & 2362 \\
\hline HADS & 68 & 8.48 & 5.679 & 68 & 6.15 & 3.798 & .0055 \\
\hline anxiety subscale & 68 & 5.35 & 3.631 & 68 & 3.69 & 2.439 & .0021 \\
\hline depression subscale & 68 & 3.13 & 2.785 & 68 & 2.45 & 2.025 & .1076 \\
\hline MADRS & 68 & 5.68 & 5.908 & 68 & 2.21 & 2.789 & $<.0001$ \\
\hline dysphoria & 68 & 1.38 & 1.924 & 68 & 0.32 & 0.854 & $<.0001$ \\
\hline retardation & 68 & 2.50 & 2.713 & 68 & 0.73 & 1.114 & $<.0001$ \\
\hline vegetative symptoms & 68 & 1.79 & 1.920 & 68 & 1.15 & 1.489 & .0298 \\
\hline $\mathrm{BDI}$ & 67 & 4.07 & 3.448 & 68 & 2.41 & 2.592 & .0019 \\
\hline somatic factor & 67 & 2.70 & 2.089 & 68 & 1.65 & 1.708 & .0017 \\
\hline cognitive factor & 68 & 1.35 & 1.922 & 68 & 0.76 & 1.235 & .0356 \\
\hline HAM-A & 68 & 7.30 & 6.766 & 68 & 2.06 & 2.285 & $<.0001$ \\
\hline somatic anxiety & 68 & 2.82 & 3.243 & 68 & 1.03 & 1.338 & $<.0001$ \\
\hline psychic anxiety & 68 & 4.48 & 4.070 & 68 & 1.03 & 1.466 & $<.0001$ \\
\hline STAI & 67 & 34.85 & 7.622 & 68 & 33.56 & 6.414 & .2883 \\
\hline mood dimension & 67 & 21.88 & 4.276 & 68 & 21.21 & 4.202 & .3568 \\
\hline worrying dimension & 67 & 12.97 & 3.754 & 68 & 12.35 & 2.544 & .2648 \\
\hline
\end{tabular}




\section{REFERENCES}

Andrade L, Gorenstein C, Vietra Filho AH, Tung TC, Artes R (2001). Psychometric properties of the Portuguese version of the State Trait Anxiety Inventory applied to college students: factor analysis and relation to the Beck Depression Inventory. Braz J Med Biol Res 34;367-74.

Arnau RC, Meagher MW, Norris MP, Bramson R (2001). Psychometric evaluation of the Beck Depresion Inventory - II with primary care medical patients. Health Psychol 20(Suppl 2);112-9.

Beck AT, Ward CH, Mendelson M, et al (1961). An inventory for measuring depression. Arch Gen Psychiatry 4;561-71.

Black DW, Zimmerman M, Coryell WH (1999). Cigarette smoking and psychiatric disorder in a community sample. Ann Clin Psychiatry 11;(Suppl 3):129-36.

Brown C, Madden PA, Palenchar DR, Cooper-Patrick L (2000). The association between depressive symptoms and cigarette smoking in an urban primary care sample. Int $\mathrm{J}$ Psychiatry Med 30(Suppl 1);15-26.

Brown RA, Lejuez CW, Kahler CW, Strong DR, Zvolensky MJ (2005). Distress tolerance and early smoking lapse. Clin Psychol Rev 25(Suppl 6);713-33.

Chetwynd J (1986) . Some characteristics of women smokers. N Z Med J 99 (Suppl 794);14-7.

Desmond DM, MacLachlan M (2006). Affective distress and amputation- related pain among older men with long-term, traumatic limb amputations. J Pain Symptom Manage 31(Suppl 4);362-8.

Dilsaver SC (1987). Nicotine and panic attacks. Am J Psychiatry 144(Suppl 9);1245-6.

Dudas RB, Hans K, Barabas K (2005). Anxiety, depression and smoking in schoolchildren--implications for smoking prevention. J R Soc Health 125(Suppl 2);87-92.

Fagerström KO (1978). Measuring degree of physical dependence to tobacco smoking with reference to individualization of treatment. Addict Behav 3;235-41.

Fakhfakh R, Aouina H, Gharbi L, Hsairi H, Achour N, Langrue G, Bouacha H (2003). Dependence tabagique et troubles anxio-depressifs chez le fumeur tunisien. Rev Mal Respir 20;850-7.

Fergusson DM, Lynskey MT, Horwood LJ (1996). Comorbidity between depressive disorders and nicotine dependence in a cohort of 16-year-old. Arch Gen Psychiatry 53;1043-7.

Frederick T, Frerichs RR, Clark VA (1988). Personal health habits and symptoms of depression at the community level. Prev Med 17(Suppl 2);173-82.

Friend KB, Pagano ME (2005). Changes in cigarette consumption and drinking outcomes: findings from 
Project MATCH. J Subst Abuse Treat 29(Suppl 3);221-9.

Gee A, Troop NA (2003). Shame, depressive symptoms and eating, weight and shape concerns in a nonclinical sample. Eat Weight Disord 8(Suppl 1);72-5.

Grant BF, Hasin DS, Chou SP, Stinson FS, Dawson DA (2004). Nicotine dependence and psychiatric disorders in the United States. Results from the National Epidemiologic Survey on Alcohol and related conditions. Arch Gen Psychiatry 61;1107-15.

Hamilton MC (1959). The assessment of anxiety states by rating. Br J Med Psychol 32;50-5.

Haukkala A, Uutela A, Vartiainen E, McAlister A, Knekt P (2000). Depression and smoking cessation: the role of motivation and self-efficacy. Addict Behav 25(Suppl 2);311-6.

Johnson JG, Cohen P, Pine DS, Klein DF, Kasen S, Brook JS (2000). Association between cigarette smoking and anxiety disorders during adolescence and early adulthood. JAMA 284(Suppl 8);2348-51.

Karp I, O'Loughlin J, Hanley J, Tyndale RF, Paradis G (2006). Risk factors for tobacco dependence in adolescent smokers. Tobacco Control 15;199-204.

Kick SD, Colley DD (1997). Depressive, not anxiety, symptoms are associated with current cigarette smoking among university internal medical patients. Psychosomatics 38(Suppl 2);132-9.

Kuijpers PM, Denollet J, Lousberg R, Wellens HJ, Crijns H, Honig A (2003). Validity of the hospital anxiety and depression scale for use with patients with noncardiac chest pain. Psychosomatics 44(Suppl 4);329-35.

Lagrue G, Dupont P, Fakhfakh R (2002). Anxiety and depressive disorders in tobacco dependence. Encephale 28(Suppl 4);374-7.

Ludman EJ, Curry SJ, Grothaus LC, Graham E, Stout J, Lozano P (2002). Depressive symptoms, stress, and weight concerns among African American and European American low-income female smokers. Psychol Addict Behav 16(Suppl 1);68-71.

Monden CW, de Graaf ND, Kraaykamp G (2003). How important are parents and partners for smoking cessation in adulthood? An event history analysis. Prev Med 36(Suppl 2);197-203.

Montgomery SA, Asberg M (1979). A new depression scale designed to be sensitive to change. $\mathrm{Br} \mathrm{J}$ Psychiatry 134;382-9.

Perez-Stable EJ, Marin G, Marin BV, Katz MH (1990). Depressive symptoms and cigarette smoking among Latinos in San Francisco. Am J Public Health 80(Suppl 12);1500-2. 
Sheehan DV, Lecrubier Y, Sheenan KH, Amorim P, Janavs J, Weiller E, Hergueta T, Baker R, Dunbar GC (1998). The Mini-International Neuropsychiatric Interview (M.I.N.I.) the development and validation of a structured diagnostic psychiatric interview for DSM-IV and ICD-10. J Clin Psychiatry 59(Suppl 20);22-33.

Shiffman S, Gwaltney CJ, Balabanis MH, Liu KS, Paty JA, Kassel JD, Hickcox M, Gnys M (2002). Immediate antecedents of cigarette smoking: an analysis from ecological momentary assessment. J Abnorm Psychol 111(Suppl 4);531-45.

Snaith RP, Zigmond AS (1986). The hospital anxiety and depression scale. Br Med J (Clin Res Ed) 292(Suppl 6516);344.

Son BK, Markovitz JH, Winders S, Smith D (1997). Smoking, nicotine dependence, and depressive symptoms in the CARDIA study. Am J Epidemiology 145(Suppl 2);110-6.

Spielberger CD, Gorsuch RL, Lusene RE (1970). STAI Manual for the State-trait Anxiety Inventory Palo Alto, CA: Consulting Psychologists Press.

Suzuki A, Aoshima T, Fukasawa T, Yoshida K, Higuchi H, Shimizu T, Otani K (2005). A three-factor model of the MADRS in major depressive disorder. Depress Anxiety 21(Suppl 2);95-7.

Tselebis A, Papaleftheris E, Balis E, Heotoka I, llias I (2003). Smoking related to anxiety and depression in Greek medical staff. Psychol Rep 92(Suppl 2); 529-32.

Williams SG, Hudson A, Redd C (1982). Cigarette smoking, manifest anxiety and somatic symptoms. Addict Behav 7(Suppl 4);427-8.

Yun AJ, Bazar KA, Lee PY, Gerber A, Daniel SM (2005). The smoking gun: many conditions associated with tobacco exposure may be attributable to paradoxical compensatory autonomic responses to nicotine. Med Hypotheses 64(Suppl 6);1073-9.

Zvolensky MJ, Baker KM, Leen-Feldner E, Bonn-Miller MO, Feldner MT, Brown RA (2004). Anxiety sensitivity: association with intensity of retrospectively-rated smoking-related withdrawal symptoms and motivation to quit. Cogn Behav Ther 33(Suppl 3);114-25. 
Chapter 8|

\title{
CHAPTER 8
}

\section{Nicotine dependence, personality traits, psychological distress and withdrawal symptoms as possible predictors of smoking cessation. Results from a double blind study with nicotine patch}

\begin{abstract}
Nicotine replacement therapy (NRT) is an effective treatment for smokers who want to quit, however the rates of successful quitting can still be improved. In this frame, nicotine dependence, personality traits, psychological distress and withdrawal symptoms were evaluated as possible predictors of smoking cessation.

Methods. The study is part of a NRT double-blind, parallel group, randomised trial. At baseline, nicotine dependence was assessed via the Fagerström Tolerance Questionnaire (FTQ), personality traits via the Eysenck Personality Inventory, distress and psychiatric symptoms via the Symptom Rating Test (SRT). At follow up visits (week 12, 26 and 52) subjects were asked about withdrawal symptoms and filled the Symptom Rating Scale.
\end{abstract}

Results. 297 cigarette smokers were followed for one year. Of these 42 were abstainers at week 12, 38 at week 26 and 34 at week 52. The multivariate analysis, adjusted for treatment, evidenced that FTQ and EPI psycoticism scores were the strongest predictors of quitting failure.

No statistically significant results were found for psychiatric symptoms. Among withdrawal symptoms, severity of craving and difficulty in concentrating influenced the rate of success.

Discussion. Nicotine dependence seems to influence the medium long term outcome as a result of physical and psychological dependence. Psychoticism seems to play a key role as it implies personality traits which may favour nicotine dependence and discourage in persisting a task such as quitting smoking.

Conclusion. In the present study nicotine dependence and psychoticism scores were the main factors influencing the outcome of smoking cessation under NRT. 


\section{Introduction}

Nicotine replacement therapy (NRT) is an effective treatment for smokers who want to quit. Nevertheless, though improvement is significant when compared to placebo (Silagy et al 2000; Stead et al 2005), in randomized clinical trials the rate of success is still between 16 and $39 \%$ after 12 weeks of treatment, 13$26 \%$ at six months and $7-25 \%$ at 12 month follow up (Fiore et al 1994; Blondal et al 1999; Hughes et al 1999; Jorenby et al 1999; Fiore et al 2000). In an effort to increase these rates, factors that may influence the occurrence of relapse have become increasingly the focus of research.

Two approaches have been used to evaluate the risk of failure. One focuses on pharmacological factors and the other focuses on clinical factors (behavioural dependence of smoking, withdrawal symptoms, psychological distress).

Pharmacological studies found that the risk of failure was higher in smokers with high baseline plasma cotinine levels (Paoletti et al 1996; Tonnesen et al 1999) or with inadequate NRT (Sachs et al 1995; Hughes et al 1999). However, not all authors agree with this latest point (Daughton et al 1999; Killen et al 1999). Unsuccessful quitting also is more behalf to occur with inappropriate length of treatment (Sims et al 2002), with poor compliance and obviously when the patients go on smoking while wearing the nicotine patch (Nerin et al 2004).

Clinical studies have demonstrated that high dependence of smoking increases from 1.63 (95\% Cl: 1.13$2.35 ; p=0.009)$ to $2.30(95 \% \mathrm{Cl}, 1.25-4.26 ; p=0.008)$ times the risk to fail in quitting (Chatkin et al 2004; Ong et al 2005). Some studies evaluated the risk of failure on the basis of the Fagerström Test. Ferguson et al (2003) found that a Fagerström Test for Nicotine Dependence (FTND) score higher than 5 was a variable associated with failure.

The urgent need for tobacco, craving for nicotine, smoking to avoid withdrawal symptoms are commonly referred reasons for unsuccessful quitting (Stapleton 1998; John et al 2004). However, results of the literature are equivocal (Patten et al 1996) and NRT is known to reduce the severity of withdrawal symptoms, thus decreasing the risk to fail for such cause (Molander et al 2000; Shiffman et al 2000; Shiffman et al 2006).

Still discussed is the role of psychological distress (Catley et al 2003; John et al 2004; Raherison et al 2005). Some authors observed that failure by the end of a treatment to quit smoking is predicted by a history of psychiatric disorders (Ferguson et al 2003), post cessation depression (Glassman et al 1990), 
changes in negative affect (e.g. anxiety, sadness, anger, and confusion) and psychological stress (Doherty et al 1995; Strasser et al 2005).

Finally, it is noteworthy that some smokers tolerate the discomfort of smoking cessation whereas other do not. The ability to tolerate this discomfort may likely involve a confluence of several inter-individual factors such as self-efficacy (Bandura 1997; Amodei et al 2005), motivation (Miller et al 2002), readiness for change in the addictive disorders (Prochaska et al 1997), and personality.

Few studies have been conducted on personality. Doran et al (2004) found that greater impulsivity predicted more rapid failure in quitting smoking. Hooten et al (2005) found that high scores on neuroticism and low scores on agreeableness and conscientiousness were predictors of poor outcome. In this frame, the purpose of the present paper was to evaluate nicotine dependence, personality traits, psychological distress and withdrawal symptoms as possible predictors of smoking cessation in smokers participating in a randomised double-blind trial with nicotine patch (Paoletti et al 1996).

\section{Methods}

\section{$\underline{\text { Study design }}$}

The present study is part of a NRT trial performed at the University Hospital of Pisa and described elsewhere (Paoletti et al 1996). Briefly, the study was conducted according to a double-blind, parallel group, randomised design. On the basis of cotinine baseline plasma values, smokers were divided into two groups: low cotinine ( $(\mathrm{CC} ; \leq 250 \mathrm{ng} / \mathrm{ml}$ ) and high cotinine ( $\mathrm{HC} ;>250 \mathrm{ng} / \mathrm{ml}$ ) (threshold equal to the median value). Smokers with LC were randomly assigned to placebo or $15 \mathrm{mg}$ nicotine patch while smokers with $\mathrm{HC}$ were randomly assigned to 15 or $25 \mathrm{mg}$ nicotine patch. Patches were applied in the morning and removed at bedtime (worn for 16 hours). Full treatment lasted for 12 weeks and was followed by a 6 week tapering period ( $10 \mathrm{mg}$ for 3 weeks and $5 \mathrm{mg}$ for 3 weeks). All the participants were followed for 52 weeks.

Approval for this study was granted by Pisa University Hospital's Medical Ethics Review Board. 


\section{$\underline{\text { Subjects }}$}

Four hundred smokers, aged between 20 and 60 years, were enrolled from the general population of the city of Pisa (about 100,000 inhabitants, Tuscany, Central Italy) through advertisements in the local newspapers. They were screened via a telephone call by trained personnel and required to have smoked at least 10 cigarettes per day for at least 3 years, to keep response heterogeneity to a minimum due to small nicotine dose effects. Smokers were excluded also in case they met diagnostic criteria for chronic dermatological disorders and/or cardiac diseases, had a past or current history of psychiatric disorders, were currently taking daily psychiatric medications, were pregnant or breast feeding.

After the telephone interview, 350 smokers were invited to the University Hospital of Pisa and 297 subjects were recruited.

\section{Baseline evaluation}

At first visit, a physical examination was performed by a medical doctor, a detailed clinical and smoking history were collected and physiological parameters measured (body weight, blood pressure, respiratory rate, and expired carbon monoxide (CO) [Bedfont monitor, Sittingbourne UK]). A blood sample was collected to measure nicotine and cotinine plasma values.

Nicotine dependence was evaluated through the Fagerström Tolerance Questionnaire (FTQ) (Fagerström 1978). This is a standardised self-administered questionnaire which counts 8 items with a score ranging from 0 to 11. A total score of 6 or below indicates a low to moderate nicotine dependence, a total score greater or equal than 7 suggests a high nicotine dependence.

Personality was evaluated by means of the Eysenck Personality Inventory (EPI) (Eysenck et al 1964). This is a self-reported inventory based on Eysenck's factor analysis of personality which assumes three basic factors: extraversion, neuroticism and psychoticism. The dimension of extraversion is characterised by sociability, liveliness, jocularity and impulsiveness. The extroversion score is mainly a measure of social orientation and sensation seeking. Neuroticism is characterised by high levels of negative affect such as depression and anxiety, and the neuroticism score is mainly a measure of trait anxiety, emotional dysfunction and increased liability to develop abnormal reactions to stressful events. Psychoticism is associated with the susceptibility to exhibit a certain recklessness, a disregard for common sense or 
conventions, and a degree of inappropriate emotional expression. The psychoticism score measures paranoid tendencies and antisocial behaviours.

The Symptom Rating Test (SRT), Italian version (Fava et al 1983), is a measure of distress and psychiatric symptoms. It is a self administered scale which involves 30 items on four sub-scales: depression, anxiety, somatization, inadequacy. The total score ranges from 0 to 120 , anxiety and depression subscales have a 0-32 point range and somatization and inadequacy scales range each from 0 to 28 . The SRT was administered referring to the week before the baseline day.

\section{Follow up evaluations}

Follow up visits performed at week 12, 26 and 52 were taken into account for the present research. At each visit subjects were evaluated by a physician and asked about cigarette consumption.

Expired $\mathrm{CO}$ and body weight were measured and a blood sample was collected to obtain nicotine and cotinine plasma values, to retrospectively assess the consistency of smoking status during follow-up.

Subjects were asked to fill the Symptom Rating Scale referring to the week before the visit.

Finally, the assessment of withdrawal symptoms was realised focussing on the symptoms listed in the DSM IV (APA 1994) definition of withdrawal from nicotine (dysphoric or depressed mood, insomnia, irritability or frustration or anger, anxiety, difficulty concentrating, restlessness, decreased heart rate, appetite or weight gain) as well as on craving. They were scored by means of a graded scoring system (from $0=$ absent, to $3=$ severe).

Data collected via FTQ, EPI, SRT and the withdrawal symptoms list have been the focus of the present research.

\section{Definition of success in quitting smoking}

Success was defined as complete sustained abstinence, self reported, from week 1 up to each follow up visit and verified by expired $\mathrm{CO}<10 \mathrm{ppm}$. Those who did not meet these criteria were considered failures. Subjects who did not return for the scheduled follow-up visits were assumed to be drop-out and considered failures as well. 
$\underline{\text { Statistics }}$

Mann-Whitney test for independent samples was performed to compare smokers and abstainers regarding FTQ, SRT, and EPI scores as the data are not normally distributed.

A multivariate logistic analysis was carried out to evaluate the association between being failures (binomial variable evaluated at week 12, 26 or 52) and the main effects (continuous variables as FTQ, SRT anxiety, SRT depression, SRT somatization, EPI nuroticism, EPI extraversion, EPI psychoticism). Adjustment was performed for treatment received (categorical variable with placebo used as the reference and LC $15 \mathrm{mg} /$ day nicotine, HC $15 \mathrm{mg} /$ day nicotine, HC $25 \mathrm{mg} /$ day nicotine used as dummies). Repeated measures analysis of variance was performed by means of the general linear model and applied to the SRT subscale scores as well as to the severity scores of withdrawal symptoms.

Significance levels were set at $p<0.05$ (two-tailed).

All the analyses were performed by the statistical package SPSS 11.0 or SAS 9.1 .

\section{Results}

This study included 297 cigarette smokers. Of these 120 had low cotinine plasma levels at baseline and 177 had high cotinine plasma levels. Among the LC subjects, 60 received placebo and 60 nicotine $15 \mathrm{mg}$. Of the $\mathrm{HC}$ subjects, 90 received nicotine $15 \mathrm{mg}$ and 87 nicotine $25 \mathrm{mg}$ as an intervention to quit smoking. The baseline characteristics of the smokers in the four treatment groups as well as the rates of success have been reported in Paoletti et al (1996). Briefly, age, body weight, sex distribution, personality and stress condition did not significantly differ among the four groups of treatment at baseline. As expected, the number of cigarettes smoked per day, baseline expired $\mathrm{CO}$, pack-year, baseline nicotine and cotinine plasma levels and FTQ varied across the treatment groups (Paoletti et al 1996).

At week 52 a significant higher success rate was reported in the LC $15 \mathrm{mg}$ group when compared to the placebo $(28 \%$ vs $9 \% ; p<.001)$. There was no significant difference in sustained abstinence rates between the HC $15 \mathrm{mg}$ and the HC $25 \mathrm{mg}$ groups (11\% vs $9 \%$ ), and differences in abstinence rates for these groups were lower than those reported for the LC $15 \mathrm{mg}$ group (Paoletti et al 1996).

The present paper focuses on results concerning: 1. nicotine dependence (FTQ) and personality (EPI) as 
assessed at baseline; 2. psychological distress (SRT) measured at baseline and at the follow up visits (week 12, 26 and 52); 3. severity of withdrawal symptoms (week 1 up to week 12, 26 and 52).

Table 1 reports the comparison between abstainers and smokers at week 12, 26 and 52 with regard to mean scores of FTQ, EPI and SRT at baseline. The outcome seems to be influenced by FTQ, SRT subscale and total scale as well as by EPI neuroticism and psychoticism scores. Table 2 proposes the same data stratifying for treatment received, i.e. considering separately $\mathrm{HC}$ and LC subjects. In HC subjects the outcome seems to be influenced by FTQ, EPI neuroticism and psychoticism scores. In LC subjects there is some evidence in favour of SRT depression subscale and SRT total scale scores.

Table 3 reports the odds ratios (ORs) as an interpretation of the multivariate model.

The final subset of predictors (FTQ, EPI and SRT at baseline) has been adjusted for the treatment received, included in the model as dummies. The model evaluates the effects of predictors in influencing the risk of failure. FTQ and EPI psycoticism scores seem to be the strongest predictors of failure.

Repeated measure analysis of variance was performed to evaluate the influence of distress (SRT anxiety, SRT depression, SRT somatization, SRT inadequacy, SRT total) and withdrawal symptoms on the risk of failure in quitting smoking. The analysis was run referring to the period between baseline and week 12, baseline and week 26, baseline and week 52 .

No statistically significant results were found evaluating psychiatric symptoms, with the only exception of the SRT inadequacy subscale (abstainers: least squares mean $=1.117$, Error Standard $=0.25$; smokers: least squares mean $=1.728$, Error Standard $=0.120 ; p<.05$ ) if evaluated between baseline and week 26. Psychiatric symptoms in fact seems to strongly decrease between baseline and week 3 and thereafter reach a plateau.

As what concerns withdrawal symptoms, severity of craving influenced the rate of success at week 12 and $26(p<.001 ; p<.005)$ while difficulty in concentrating influenced the rate of success at week 52 ( $p$ $<.05)$.

\section{Discussion}

In this study, we evaluated the factors influencing the risk of failure in quitting smoking in the mediumlong term (12, 26 and 52 weeks) among smokers participating in a randomised double-blind trial with 
nicotine patch.

The risk of failure was found to increase with higher baseline FTQ and EPI psychoticism mean scores. The occurrence of craving and difficulty concentrating as withdrawal symptoms seamed to affect the ability to persist quitting smoking.

Psychological distress did not have a clear-cut effect.

More specifically, considering the whole sample FTQ, SRT anxiety, depression, somatization and total scale scores, as well as EPI neuroticism and psychoticism scores influenced the risk to relapse at week $12(p<.05)$. FTQ, SRT anxiety, depression and total scale scores as well as EPI neuroticism and psychoticism $(p<.05)$ had an influence at week 26 and 52.

According to these findings, it is likely that smoking outcome is influenced by the baseline level of nicotine dependence, the baseline level of distress and by personality characteristics of quitters.

Stratifying for baseline cotinine plasma level (HC and LC subjects) results differed. In the HC sub-sample, smoking outcome at week 12 was influenced by FTQ, EPI neuroticism and psychoticism scores, and at week 26 and 52 by FTQ and EPI neuroticism. In the LC sub-sample, the smoking outcome at week 12 was not influenced by the factor analysed. At week 26 it seemed modified by SRT total scale score and at week 52 by SRT somatization subscale and SRT total scale.

According to these results, the level of nicotine dependence (mean baseline FTQ score) and the personality characteristics seemed to influence the outcome in $\mathrm{HC}$ subjects while the level of distress slightly modified the outcome in LC subjects.

In the multivariate analysis, adjusted for treatment, the strongest predictors of smoking outcome were the baseline FTQ and EPI psychoticism scores. These results were supported by statistically significance or trend to significance according to the period considered. The trend to significance may be due to the numeric decrease over time in the sample of abstainers, thus reducing the power of the analysis. However, the risk to relapse increases if the baseline level of nicotine dependence is high and in case subjects have psychotic personality characteristics.

These findings are consistent with the literature as what concerns nicotine dependence (Ferguson et al 2003; Chatkin et al 2004; Ong et al 2005) while personality traits and smoking outcome are still a matter of discussion. To our knowledge the only results evaluating personality and smoking outcome have been proposed by Doran et al (2004) and by Hooten et al (2005). However, the authors evaluated personality with an instrument different from EPI and Doran et al (2004) studied subjects who could have had a 
history of major depression.

The lack of influence of psychological distress on smoking cessation medium and long term outcome is consistent with some authors (Catley et al 2004; Raherison et al 2005). This absence of significance was expected as SRT subscale and total scores strongly decreased during the first 3 weeks of treatment and thereafter reached a plateau.

This observation supports the hypothesis that psychological distress increases the risk of failure only in the short term, thus stressing the importance to treat such symptoms for a limited period (Cook et al 2004).

As what concerns withdrawal symptoms, craving influenced the smoking outcome from baseline to week 12 and 26, while difficulty concentrating influenced the outcome from baseline to week 52 . The link between craving and outcome is widely confirmed by the literature (Nil 1991; Swan et al 1996; Stapleton 1998, John et al 2004), while the role of difficulty in concentrating is less clear cut (Gross et al 1989).

The findings confirm the results of the literature which shows that withdrawal symptoms, with the widely accepted exception of craving, usually return to the pre cessation level by about 1 month, thus influencing the risk of failure only in the short term. The results also suggest a robustness of craving and difficulty concentrating as determinants of unsuccessful quitting and confirm the efficacy of NRT in reducing the severity of the other withdrawal symptoms (Molander et al 2000; Shiffman et al 2006).

In sum, the main factors influencing smoking sustained abstinence are the baseline level of nicotine dependence and psychoticism.

The first topic has been widely highlighted in the literature and can be explained considering the importance of the physical and psychological dependence due to nicotine as a substance of addiction. Nicotine has been considered a substance of abuse since the diagnosis of tobacco dependence was first added to the DSM III (Diagnostic and Statistical Manual of Mental Disorders, third edition, APA) in 1980 and thereafter changed to nicotine dependence in the subsequent editions.

As what concerns the role of psychoticism, there are less clear cut confirmations and explanations. It could be argued that subjects with a high psychoticism score are at higher risk of nicotine dependence as they have a greater amount of smoking and earlier age of starting smoking (Arai et al 1997). However, it can also be argued that high psychoticism means recklessness, disregard for common sense, inappropriate emotional expression, impulsiveness, lack of cooperation, low social sensitivity, low persistence, lack of anxiety and lack of feelings of inferiority (Howarth 1986) which are aspects strongly 
| Chapter 8

discouraging in persisting a task such as quitting smoking.

\section{Acknowledgments}

The authors thank Prof E. Griez and Dr. K Scrhuers (University of Maastricht) for the scientific advice, F Maggiorelli (University-Hospital of Pisa) and R Puntoni (CNR, Institute of Clinical Physiology) for data collection and laboratory analyses of cotinine, respectively.

The present project was grant-supported by Pharmacia. 
Table 1. Baseline mean score of Fagerström Tolerance Questionnaire (FTQ), Symptom Rating Test (SRT), and Eysenck Personality Inventory (EPI) by smoking status at week 12, 26, 52 for the whole sample.

\begin{tabular}{|l|r|r|r|r|r|r|r|}
\hline & \multicolumn{3}{|c|}{ Smokers } & \multicolumn{3}{c|}{ abstainers } & \\
\cline { 2 - 8 } & \multicolumn{1}{|c|}{$\mathbf{N}$} & \multicolumn{1}{c|}{ mean } & \multicolumn{1}{c|}{ SD } & N & \multicolumn{1}{c|}{ mean } & \multicolumn{1}{c|}{ SD } & \multicolumn{1}{c|}{$\mathbf{p}^{*}$} \\
\hline WEEK 12 & & & & & & & \\
\hline FTQ & 255 & 6.49 & 2.153 & 42 & 5.14 & 1.983 & .000 \\
\hline SRT anxiety & 255 & 6.13 & 4.262 & 42 & 4.38 & 3.084 & .014 \\
\hline SRT depression & 255 & 5.10 & 4.253 & 42 & 3.62 & 3.588 & .022 \\
\hline SRT somatization & 255 & 4.11 & 3.393 & 42 & 2.86 & 2.395 & .041 \\
\hline SRT inadequacy & 255 & 4.60 & 3.670 & 42 & 3.67 & 3.383 & .100 \\
\hline SRT total & 255 & 19.94 & 13.416 & 42 & 14.52 & 10.930 & .010 \\
\hline EPI neuroticism & 255 & 11.15 & 5.122 & 42 & 8.95 & 5.156 & .011 \\
\hline EPI extraversion & 255 & 12.55 & 4.251 & 42 & 13.14 & 3.917 & .429 \\
\hline EPI psychoticism & 255 & 4.25 & 2.334 & 42 & 3.43 & 2.360 & .033 \\
\hline WEEK 26 & & & & & & & \\
\hline FTQ & 259 & 6.47 & 2.153 & 38 & 5.16 & 2.021 & .001 \\
\hline SRT anxiety & 259 & 6.09 & 4.253 & 38 & 4.45 & 3.117 & .029 \\
\hline SRT depression & 259 & 5.06 & 4.237 & 38 & 3.71 & 3.712 & .040 \\
\hline SRT somatization & 259 & 4.09 & 3.379 & 38 & 2.89 & 2.458 & .062 \\
\hline SRT inadequacy & 259 & 4.58 & 3.657 & 38 & 3.71 & 3.471 & .127 \\
\hline SRT total & 259 & 19.82 & 13.366 & 38 & 14.76 & 11.305 & .019 \\
\hline EPI neuroticism & 259 & 11.08 & 5.127 & 38 & 9.13 & 5.246 & .030 \\
\hline EPI extraversion & 259 & 12.56 & 4.276 & 38 & 13.08 & 3.694 & .523 \\
\hline EPI psychoticism & 259 & 4.24 & 2.358 & 38 & 3.45 & 2.214 & .064 \\
\hline WEEK 52 & & & & & & & \\
\hline FTQ & 263 & 6.43 & 2.167 & 34 & 5.26 & 2.005 & .003 \\
\hline SRT anxiety & 263 & 6.08 & 4.225 & 34 & 4.35 & 3.246 & .022 \\
\hline SRT depression & 263 & 5.07 & 4.224 & 34 & 3.50 & 3.703 & .019 \\
\hline SRT somatization & 263 & 4.09 & 3.379 & 34 & 2.76 & 2.284 & .051 \\
\hline SRT inadequacy & 263 & 4.57 & 3.648 & 34 & 3.68 & 3.531 & .125 \\
\hline SRT total & 263 & 19.81 & 13.327 & 34 & 14.29 & 11.312 & .013 \\
\hline EPI neuroticism & 11.11 & 5.112 & 34 & 8.68 & 5.227 & .010 \\
\hline EPI extraversion & 12.59 & 4.256 & 34 & 12.91 & 3.825 & .729 \\
\hline EPI psychoticism & 263 & 4.24 & 2.343 & 34 & 3.29 & 2.277 & .027 \\
\hline
\end{tabular}

* by Mann-Whitney Test for non parametric variables 
Table 2. Baseline mean score of Fagerström Tolerance Questionnaire (FTQ), Symptom Rating Test (SRT), and Eysenck Personality Inventory (EPI) by smoking status at week 12, 26, 52, stratifying for cotinine baseline plasma values.

\begin{tabular}{|c|c|c|c|c|c|c|c|}
\hline \multicolumn{8}{|c|}{ Subjects with high cotinine (HC) baseline plasma value } \\
\hline & \multicolumn{3}{|c|}{ HC smokers } & \multicolumn{3}{|c|}{$\mathrm{HC}$ abstainers } & \multirow[b]{2}{*}{$\mathrm{p}^{*}$} \\
\hline & $\bar{N}$ & mean & SD & $\mathbf{N}$ & mean & SD & \\
\hline \multicolumn{8}{|l|}{ WEEK 12} \\
\hline FTQ & 161 & 7.09 & 1.816 & 16 & 6.06 & 1.731 & .040 \\
\hline SRT anxiety & 161 & 6.28 & 4.317 & 16 & 4.63 & 3.538 & .117 \\
\hline SRT depression & 161 & 5.48 & 4.426 & 16 & 4.38 & 4.573 & .216 \\
\hline SRT somatization & 161 & 4.09 & 3.510 & 16 & 2.94 & 2.568 & 273 \\
\hline SRT inadequacy & 161 & 4.76 & 3.801 & 16 & 4.44 & 4.163 & .633 \\
\hline SRT total & 161 & 20.61 & 13.970 & 16 & 16.38 & 13.623 & .180 \\
\hline EPI neuroticism & 161 & 11.46 & 5.100 & 16 & 7.44 & 6.196 & .003 \\
\hline EPI extraversion & 161 & 12.21 & 4.289 & 16 & 13.38 & 3.948 & .345 \\
\hline EPI psychoticism & 161 & 4.11 & 2.408 & 16 & 2.63 & 2.217 & .029 \\
\hline \multicolumn{8}{|l|}{ WEEK 26} \\
\hline FTQ & 162 & 7.09 & 1.810 & 15 & 6.00 & 1.773 & .035 \\
\hline SRT anxiety & 162 & 6.25 & 4.324 & 15 & 4.87 & 3.523 & .227 \\
\hline SRT depression & 162 & 5.46 & 4.426 & 15 & 4.60 & 4.641 & .337 \\
\hline SRT somatization & 162 & 4.07 & 3.508 & 15 & 3.07 & 2.604 & .379 \\
\hline SRT inadequacy & 162 & 4.73 & 3.808 & 15 & 4.73 & 4.131 & .935 \\
\hline SRT total & 162 & 20.51 & 13.995 & 15 & 17.27 & 13.609 & .335 \\
\hline EPI neuroticism & 162 & 11.41 & 5.118 & 15 & 7.67 & 6.343 & .008 \\
\hline EPI extraversion & 162 & 12.25 & 4.308 & 15 & 13.00 & 3.780 & .588 \\
\hline EPI psychoticism & 162 & 4.09 & 2.422 & 15 & 2.80 & 2.178 & .071 \\
\hline \multicolumn{8}{|l|}{ WEEK 52} \\
\hline FTQ & 162 & 7.09 & 1.810 & 15 & 6.00 & 1.773 & .035 \\
\hline SRT anxiety & 162 & 6.25 & 4.324 & 15 & 4.87 & 3.523 & .227 \\
\hline SRT depression & 162 & 5.46 & 4.426 & 15 & 4.60 & 4.641 & .337 \\
\hline SRT somatization & 162 & 4.07 & 3.508 & 15 & 3.07 & 2.604 & .379 \\
\hline SRT inadequacy & 162 & 4.73 & 3.808 & 15 & 4.73 & 4.131 & .935 \\
\hline SRT total & 162 & 20.51 & 13.995 & 15 & 17.27 & 13.609 & .335 \\
\hline EPI neuroticism & 162 & 11.41 & 5.118 & 15 & 7.67 & 6.343 & .008 \\
\hline EPI extraversion & 162 & 12.25 & 4.308 & 15 & 13.00 & 3.780 & .588 \\
\hline EPI psychoticism & 162 & 4.09 & 2.422 & 15 & 2.80 & 2.178 & .071 \\
\hline
\end{tabular}


(continued)

\begin{tabular}{|c|c|c|c|c|c|c|c|}
\hline \multicolumn{8}{|c|}{ Subjects with low cotinine (LC) baseline plasma value } \\
\hline & \multicolumn{3}{|c|}{ LC smokers } & \multicolumn{3}{|c|}{ LC abstainers } & \multirow[b]{2}{*}{$p^{*}$} \\
\hline & $\mathrm{N}$ & mean & SD & $\mathrm{N}$ & mean & SD & \\
\hline \multicolumn{8}{|l|}{ WEEK 12} \\
\hline FTQ & 94 & 5.46 & 2.299 & 26 & 4.58 & 1.943 & .075 \\
\hline SRT anxiety & 94 & 5.87 & 4.177 & 26 & 4.23 & 2.833 & .097 \\
\hline SRT depression & 94 & 4.44 & 3.873 & 26 & 3.15 & 2.824 & .141 \\
\hline SRT somatization & 94 & 4.15 & 3.199 & 26 & 2.81 & 2.333 & .066 \\
\hline SRT inadequacy & 94 & 4.33 & 3.437 & 26 & 3.19 & 2.786 & .134 \\
\hline SRT total & 94 & 18.79 & 12.396 & 26 & 13.38 & 9.003 & .054 \\
\hline EPI neuroticism & 94 & 10.61 & 5.141 & 26 & 9.88 & 4.265 & .570 \\
\hline EPI extraversion & 94 & 13.12 & 4.145 & 26 & 13.00 & 3.970 & .888 \\
\hline EPI psychoticism & 94 & 4.49 & 2.194 & 26 & 3.92 & 2.348 & .180 \\
\hline \multicolumn{8}{|l|}{ WEEK 26} \\
\hline FTQ & 97 & 5.42 & 2.281 & 23 & 4.61 & 2.017 & .117 \\
\hline SRT anxiety & 97 & 5.84 & 4.140 & 23 & 4.17 & 2.871 & .099 \\
\hline SRT depression & 97 & 4.40 & 3.832 & 23 & 3.13 & 2.928 & .142 \\
\hline SRT somatization & 97 & 4.11 & 3.168 & 23 & 2.78 & 2.411 & .072 \\
\hline SRT inadequacy & 97 & 4.33 & 3.396 & 23 & 3.04 & 2.868 & .082 \\
\hline SRT total & 97 & 18.68 & 12.229 & 23 & 13.13 & 9.488 & .048 \\
\hline EPI neuroticism & 97 & 10.54 & 5.122 & 23 & 10.09 & 4.274 & .789 \\
\hline EPI extraversion & 97 & 13.08 & 4.192 & 23 & 13.13 & 3.721 & .973 \\
\hline EPI psychoticism & 97 & 4.48 & 2.237 & 23 & 3.87 & 2.181 & .206 \\
\hline \multicolumn{8}{|l|}{ WEEK 52} \\
\hline FTQ & 101 & 5.38 & 2.280 & 19 & 4.68 & 2.029 & .215 \\
\hline SRT anxiety & 101 & 5.81 & 4.069 & 19 & 3.95 & 3.045 & .067 \\
\hline SRT depression & 101 & 4.45 & 3.817 & 19 & 2.63 & 2.565 & .041 \\
\hline SRT somatization & 101 & 4.11 & 3.178 & 19 & 2.53 & 2.038 & .051 \\
\hline SRT inadequacy & 101 & 4.32 & 3.379 & 19 & 2.84 & 2.814 & .067 \\
\hline SRT total & 101 & 18.68 & 12.162 & 19 & 11.95 & 8.797 & .027 \\
\hline EPI neuroticism & 101 & 10.63 & 5.091 & 19 & 9.47 & 4.155 & .422 \\
\hline EPI extraversion & 101 & 13.14 & 4.133 & 19 & 12.84 & 3.962 & .786 \\
\hline EPI psychoticism & 101 & 4.50 & 2.198 & 19 & 3.68 & 2.335 & .118 \\
\hline
\end{tabular}

* by Mann-Whitney Test for non parametric variables. 
| Chapter 8

Table 3. Multivariate analysis. Risk of failure versus abstinence, adjusted for treatment (placebo vs LC 15 $\mathrm{mg} /$ day vs HC $15 \mathrm{mg} /$ day vs HC $25 \mathrm{mg} /$ day).

\section{Model information}

\begin{tabular}{|c|c|c|c|}
\hline & OR & $95 \% \mathrm{Cl}$ & $p$ \\
\hline \multicolumn{4}{|l|}{ WEEK 12} \\
\hline Placebo & 1 & & \\
\hline $\mathrm{LC} 15 \mathrm{mg}$ & 0.264 & $0.095-0.733$ & .0106 \\
\hline $\mathrm{HC} 15 \mathrm{mg}$ & 0.779 & $0.253-2.401$ & .6641 \\
\hline $\mathrm{HC} 25 \mathrm{mg}$ & 1.612 & $0.462-5.621$ & .4539 \\
\hline FTQ & 1.211 & $1.007-1.458$ & .0421 \\
\hline SRT anxiety & 1.108 & $0.934-1.314$ & .2415 \\
\hline SRT depression & 0.961 & $0.811-1.137$ & .6406 \\
\hline SRT somatization & 1.119 & $0.956-1.309$ & .1603 \\
\hline SRT inadequacy & 0.907 & $0.760-1.082$ & .2774 \\
\hline EPI neuroticism & 1.058 & $0.959-1.168$ & .2625 \\
\hline EPI extraversion & 0.974 & $0.884-1.072$ & .5904 \\
\hline EPI psychoticism & 1.189 & $1.010-1.400$ & .0372 \\
\hline \multicolumn{4}{|l|}{ WEEK 26} \\
\hline Placebo & 1 & & \\
\hline $\mathrm{LC} 15 \mathrm{mg}$ & 0.199 & $0.065-0.612$ & .0048 \\
\hline $\mathrm{HC} 15 \mathrm{mg}$ & 0.527 & $0.155-1.789$ & .3042 \\
\hline $\mathrm{HC} 25 \mathrm{mg}$ & 1.332 & $0.333-5.318$ & .6851 \\
\hline FTQ & 1.210 & $0.996-1.469$ & .0546 \\
\hline SRT anxiety & 1.101 & $0.921-1.316$ & .2910 \\
\hline SRT depression & 0.963 & $0.809-1.147$ & .6742 \\
\hline SRT somatization & 1.118 & $0.950-1.317$ & .1801 \\
\hline SRT inadequacy & 0.913 & $0.760-1.096$ & .3281 \\
\hline EPI neuroticism & 1.047 & $0.945-1.160$ & .3828 \\
\hline EPI extraversion & 0.975 & $0.881-1.078$ & .6215 \\
\hline EPI psychoticism & 1.180 & $0.998-1.396$ & .0529 \\
\hline
\end{tabular}


(continued)

\begin{tabular}{|l|c|c|c|}
\hline & OR & $\mathbf{9 5 \%}$ Cl & $\mathbf{p}$ \\
\hline WEEK 52 & & & \\
\hline Placebo & 1 & & .0086 \\
\hline LC 15 mg & 0.192 & $0.056-0.657$ & .1872 \\
\hline HC 15 mg & 0.415 & $0.112-1.533$ & .9425 \\
\hline HC 25 mg & 1.055 & $0.245-4.554$ & .1098 \\
\hline FTQ & 1.180 & $0.963-1.444$ & .4288 \\
\hline SRT anxiety & 1.080 & $0.893-1.307$ & .9911 \\
\hline SRT depression & 0.999 & $0.828-1.205$ & .1879 \\
\hline SRT somatization & 1.124 & $0.944-1.338$ & .2386 \\
\hline SRT inadequacy & 0.892 & $0.738-1.079$ & .1795 \\
\hline EPI neuroticism & 1.076 & $0.967-1.199$ & .9999 \\
\hline EPI extraversion & 1.000 & $0.902-1.109$ & .0401 \\
\hline EPI psychoticism & 1.203 & $1.008-1.434$ & \\
\hline
\end{tabular}


| Chapter 8

Figure 1. SRT total scores from baseline to week 52 in abstainers $(n=34)$, in $L C$ abstainers $(n=19)$ and HC abstainers $(n=15)$.

$\longrightarrow$ abstainers $\longrightarrow$ LC abstainers $\rightarrow \mathrm{HC}$ abstainers

\section{SRT total score}

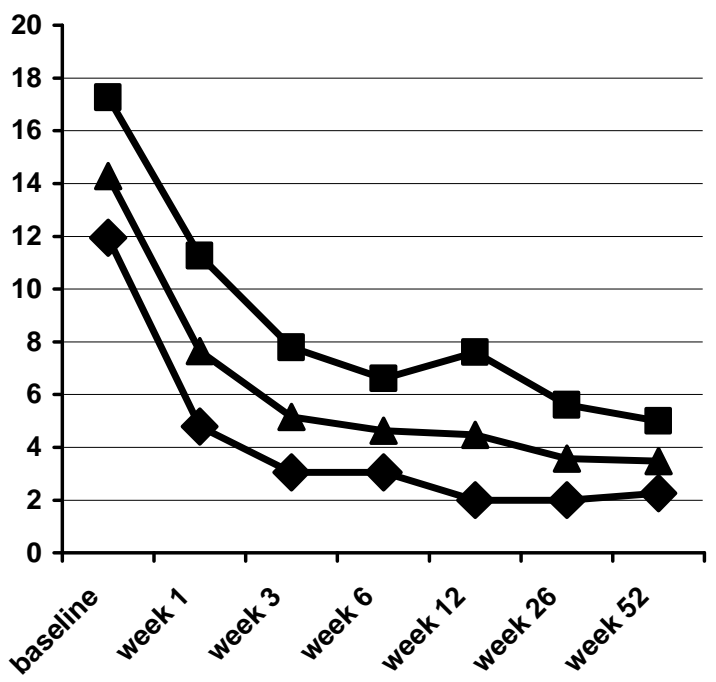




\section{REFERENCES}

American Psychiatric Association (1980). Diagnostic and Statistical Manual of Mental Disorders. $3^{\text {rd }}$ ed Washington DC. American Psychiatric Association.

American Psychiatric Association (1994). Diagnostic and statistical manual of mental disorders. $4^{\text {thed. }}$ Washington, DC. American Psychiatric Association.

Amodei N, Lamb RJ (2005). Predictors of initial abstinence in smokers enrolled in a smoking cessation program. Subst Use Misuse 40(2);141-9.

Arai Y, Hosokawa T, Fukao A, Izumi Y, Hisamichi S (1997). Smoking behaviour and personality: a population-based study in Japan. Addiction 92(8);1023-33.

Bandura A (1997). Self-efficacy: the exercise of control. New York: Freeman.

Blondal T, Gudmundsson LJ, Olafsdottir I, Gustavsson G, Westin A (1999). Nicotine nasal spray with nicotine patch for smoking cessation: randomised trial with six year follow up. BMJ 318(7179);285-8.

Catley D, Ahluwalia JS, Resnicow K, Nazir N (2003). Depressive symptoms and smoking cessation among inner-city African Americans using the nicotine patch. Nicotine Tob Res 5(1);61-8.

Chatkin JM, Mariante de Abreu C, Haggstram FM, Wagner MB, Fritscher CC (2004). Abstinence rates and predictors of outcome for smoking cessation: do Brazilian smokers need special strategies? Addiction 99(6);778-84.

Cook JW, Spring B, McChargue DE, Borrelli B, Hitsman B, Niaura R, Keuthen NJ, Kristeller J (2004). Influence of fluoxetine on positive and negative affect in a clinic-based smoking cessation trial. Psychopharmacology (Berl) 173(1-2);153-159.

Daughton DM, Fortmann SP, Glover ED, Hatsukami DK, Heatley SA, Lichtenstein E, Repsher L, Millatmal T, Killen JD, Nowak RT, Ullrich F, Patil KD, Rennard SI (1999). The smoking cessation efficacy of varying doses of nicotine patch delivery systems 4 to 5 years post-quit day. Prev Med 28(2);113-8.

Doherty K, Kinnunen T, Militello FS, Garvey AJ 1995). Urges to smoke during the first month of abstinence: relationship to relapse and predictors. Psychopharmacology (Berl) 119(2);171-8.

Doran N, Spring B, McChargue D, Pergadia M, Richmond M (2004). Impulsivity and smoking relapse. Nicotine Tob Res 6(4);641-7.

Eysenck HJ, Eysenck SBJ (1964). Manual of the Eysenck Personality Inventory. London: University of 
London Press.

Fagerström KO (1978). Measuring degree of physical dependence to tobacco smoking with reference to individualization of treatment. Addict Behav 3;235-41.

Fava GA, Kellner R, Perini GI, Fava M, Michelacci L, Munari F, Evangelisti LP, Grandi S, Bernardi M, Mastrogiacomo I (1983). Italian validation of the Symptom Rating Test (SRT) and Symptom Questionnaire (SQ). Can J Psychiatry 28(2);117-23.

Ferguson JA, Patten CA, Schroeder DR, Offord KP, Eberman KM, Hurt RD (2003). Predictors of 6-month tobacco abstinence among 1224 cigarette smokers treated for nicotine dependence. Addict Behav 28(7);1203-18.

Fiore MC, Bailey WC, Cohen SJ, Dorfman SF, Goldstein MG, Gritz ER, Heyman RB, Jaén CR, Kottke TE, Lando HA, Mecklenburg RE, Mullen PD, Nett LM, Robinson L, Stitzer ML, Tommasello AC, Villejo L, Wewers ME (2000). Treating tobacco use and dependence. Clinical Practice Guideline. Rockville MD: U.S. Department of Health and Human Services. Public Health Service.

Fiore MC, Smith SS, Jorenby DE, Baker TB (1994). The effectiveness of the nicotine patch for smoking cessation. A meta-analysis. JAMA 271(24);1940-7.

Glassman AH, Helzer JE, Covey LS, Cottler LB, Stetner F, Tipp JE, Johnson J (1990). Smoking, smoking cessation, and major depression. JAMA 264(12);1546-9.

Gross J, Stitzer ML (1989). Nicotine replacement: ten-week effects on tobacco withdrawal symptoms. Psychopharmacology (Berl) 98(3);334-41.

Hooten WM, Ames SC, Vickers KS, Hays JT, Wolter TD, Hurt RD, Offord KP (2005). Personality correlates related to tobacco abstinence following treatment. Int J Psychiatry Med 35(1);59-74.

Howarth E (1986). What does Eysenck's psychoticism scale really measure? Br J Psychol 77(Pt 2);2237.

Hughes JR, Lesmes GR, Hatsukami DK, Richmond RL, Lichtenstein E, Jorenby DE, Broughton JO, Fortmann SP, Leischow SJ, McKenna JP, Rennard SI, Wadland WC, Heatley SA (1999). Are higher doses of nicotine replacement more effective for smoking cessation? Nicotine Tob Res 1(2);169-74.

John U, Meyer C, Hapke U, Rumpf HJ, Schumann A (2004). Nicotine dependence, quit attempts, and quitting among smokers in a regional population sample from a country with a high prevalence 
of tobacco smoking. Prev Med 38(3);350-8.

John U, Meyer C, Rumpf HJ, Hapke U (2004). Depressive disorders are related to nicotine dependence in the population but do not necessarily hamper smoking cessation. J Clin Psychiatry 65(2);169-76.

Jorenby DE, Leischow SJ, Nides MA, Rennard SI, Johnston JA, Hughes AR, Smith SS, Muramoto ML, Daughton DM, Doan K, Fiore MC, Baker TB (1999). A controlled trial of sustained-release bupropion, a nicotine patch, or both for smoking cessation. N Engl J Med 340(9);685-91.

Killen JD, Fortmann SP, Davis L, Strausberg L, Varady A (1999). Do heavy smokers benefit from higher dose nicotine patch therapy? Exp Clin psychopharmacol 7(3);226-33.

Miller WR, Rollnick S (2002). Motivational interviewing: preparing people for change. $2^{\text {nd }}$ ed. The Guilford Press: New York.

Molander L, Lunell E, Fagerström KO (2000). Reduction of tobacco withdrawal symptoms with a sublingual nicotine tablet: a placebo controlled study. Nicotine Tob Res 2(2);187-91.

Nerin I, Novella P, Crucelaegui A, Beamonte A, Sobradiel N, Gargallo P (2004). Predictors of success at 6-month follow-up for smokers treated at a smoking cessation clinic. Arch Bronconeumol 40(12);558-62.

Nil R (1991). A psychopharmacological and psychophysiological evaluation of smoking motives. Rev Environ Health 9(2);85-115.

Ong KC, Cheong GN, Prabhakaran L, Earnest A (2005). Predictors of success in smoking cessation among hospitalized patients. Respirology 10(1);63-9.

Paoletti P, Fornai E, Maggiorelli F, Puntoni R, Viegi G, Carrozzi L, Corlando A, Gustavsson G, Sawe U, Giuntini C (1996). Importance of baseline cotinine plasma values in smoking cessation: results from a double-blind study with nicotine patch. Eur Respir J 9;643-51.

Patten CA, Martin JE (1996). Does nicotine withdrawal affect smoking cessation? Clinical and theoretical issues. Ann Behav Med 18;190-200.

Prochaska JO, Velicer WF (1997). The transtheoretical model of health behaviour change. Am J Health Promotion 12;38-48.

Raherison C, Marjary A, Valpromy B, Prevot S, Fossoux H, Taytard A (2005). Evaluation of smoking cessation success in adults. Respir Med 99(10);1303-10.

Sachs DPL, Benowitz NL, Bostrom AG, Hansen MD (1995). Percent serum replacement and success of 
nicotine patch therapy. Am J Respir Crit Care Med 151;A688.

Shiffman S, Ferguson SG, Gwaltney CJ, Balabanis MH, Shadel WG (2006). Reduction of abstinenceinduced withdrawal and craving using high-dose nicotine replacement therapy. Psychopharmacology (Berl) 184(3-4);637-644. Epub 2005 Nov 1.

Shiffman S, Khayrallah M, Nowak R (2000). Efficacy of the nicotine patch for relief of craving and withdrawal 7-10 weeks after cessation. Nicotine Tob Res 2(4);371-8.

Silagy C, Mant D, Fowler G, Lancaster T (2000). Nicotine replacement therapy for smoking cessation. Cochrane database of systematic reviews (Online), (3), CD000146.

Sims TH, Fiore MC (2002). Pharmacotherapy for treating tobacco dependence: what is the ideal duration of therapy? CNS Drugs 16(10);653-62.

Stapleton J (1998). Cigarette smoking prevalence, cessation and relapse. Stat Methods Med Res 7(2);187-203.

Stead L, Lancaster T (2005). Nicotine replacement therapy for smoking cessation: Cochrane systematic review. Int J Epidemiol 34(5);1001-2.

Strasser AA, Kaufmann V, Jepson C, Perkins KA, Pickworth WB, Wileyto EP, Rukstalis M, AudrainMcGovern J, Lerman C (2005). Effects of different nicotine replacement therapies on postcessation psychological responses. Addict Behav 30(1);9-17.

Swan GE, Ward MM, Jack LM (1996). Abstinence effects as predictors of 28-day relapse in smokers. Addict Behav 21(4);481-90.

Tonnesen P, Paoletti P, Gustavsson G, Russell MA, Saracci R, Gulsvik A, Rijcken B, Sawe U (1999). Higher dosage nicotine patches increase one-year smoking cessation rates: results from the European CEASE trial. Collaborative European Anti-Smoking Evaluation. European Respiratory Society. Eur Respir J 13(2);238-46. 


\section{CHAPTER 9}

\section{General discussion}

The initial part of the thesis concerns the relationship between panic disorder and the abuse of alcohol. Numerous previous works have showed that panic and alcohol co-occur at a rate which cannot be explained by chance. Two main explanations have been put forward for such a co-occurrence. Panic may promote pathological alcohol use as self-medication, and chronic alcohol use or alcohol withdrawal may induce changes in the neurochemical system that trigger panic. A third factor has been considered as familial transmission might promote both conditions.

Considering that the debate on how to explain such a co-occurrence is still widely open, chapter two provides a critical review of the literature on PD and alcohol use disorders. The review highlights that alcohol lessens anxious apprehension in panic subjects, thereby decreasing the likelihood of panic. In alcoholics, alcohol increases $\mathrm{CO}_{2}$ sensitivity, thereby promoting panic. In both cases, a significant familial transmission contributes to the co-occurrence of the two disorders.

The literature study therefore concludes that apparently panic and alcohol use disorders both serve to initiate the other, via independent mechanisms. As a consequence, the self medication and the neurochemical hypotheses, although acting in opposite directions, are not mutually exclusive. The first one explains the mechanism of the comorbidity when panic occurs prior to alcohol use, the latter one when alcohol use disorder is temporally prior to panic.

These conclusions, however, call for further verification. Thus, epidemiological investigations, especially if conducted in clinical setting and using well-standardized methods, would be important to replicate what has been already published. Moreover, genetic studies may add information on the pattern of cooccurrence of panic and alcohol abuse. For instance, it may be worth clarifying if panic disorder and alcoholism co-occur in same families as an apparent phenotype or if the disorders tend to co-occur in isolation in relatives.

Chapter three and chapter four are devoted to verify the self medication hypothesis and, more specifically, the effect of alcohol on the unexpected panic attack which is the core of panic disorder. In these studies, the $35 \% \mathrm{CO}_{2}$ challenge is used as an experimental model for the key element of panic 
disorder.

In chapter three a moderate dose of an alcoholic drink or placebo was administered to healthy volunteers undergoing the $35 \% \mathrm{CO}_{2}$ challenge. Outcome measures, represented by both subjective reports of anxiety and neurovegetative symptoms, showed a decrease of the response to a $35 \% \mathrm{CO}_{2}$ panic challenge without a decreasing of the anticipatory anxiety. Thus, alcohol had a specific anti panic effect decreasing the level of anxiety following the $35 \% \mathrm{CO}_{2}$ challenge.

In chapter four, the experiment was repeated with some methodological modifications. The effect of the $35 \% \mathrm{CO}_{2}$ challenge was evaluated both in drug free PD patients and in healthy volunteers. Ethanol and placebo were administered intravenously to evaluate more clearly the pharmacological effect of alcohol and eliminate any cognitive bias due to the act of drinking. Compared to the placebo condition, the response to the $35 \% \mathrm{CO}_{2}$ challenge was significantly smaller after ethanol infusion in panic disorder patients and tended to decrease in healthy volunteers. No sedating effect was found in the pre challenge phase.

The results proposed in chapter three and four give support to the self medication hypothesis. Alcohol had a specific antipanic effect which seemingly was related to a direct pharmacological action.

The findings also add to the suspicion that the pharmacological effects of alcohol may serve as a reinforcement for drinking behavior among those with panic disorder.

Moreover, alcohol and ethanol did not produce any noticeable sedation before the $\mathrm{CO}_{2}$ challenge. This means that the response to $\mathrm{CO}_{2}$ was not related to a decrease in anticipatory anxiety, but rather to a specific direct inhibitory action of alcohol/ethanol on experimental panic.

Taken together, these data seem to highlight that state anxiety and panic may be modulated independently.

The findings of chapter three and four invite replications using the $35 \% \mathrm{CO}_{2}$ challenge or other validated panic provoking procedures.

From a clinical point of view, the paradigm we have used with the $\mathrm{CO}_{2}$ challenge may help shedding light on the relative efficacy of pharmacological and psychological intervention in double diagnosed patients. Three groups of patients may undergo $\mathrm{CO}_{2}$ challenge before and after receiving treatment for alcohol addiction. Their response to the provocative test might be compared. Group A and B would be treated both for alcohol related disorders and panic, group $C$ would simply receive treatment for alcohol use disorders. In particular, group A would be pharmacologically treated, for instance using antidepressants 
with a specific antipanic effect. Group B would receive a psychological intervention, for instance cognitive behavioural therapy specific for panic.

This might predict which specific intervention to propose to double diagnosed subjects when treated in clinical settings.

The second part of the thesis is devoted to the relationship between panic and nicotine dependence.

Nicotine, similarly to alcohol, is strongly related to panic. Once again, two major etiologic hypotheses have been formulated. On one hand, anxious individuals have been considered at elevated risk for smoking initiation because of the calming effects of smoking (the self medication theory). On the other hand, cigarette smoking has been thought to contribute to the development of panic. Finally, a genetic vulnerability to both disorders has been proposed.

Chapter five and six are devoted to verify the pharmacological relationship between nicotine, or at least cigarette smoking, and panic. Once again, the $35 \% \mathrm{CO}_{2}$ challenge is used as an experimental model.

In chapter five, the acute effect of nicotine on panic was examined. Nicotine was transdermally administered to healthy non smokers who thereafter underwent a $35 \% \mathrm{CO}_{2}$ challenge. Nicotine did not affect the challenge response if compared to placebo but it induced an aspecific noradrenergic-like response prior to the challenge. The findings in chapter five cast some doubts on the hypothesis for which smoking has a calming effect. They more properly support the possibility that nicotine contributes in inducing anxiety in healthy subjects possibly via an aspecific noradrenergic system stimulation.

In chapter six, habitual cigarette smokers were evaluated. The effect of the $35 \% \mathrm{CO}_{2}$ challenge was observed in panic disorder smokers and non smokers with the aim of studying individuals vulnerable to panic chronically exposed to nicotine. Smokers and non smokers did not differ for baseline clinical characteristics of panic and for pre challenge level of anxiety. Nevertheless, smokers had a significantly higher response to the challenge and a higher rate of $\mathrm{CO}_{2}$ elicited panic attacks. These findings suggest that cigarette smoking, used as a proxy of chronic exposure to nicotine, has a specific panicogenic effect in $\mathrm{PD}$ patients.

Taken together, the data proposed in chapter five and six highlight that state anxiety in healthy volunteers and panic in PD patients is modulated independently by nicotine.

These findings call for further studies. On one hand, PD patients under nicotine or placebo conditions could be evaluated. Their $\mathrm{CO}_{2}$ challenge response would be compared using the study design proposed in chapter five. Similarly, a comparison of $\mathrm{CO}_{2}$ challenge response of healthy smokers and non smokers, 
applying the design proposed in chapter six, seems worthwhile. These kind of studies may clarify the role of acute and chronic use of nicotine in vulnerable and non vulnerable subjects and add information to the different action of nicotine in healthy volunteers and PD patients.

It would be also relevant to use the challenge to experimentally test psychological and pharmacological treatments to be used in case of co-occurrence of the two disorders.

Should PD smokers attending for smoking cessation programmes be treated with antipanic drugs? And if so, should antidepressants be used or benzodiazepine? Should they be treated by a complementary psychotherapy, for instance cognitive behavioural therapy?

These questions call for additional clinical trials which would use PD applicants simply treated to quit smoking as comparison sample.

This may allow to understand if antipanic treatment, and which one, increases the rate of success in quitting or the duration of smoking abstinence.

As cigarette smoking is linked to panic but also to negative affective symptoms and those symptoms may influence the possibility to quit, smokers applying for smoking cessation clinics and smokers of the general population were compared in chapter seven. The results show that smokers applying for smoking cessation clinics have more negative affectivity than smokers from the general population. According to this, the occurrence of anxious and/or depressive symptoms strongly complicates cigarette smoking dependence in smokers who ask for a specialised intervention to quit.

This observation may have interesting implications in clinical practice. The assessment of the level of negative affectivity at first visit may be important as well as a specific psychological or pharmacological intervention aimed at reducing the level of negative affectivity. Once again, these strategies may increase the rate of success in quitting or the duration of smoking abstinence.

However, anxious and depressive symptoms should be further studied.

The design proposed in chapter seven may be used to compare smokers who quit in specialised clinics with smokers who quit without any support. This may allow to understand if the occurrence of affective symptoms is always the reason to quit smoking or if applicants for smoking cessation programmes are subjects particularly vulnerable to negative affectivity. In that case, smoking cessation clinics should propose an integrated treatment addressing the substance use disorder, the mood disorder (full or incomplete) and the psychological distress. This may raise the issue as whether more specialists should be involved in smoking cessation programmes. 
Finally, nicotine dependence, psychological distress and personality characteristics were analysed as possible factors inducing failures in quitting smoking.

Chapter eight showed that smokers who failed in quitting have a higher baseline nicotine dependence and psychotic personality than smokers who succeeded. No statistically significant results were found for psychological distress. According to this study, nicotine dependence and psychoticism are the strongest predictors of medium-long term outcome of quitting smoking. Nicotine dependence may influence the outcome because it induces physical and psychological dependence. Psychoticism may influence the outcome because it favours nicotine dependence and implies personality characteristics which discourage in persisting tasks such as quitting.

Further analysis on personality characteristics of quitters are warranted. The replication of the findings proposed in chapter eight in a clinical naturalistic setting may add information to the profile of smokers who succeed in quitting and those who fail. Smokers attending a smoking cessation programme should be evaluated and followed for at least 6 months. Then, successful quitters would be compared with failures. This may draw a more accurate picture of patients who have a high chance to quit and of those who may need more specific intervention and support to reach the same result.

The present thesis points out the relevance of the pharmacological effects of alcohol and nicotine in their causal relationship with panic. It also highlights the role of clinical and psychological factors in such a cooccurrence.

For instance, subjects abusing of alcohol or nicotine usually do not recognise or underestimate the severity of such a dependence. This may imply an underreporting of the psychiatric symptoms due and associated to the dependence, the lack of interest in being assessed, the low compliance in the treatment proposed or a reluctance in being recruited for clinical trials.

Epidemiological, family and experimental studies offer fascinating possibilities to disentangle the relationship between panic and alcohol/nicotine use. Considering the significance of these pathologies in terms of public health, investigators should spend more energy to conduct additional research in this field. 
| Summary and concluding remarks

\section{Summary and concluding remarks}

The topic of the current thesis is the relationship between panic disorder (PD) and alcohol or nicotine use disorders.

Chapter one provides a general introduction into alcohol and nicotine use disorders and their clinical implications. Indeed, the misuse of such substances may have severe clinical implications in terms of comorbidity with organic disease as well as psychiatric disorders. In particular, the co-occurrence with panic disorder exceeds what is expected by chance and the relationship underlying such a co-occurrence is still discussed.

The following three chapters concerns the relationship between panic and alcohol use disorders. Such a comorbidity has two main explanations which refer to the self-medication hypothesis and the neurochemical hypothesis. According to the first alcohol may reduce panic, according to the latter alcohol may trigger panic. A third relevant factor is familial transmission which might promote both conditions.

Chapter two provides a critical review of the literature on PD and alcohol use disorders. Alcohol seems to lessen anxious apprehension in panic subjects, thereby decreasing the likelihood of panic. In alcoholics, alcohol increases $\mathrm{CO}_{2}$ sensitivity, thereby promoting panic. In both cases, a significant familial transmission contributes to the co-occurrence of the two disorders. Thus, the self medication hypothesis may explain the mechanism of the comorbidity when panic occurs prior to alcohol use, the neurochemical hypothesis when alcohol use disorder is temporally prior to panic.

The following two chapters describe experimental studies in which the effects of alcohol on panic induction is monitored. The $35 \% \mathrm{CO}_{2}$ challenge is used as an experimental model for the key element of panic disorder.

Chapter three focuses on the effects of a moderate dose of an alcoholic drink in healthy volunteers. Alcohol induces a decrease of the response to a $35 \% \mathrm{CO}_{2}$ panic challenge without decreasing anticipatory anxiety. Thus, alcohol has a specific anti panic effect decreasing the level of anxiety following the $35 \% \mathrm{CO}_{2}$ challenge.

In chapter four, the experiment was repeated evaluating drug free PD patients and healthy volunteers, and administering ethanol intravenously. Compared to the placebo, the response to the $35 \% \mathrm{CO}_{2}$ challenge was significantly smaller after ethanol infusion in panic disorder patients and tended to decrease in healthy volunteers. No sedating effect was found in the pre challenge phase. Once again 
alcohol has a specific anti panic effect which seems due to a direct pharmacological action.

The results support the self medication hypothesis and add to the suspicion that the pharmacological effects of alcohol may serve as a reinforcement for drinking behaviour among those with panic disorder. Moreover, as alcohol and ethanol did not produce any noticeable sedation before the $\mathrm{CO}_{2}$ challenge and the response to $\mathrm{CO}_{2}$ was not related to a decrease in anticipatory anxiety, state anxiety and panic seem to be modulated independently.

The second part of the thesis is devoted to the relationship between panic and nicotine dependence. Nicotine, similarly to alcohol, is strongly related to panic. Once again, two major etiologic hypotheses have been formulated. On one hand, a self medication theory; on the other hand, cigarette smoking has been thought to contribute to the development of panic. Finally, a genetic vulnerability to both disorders has been proposed.

Chapter five and six are devoted to verify the pharmacological relationship between nicotine, or at least cigarette smoking, and panic. Once again, the $35 \% \mathrm{CO}_{2}$ challenge is used as an experimental model.

Chapter five focuses on the acute effect of nicotine on healthy non smokers. Nicotine did not affect the $35 \% \mathrm{CO}_{2}$ challenge response if compared to placebo.

However, it induced an aspecific noradrenergic-like response prior to the challenge. These results cast some doubts on the calming effects of nicotine but support the idea that nicotine contributes in inducing anxiety in healthy subjects via an aspecific noradrenergic system stimulation.

In chapter six, the $\mathrm{CO}_{2}$ paradigm was used comparing challenge response of panic disorder smokers and panic disorder non smokers. Smokers had a significantly higher response to the challenge and a higher rate of $\mathrm{CO}_{2}$ elicited panic attacks than non smokers. They did not differ for baseline clinical characteristics of panic and for pre challenge level of anxiety. These findings suggest that cigarette smoking, used as a proxy of chronic exposure to nicotine, has a specific panicogenic effect in PD patients. Taken together, the data proposed in chapter five and six highlight that state anxiety in healthy volunteers and panic in PD patients is modulated independently by nicotine.

As cigarette smoking is linked to panic but also to negative affectivity in general, and affective symptoms may influence the possibility to quit, smokers applying for smoking cessation clinics and smokers of the general population were compared in chapter seven. Smokers applying for smoking cessation clinics proved to have more negative affectivity than smokers from the general population. Thus, the occurrence of anxious and/or depressive symptoms strongly complicate cigarette smoking dependence in smokers 
| Summary and concluding remarks

who ask for a specialised intervention to quit.

Finally, nicotine dependence, psychological distress and personality characteristics were analysed as possible factors of failure in quitting smoking. Chapter eight showed that smokers who failed in quitting have a higher baseline nicotine dependence and psychotic personality than smokers who succeeded. Nicotine dependence may influence the outcome because it induces physical and psychological dependence. Psychoticism may influence the outcome because it favours nicotine dependence and implies personality characteristics which may discourage in persisting tasks such as quitting.

Chapter nine provides a general discussion that integrates the results of the different chapters.

The present thesis points out the relevance of the pharmacological effects of alcohol and nicotine in their causal relationship with panic. However, it also highlights the role of clinical and psychological factors in such a co-occurrence. 


\section{Onderzoek naar de relatie tussen alcohol of nicotine gebruik en paniek}

\section{Samenvatting en conclusies}

Het onderwerp van dit proefschrift betreft de relatie tussen de paniekstoornis (PS) en alcohol of nicotine afhankelijkheid.

Hoofdstuk één verschaft een algemene introductie over alcohol en nicotine afhankelijkheid en de klinische implicaties hiervan. Uiteraard kan het misbruik van dergelijke middelen ernstige klinische implicaties hebben in termen van co-morbiditeit met organische aandoeningen evenals met psychiatrische aandoeningen. Met name het gelijktijdig voorkomen van deze aandoeningen met de paniekstoornis komt vaker voor dan wat op basis van kans verwacht zou worden en de relatie die ten grondslag ligt aan een dergelijke co-morbiditeit is nog onderwerp van discussie.

De drie daarop volgende hoofdstukken betreffen de relatie tussen paniek en alcohol afhankelijkheid. Er bestaan twee belangrijke verklaringen voor deze co-morbiditeit welke terug zijn te voeren tot de zelfmedicatie hypothese en de neurochemische hypothese. Volgens de eerste zou alcohol paniek kunnen reduceren, volgens de laatste zou alcohol paniek kunnen uitlokken. Een derde relevante factor is familiale transmissie hetgeen beide condities zou kunnen stimuleren.

Hoofdstuk twee verschaft een kritisch overzicht van de literatuur over PS en alcohol afhankelijkheid. Alcohol lijkt de angstige voorgevoelens van paniekpatiënten te verminderen en daarmee de kans op paniek te verkleinen. Bij alcoholisten verhoogt alcohol de gevoeligheid voor $\mathrm{CO}_{2}$ en stimuleert daarmee paniek. In beide gevallen draagt een significante familiale transmissie bij aan de co-morbiditeit van de twee aandoeningen. Aldus zou de zelf-medicatie hypothese het mechanisme van de co-morbiditeit verklaren wanneer paniek voorafgaat aan het alcohol gebruik en de neurochemische hypothese wanneer de alcohol afhankelijkheid voorafgaat aan de paniek.

De daarop volgende twee hoofdstukken beschrijven experimentele studies waarbij de effecten van alcohol op paniek opwekking worden gevolgd. De $35 \% \mathrm{CO}_{2}$ challenge wordt gebruikt als een experimenteel model voor het belangrijkste aspect van de paniekstoornis. Hoofdstuk drie richt zich op de effecten van een matige hoeveelheid van een alcoholische drank bij gezonde vrijwilligers. Alcohol induceert een afname in de response op een $35 \% \mathrm{CO}_{2}$ paniek challenge zonder de anticipatie angst te 
| Samenvatting en conclusies

verlagen. Dus, alcohol heeft een specifiek anti-paniek effect wat het angstniveau volgend op de $35 \% \mathrm{CO}_{2}$ challenge verlaagd.

In hoofdstuk vier is het experiment herhaald waarbij medicatievrije PS patiënten en gezonde vrijwilligers beschouwd werden en ethanol intraveneus werd toegediend. Vergeleken met placebo was de respons op de $35 \% \mathrm{CO}_{2}$ challenge na ethanol infusie significant minder sterk bij paniekstoornis patiënten en bij de gezonde vrijwilligers was er een tendens tot afname. Er werd geen sedatief effect gevonden in de fase voorafgaand aan de challenge. Wederom had alcohol een specifiek anti- paniek effect wat veroorzaakt lijkt te worden door een directe farmacologische werking.

De resultaten ondersteunen de zelf-medicatie hypothese en dragen bij aan het vermoeden dat de farmacologische effecten van alcohol drankgebruik onder paniekstoornis patiënten kunnen bekrachtigen. Bovendien, aangezien de alcohol en ethanol geen noemenswaardige sedatie veroorzaakten voorafgaand aan de $\mathrm{CO}_{2}$ challenge en de respons op $\mathrm{CO}_{2}$ niet gerelateerd was aan een daling van anticipatie angst, worden toestandsangst en paniek schijnbaar onafhankelijk gemoduleerd.

Het tweede gedeelte van het proefschrift is gewijd aan de relatie tussen paniek en nicotine afhankelijkheid.

Nicotine, overeenkomstig met alcohol, is sterk gerelateerd aan paniek. Wederom zijn er twee belangrijke etiologische hypotheses geformuleerd. Enerzijds, een zelf-medicatie theorie; anderzijds, wordt gedacht dat roken bijdraagt aan het ontwikkelen van paniek. Tenslotte is er een genetische kwetsbaarheid geopperd bij beide aandoeningen.

Hoofdstuk vijf en zes zijn gewijd aan het onderzoeken van de farmacologische relatie tussen nicotine, of in ieder geval roken, en paniek. Wederom werd de $35 \% \mathrm{CO}_{2}$ challenge als experimenteel model gebruikt. Hoofdstuk vijf richt zich op de acute effecten van nicotine bij gezonde niet-rokers. Nicotine had geen invloed op de respons op de $35 \% \mathrm{CO}_{2}$ challenge in vergelijking met de placebo.

Echter, het induceerde een aspecifieke noradrenerg-achtige respons voorafgaand aan de challenge. Deze resultaten trekken de kalmerende effecten van nicotine enigszins in twijfel, maar ondersteunen het idee dat nicotine bijdraagt aan het induceren van angst bij gezonde vrijwilligers via een specifieke stimulatie van het noradrenerge systeem.

In hoofdstuk zes wordt het $\mathrm{CO}_{2}$ paradigma gebruikt om de challenge respons van rokende PS patiënten en niet rokende PS patiënten te vergelijken. Rokers hadden een significant sterkere respons op de challenge en een groter aantal $\mathrm{CO}_{2}$-opgewekte paniekaanvallen dan niet-rokers. Ze verschilden niet in 
klinische kenmerken van paniek op baseline en het angst niveau voorafgaand aan de challenge. Deze bevindingen suggereren dat roken, gebruikt als benadering van chronische blootstelling aan nicotine, een specifiek panicogeen effect heeft bij PS patiënten. Samengevat benadrukken de data die zijn voorgelegd in hoofdstuk vijf en zes dat toestandsangst bij gezonde vrijwilligers en paniek bij PS patiënten onafhankelijk gemoduleerd wordt door nicotine.

Aangezien roken een relatie vertoont met paniek, maar ook met negatief affect in het algemeen, en affectieve symptomen de mogelijkheid om te stoppen zouden kunnen beïnvloeden, worden in hoofdstuk zeven rokers die zich aanmeldden bij een ontwenningskliniek vergeleken met rokers uit de algemene populatie. Rokers die zich aanmeldden voor ontwenningsklinieken vertoonden inderdaad meer negatieve affectiviteit dan rokers uit de algemene populatie. Dus, het vóórkomen van angstige en/of depressieve symptomen compliceert sigaret afhankelijkheid in rokers die zich aanmelden voor een gespecialiseerde interventie om te stoppen.

Tenslotte zijn nicotine afhankelijkheid, psychologische stress en persoonlijkheidskenmerken geanalyseerd als mogelijke factoren bij het niet slagen in het stoppen met roken. Hoofdstuk acht toont aan dat rokers die er niet in slaagden te stoppen op baseline een hogere mate van nicotine afhankelijkheid en psychotische persoonlijkheid hadden dan rokers die er wel in slaagden te stoppen. Nicotine afhankelijkheid zou de uitkomst kunnen beïnvloeden omdat het lichamelijke en geestelijke afhankelijkheid induceert. Psychoticisme zou de uitkomst kunnen beïnvloeden omdat het nicotine afhankelijkheid stimuleert en gepaard gaat met persoonlijkheidskenmerken die het volharden in zaken zoals stoppen met roken zouden kunnen bemoeilijken.

Hoofdstuk negen verschaft een algemene discussie die de resultaten van de verschillende hoofdstukken integreert.

Het huidige proefschrift wijst op de relevantie van de farmacologische effecten van alcohol en nicotine in causale relatie met paniek. Echter, het benadrukt ook de rol van klinische en psychologische factoren bij een dergelijke co-morbiditeit. 


\section{Thanks}

As part of the end of the present work, I would like to express my sincere thanks to all the people who contributed in realising it.

My thanks and respect are first directed to patients and healthy volunteers who participated to the experiments. They had the will and the patience to follow the steps required by the protocols even when they were not as pleasant as they could imagine. I can still remember their expression when they drunk those big glasses with grape fruit juice and vodka as part of the experiment showed in chapter two of the present thesis.

To my supervisor Eric Griez who initiated me into experimental research. He recognised my shy passion for knowledge and contributed in growing it. He taught me the steps of research: making an hypothesis, writing a protocol substantiating such a hypothesis, organizing carefully the practical matters, collecting honestly data, "looking at data" to understand what they say, making statistical analyses and writing papers. 'Thinking aloud' with me he gave me the instruments to stick to the reality of data and understand them. For his trusting welcome and expert constancy I sincerely thank him.

My co-supervisor Koen Schruers, who supported me to solve theoretical and practical matters. He gave me useful advice in formulating hypotheses of research, organizing it and critically evaluating the data. He also gave me refined suggestions in writing papers and expressing core concepts without being weak or uncertain. For his support and optimistic approach toward research I really thank him.

As co-author and friend I thank Kenneth Abrams. He supported me in the lab and in writing. He always encouraged me to improve and gave a different but interesting point of view of the topic under discussion. I also thank Marlies van Duinen, Toesja de Gooyer, Judith Rickelt with whom I worked at the "Academisch .Angstcentrum". Marlies helped me in knowing the "Academisch .Angstcentrum". Especially during my first stay in Maastricht I asked her myriad of questions. Toesja and Judith actively participated in the experiments collecting data in the lab.

I also thank the research assistants and particularly Inge Leclair for her lively help in recruiting patients and volunteers.

A special thank to Leni Noteborn for her warm support and help in bureaucratic matters.

To the staff of the Academisch .Angstcentrum, Julien Peeters, Mark Ashmann, Mariette Ubaghs, Louis Kersten, Rudy Nijssen, Marjan Böhm, François Wilms, Nicolette Bongaerts, Cindy De Bie. 
My stay at the "Academisch .Angstcentrum" has been a unique and stimulating experience to meet research and be aroused by it.

I also thank the colleagues of the smoking cessation clinic in Pisa: Laura Carrozzi and Francecso Pistelli. They kindly received me in their facility and gave me the lesson that true research can be done in any place and country if you have a firm intention to do it.

Many thanks to Emilio Maionchi and Leonardo Marini from the smoking cessation clinic in Pistoia. Emilio's words "do you really think that if you are good with the world, the world will be good with you?" are still clear in my mind.

To Giampolo Perna and Daniela Caldirola from the San Raffaele Hospital in Milan. I thank them for the friendship and willingness shown.

A warm thank to my family, friends and Massimo for their persistent support and confidence. They have been always with me. I still remember their letters, e-mail and visits during my staying in Maastricht. For their love I thank them. 


\section{Publications}

Cosci F, Schruers K, Faravelli C, Griez E (2004). The influence of alcohol oral intake on the effects of $35 \% \mathrm{CO}_{2}$ challenge. A study in healthy volunteers. Acta Neuropsychiatrica 16(2); 107-9.

Cosci F, De Gooyer T, Schruers K, Faravelli C, Griez EJL (2005). The influence of ethanol infusion on the effects of $35 \% \mathrm{CO}_{2}$ challenge. A study in panic disorder patients and healthy volunteers. Eur Psychiatry 20; 299-303.

Cosci F, Abrams K, Schruers KRJ, Rickelt J, Griez EJL (2006). Effect of nicotine on $35 \% \mathrm{CO}_{2}$ induced anxiety. A study in healthy volunteers. Nicotine \& Tobacco Research 8(4); 511-17.

Cosci F, Schruers KRJ, Abrams K, Griez EJL in press. Alcohol use disorders and panic disorder: a review of the evidence of a direct relationship. J Clin Psychiatry.

Faravelli C, Bartolozzi D, Cimminiello L, Cecchi C, Cosci F, D'Adamo D, Di Mattro MC, Di Primio C, Fabbri C, Lo lacono B, Paionni A., et al (2001). The Florence Psychiatric Interview. International Journal of Methods in Psychiatry Research 10(4); 157-71.

Faravelli C, Cosci F, Ciampelli M, Scarpato MA, Spiti R, Ricca V (2003). A self-controlled, naturalistic study of selective serotonin reuptake inhibitors versus tricyclic antidepressants. Psychoter Psychosom 72; 95-101.

Faravelli C, Abrardi L, Bartolozzi D, Cecchi C, Cosci F, D'Adamo D, Lo lacono B, Ravaldi C, Scarpato MA, Truglia E, Rosi S (2004). The Sesto Fiorentino Study: background, methods and preliminary results. Psychoter Psychosom 73; 216-25.

Faravelli C, Abrardi L, Bartolozzi D, Cecchi C, Cosci F, D'Adamo D, Lo lacono B, Ravaldi C, Scarpato MA, Truglia E, Rossi Prodi PM, Rosi S (2004). The Sesto Fiorentino Study: point and one year prevalence of psychiatric disorders in an Italian community sample using clinical interviewers. Psychoter Psychosom 73; 226-34.

Goodwin RD, Faracelli C, Rosi S, Cosci F, Truglia E, de Graaf R, Witchen HU (2005). The epidemiology of panic disorder and agoraphobia in Europe. European Neuropsychopharmacology 15; 43543.

Vannacci A, Ravaldi C, Cosci F (2005). Publication bias in complementary and conventional medicine. Eur J Clin Pharmacol 61(2); 161-2. 
Faravelli C, Ravaldi C, Truglia E, Zucchi T, Cosci F, Ricca V (2006). Clinical epidemiology of eating disorders: results from the Sesto Fiorentino Study. Psychoter Psychosom 75; 376-83.

Cosci F, Schruers KRJ, Pistelli F, Griez EJL 2006. Negative affectivity in smokers applying for smoking cessation clinics. A case control study. Submitted.

Cosci F, Corlando A, Fornai E, Pistelli F, Paoletti P, Carrozzi L 2006. Nicotine dependence, personality traits, psychological distress and withdrawal symptoms as possible predictors of smoking cessation. Results from a double blind study with nicotine patch. Submitted. 


\section{Curriculum Vitae}

Fiammetta Cosci was born on January $3^{\text {rd }} 1974$ in Empoli (Florence - Italy). She completed the high school in 1993. She graduated as a Medical Doctor at the School of Medicine of the University of Florence on October 20 1999 with an experimental thesis entitled "Esito a lungo termine della patologia psichiatrica" ("Long-term outcome of psychiatric disorders").

She graduated as a Psychiatrist at the School of Psychiatry of the University of Florence on October 24 th 2003 with an experimental thesis entitled "L'agorafobia " ("Agoraphobia").

She attended the Master degree in "Affective Neuroscience" at the Maastricht University on November $21^{\text {st }} 2003$ with a dissertation entitled "Panic disorder and misuse of alcohol and nicotine".

She frequented the Academic Anxiety Centre at the Department of Psychiatry and Neuropsychology of the University of Maastricht since August-October 2001. As part of a PhD project, she attended research programs on Panic and substance misuse and learned the techniques of the $35 \% \mathrm{CO}_{2}$ challenge. 